\title{
Effect of opening size on the effectiveness of a noise enclosure on the side facing the opening
}

\author{
Amit Damodar Hegde \\ West Virginia University
}

Follow this and additional works at: https://researchrepository.wvu.edu/etd

\section{Recommended Citation}

Hegde, Amit Damodar, "Effect of opening size on the effectiveness of a noise enclosure on the side facing the opening" (2005). Graduate Theses, Dissertations, and Problem Reports. 1597.

https://researchrepository.wvu.edu/etd/1597

This Thesis is protected by copyright and/or related rights. It has been brought to you by the The Research Repository @ WVU with permission from the rights-holder(s). You are free to use this Thesis in any way that is permitted by the copyright and related rights legislation that applies to your use. For other uses you must obtain permission from the rights-holder(s) directly, unless additional rights are indicated by a Creative Commons license in the record and/ or on the work itself. This Thesis has been accepted for inclusion in WVU Graduate Theses, Dissertations, and Problem Reports collection by an authorized administrator of The Research Repository @ WVU. For more information, please contact researchrepository@mail.wvu.edu. 


\title{
EFFECT OF OPENING SIZE ON THE EFFECTIVENESS OF A NOISE ENCLOSURE ON THE SIDE FACING THE OPENING
}

\author{
Amit Damodar Hegde \\ Thesis submitted to the College of Engineering and Mineral Resources \\ at West Virginia University \\ in partial fulfillment of the requirements \\ for the degree of \\ Master of Science \\ in \\ Industrial Engineering
}

Approved by

Steven Guffey, Ph.D., Committee Chairperson

Robert Creese, Ph.D.

Ralph Plummer, Ph.D.

Department of Industrial Engineering

Morgantown, West Virginia

2005

Keywords: Noise Reduction (NR), Insertion Loss (IL), Enclosure, Transmission Loss

(TL), Frequency

Copyright 2005 Amit Damodar Hegde 


\section{Abstract \\ EFFECT OF OPENINGS SIZE ON THE \\ EFFECTIVENESS OF A NOISE ENCLOSURE ON \\ THE SIDE FACING THE OPENING}

By Amit Damodar Hegde

Noise enclosures are an important tool in reducing noise exposures. Holes in enclosures are known to reduce the effectiveness of such enclosures. There are methods to predict the effects of openings, but those methods are largely untested in real enclosures. This study investigated the effects of hole size $(0 \%, 0.024 \%, 0.379 \%, 0.675 \%, 1.492 \%$, and $5.063 \%)$ at a distance of 5 feet $(1.524 \mathrm{~m})$ in a 96 inch $(2.46 \mathrm{~m}) \times 37$ inch $(0.94 \mathrm{~m}) \times 31$ inch $(0.79 \mathrm{~m}), 3 / 4$ inch plywood enclosure with a noise source centered in the box and the openings centered on one long face of the box. The enclosure was tested inside a relatively live room (Approx. $\mathrm{R}=3000 \mathrm{ft}^{2}$ ).

Results showed that no predictive model accurately predicted behavior. As expected, noise reduction (NR) values varied inversely with opening areas. However, the relationship was not monotonic, possibly due to resonance frequencies inside the box. In fact, spikes in NR and values occurred at the wavelengths corresponding to $500 \mathrm{~Hz}$. At $4000 \mathrm{~Hz}$, it was observed that even a small opening area of 4 sq.inch reduced the insertion loss by $14 \mathrm{~dB}$. On the other hand, at $500 \mathrm{~Hz}$ small openings did not significantly affect the Insertion Loss. 


\section{Dedication}

I would like to dedicate this work to my parents, Jyothi and Damodar Hegde, and my sister Ashwini Pai for loving me more than I can comprehend and providing me with the best things in life.

Also I would like to dedicate this work to my sweet little niece, Akansha (Anjali). 


\section{Acknowledgments}

I would like to gratefully acknowledge the enthusiastic supervision of Dr. Steve Guffey during my research. This research was possible only because of his dedication, inspiration, and great efforts. Also, I would like to thank Dr. Robert Creese and Dr. Ralph Plummer for their valuable advice and feedback.

I am thankful to NIOSH Grant \# 5 R01 OH007732 02 for providing financial support during my Masters program.

I am greatly thankful to Mr. Jim Dalton for constructing the enclosure. He was a tremendous help in woodworking and other hands-on projects.

I am grateful to my colleagues: Major Jeremy Slagley, who with his vast experience in Industrial Hygiene at USAF, his proactive approach and always helpful attitude was instrumental in providing advice and feedback throughout my research, Ahmed El Sotouhy, who with his handyman skills always helped me troubleshoot various problems, and Sumeeth Sivanagere, who provided his support whenever it was needed. Also how can I forget my friends at West Virginia University for being my surrogate family and providing me continued support during my Masters program.

Finally, I am forever indebted to my parents, sister and brother-in-law for their understanding. I am also grateful to my wonderful friend Anisha, who has provided me great moral support through out this endeavor. With endless patience she provided encouragement when it was most required. 


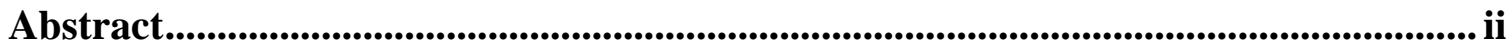

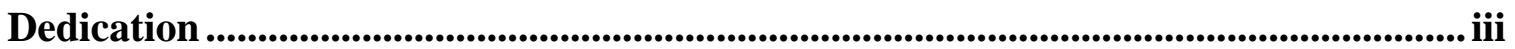

Acknowledgments ........................................................................................................... iv

List of Figures......................................................................................................... vii

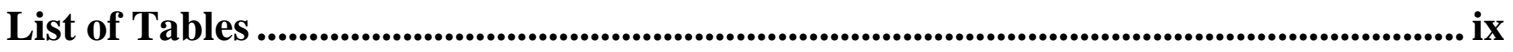

List of Symbols ......................................................................................................................... $\mathrm{x}$

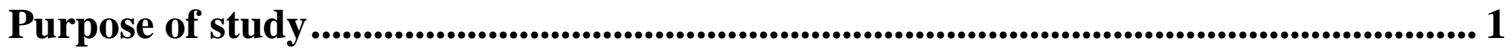

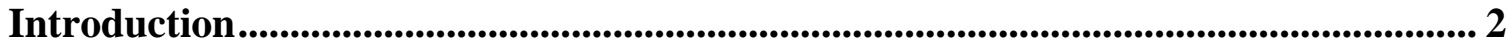

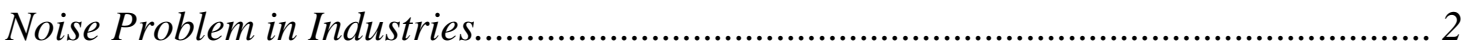

Noise Control Approaches............................................................................................. 2

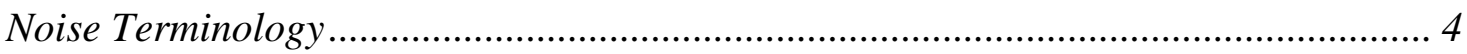

Transmission Loss .................................................................................................................. 4

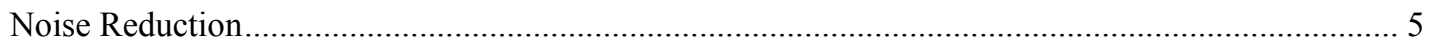

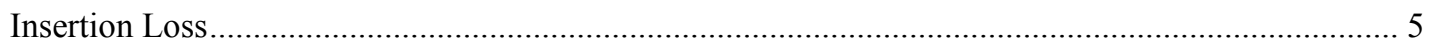

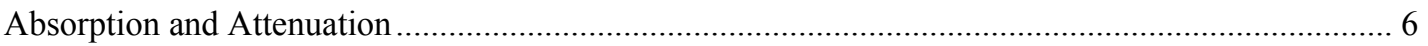

Prediction of Noise Reductions Due to Openings in Enclosures.................................... 6

Prediction of Noise Reduction .......................................................................................................... 8

Prediction of Insertion Loss .............................................................................................. 9

Literature Review .......................................................................................................... 11

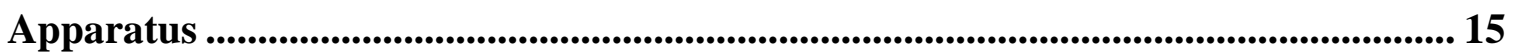

Study Design ......................................................................................................................... 19

Experimental Procedure ........................................................................................................... 20

Estimation of Transmission Loss (TL) for the Enclosure material................................. 20

Enclosure Leak Test ............................................................................................... 21

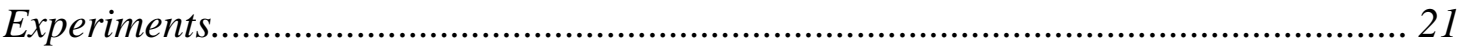

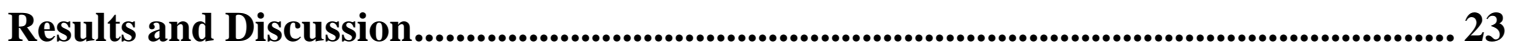

Effect of Opening size on Insertion Loss................................................................... 23

Effect of Opening size on Noise Reduction ................................................................. 31

Effect of Frequency on Insertion Loss .......................................................................... 37

Effect of Frequency on Noise Reduction........................................................................ 43

Comparison of Predicted NR and IL with Observed .................................................. 47

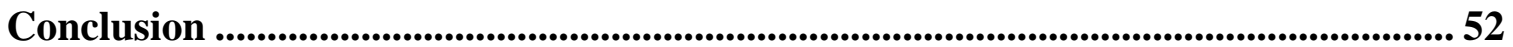

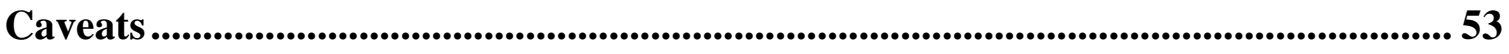

Future work considerations ............................................................................................. 54 


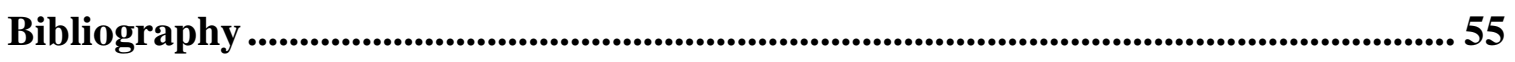

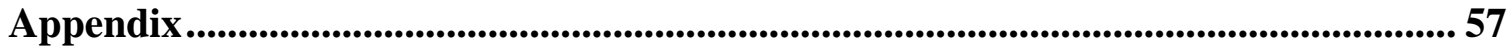

Modified Levene Test to check for Constancy of Error variance (Nutter, et.al, (1996)57 Comparison between Microphones....................................................................... 57

Curriculum Vitae ...................................................................................................... 59 


\section{List of Figures}

Figure 1. Effects of openings on potential noise reduction using $\mathrm{TL}_{\text {combined }}$ equation 12

Figure 2. OROS Multi-Channel Analyzer with PCB-ICP Microphones and Pentium-M processor, 256MB RAM processor laptop with NVGate ${ }^{\circledR}$ software 15

Figure 3. Schematic representation of Experimental Setup 17

$\begin{array}{ll}\text { Figure 4. Analyzer input settings } & 17\end{array}$

Figure 5. Experimental wooden enclosure model 18

Figure 6. Normal Probability plot of the externally studentized residuals for the Regression of IL vs. Log (Opening Area) 23

Figure 7. Variation of Insertion Loss with Opening Area for $250 \mathrm{~Hz}$

Figure 8. Variation of Insertion loss with Opening Area for $500 \mathrm{~Hz}$

Figure 9. Variation of Insertion Loss with Opening Area for $1000 \mathrm{~Hz}$

Figure 10. Variation of Insertion loss with Opening Area for $2000 \mathrm{~Hz}$

Figure 11. Variation of Insertion Loss with Opening Area for $4000 \mathrm{~Hz}$

Figure 12. Variation of Noise Reduction with Opening Area for $250 \mathrm{~Hz}$

Figure 13. Variation of Noise Reduction with Opening Area for $500 \mathrm{~Hz}$

Figure 14. Variation of Noise Reduction with Opening Area for $1000 \mathrm{~Hz}$

Figure 15. Variation of Noise Reduction with Opening Area for $2000 \mathrm{~Hz}$

Figure 16. Variation of Noise Reduction with Opening Area for $4000 \mathrm{~Hz}$

Figure 17. Variation of Insertion Loss with Frequency for Zero Opening area 38

Figure 18. Variation of Insertion Loss with Frequency for 4 Sq.Inch Opening area 38

Figure 19. Variation of Insertion Loss with Frequency for 64 Sq.Inch Opening area 39

Figure 20. Variation of Insertion Loss with Frequency for 114 Sq.Inch Opening area 39

Figure 21. Variation of Insertion Loss with Frequency for 252 Sq.Inch Opening area 40

Figure 22. Variation of Insertion Loss with Frequency for 855 Sq.Inch Opening area 40

Figure 23. Variation of Insertion Loss with Frequency for all Opening Areas 41

Figure 24. Variation of Noise reduction with Frequency for Zero Opening area 43

Figure 25. Variation of Noise reduction with Frequency for 4 Sq.Inch Opening area 43

Figure 26. Variation of Noise reduction with Frequency for 64 Sq.Inch Opening area 44 
Figure 27. Variation of Noise reduction with Frequency for 114 Sq.Inch Opening area 44 Figure 28. Variation of Noise reduction with Frequency for 252 Sq.Inch Opening area 45 Figure 29. Variation of Noise reduction with Frequency for 855 Sq.Inch Opening area 45

Figure 30. Variation of Noise Reduction with Frequency for all Opening Areas 46

Figure 31. Comparison of IL and NR, Predicted Vs Observed for $250 \mathrm{~Hz}$

Figure 32. Comparison of IL and NR, Predicted Vs Observed for $500 \mathrm{~Hz}$

Figure 33. Comparison of IL and NR, Predicted Vs Observed for $1000 \mathrm{~Hz}$

Figure 34. Comparison of IL and NR, Predicted Vs Observed for $2000 \mathrm{~Hz}$

Figure 35. Comparison of IL and NR, Predicted Vs Observed for $4000 \mathrm{~Hz}$

Figure 36. Comparison of TL obtained using Mass Law, TL from Reference Data, IL for Zero Opening and NR for Zero Opening 51 


\section{List of Tables}

Table 1. Reduction in Transmission Loss due to Leaks (Environmental Protection Department, Department of Highways, Hong Kong (2003)) 13

Table 2. Opening Sizes $\quad 16$

Table 3. Transmission Loss for $3 / 4$ inch plywood 20

Table 4. Slopes for variation of Insertion Loss with Opening Areas for average of all Microphones

Table 5. Analysis of Variance for Insertion Loss Averaged over all Microphones with all variables included

Table 6. Analysis of Variance for Insertion Loss Averaged over all Microphones with Log(Opening Area)

Table 7. Scheffe's post hoc test for comparison of Insertion Loss at different frequencies

Table 8. Slopes for variation of Noise Reduction with Opening Areas for average of all Microphones

Table 9. Analysis of Variance for effect of Opening Area and Frequency on the NR 36

Table 10. Scheffe's post hoc test for comparison of Noise Reduction at different frequencies

Table 11. Scheffe's post hoc test for comparison of Insertion Loss at different Opening Areas (Discrete Variable)

Table 12. Scheffe's post hoc test for comparison of Noise Reduction at different Opening Areas (Discrete Variable)

Table 13. Slopes for variation of Insertion Loss with Opening Areas for different individual Microphones

Table 14. $\mathrm{R}^{2}$ for variation of Insertion Loss with Opening Areas for different individual Microphones

Table 15. Slopes for variation of Noise Reduction with Opening Areas for different Microphones

Table 16. $\mathrm{R}^{2}$ for variation of Noise Reduction with Opening Areas for different Microphones 


\section{List of Symbols}

$$
\begin{aligned}
& \mathrm{NR}=\text { Noise Reduction, } \mathrm{dB} \\
& \mathrm{IL}=\text { Insertion Loss, } \mathrm{dB} \\
& \mathrm{TL}=\text { Transmission Loss, } \mathrm{dB} \\
& \mathrm{SPL}=\text { Sound Pressure Level, } \mathrm{dB} \\
& \mathrm{L}_{\mathrm{p}(\mathrm{s})}=\text { Sound Pressure Level at Source, } \mathrm{dB} \\
& \mathrm{L}_{\mathrm{p}(\mathrm{r})}=\text { Sound Pressure Level at Receiver, } \mathrm{dB} \\
& \sigma=\text { Mass per unit area of plywood panel, lbs/ } \mathrm{ft}^{2} \\
& \mathrm{f}=\text { Frequency, Hz } \\
& \mathrm{W}=\text { Sound Power Level, watts } \\
& \mathrm{Q}=\text { Directivity factor of Sound Source } \\
& \mathrm{R}=\text { Room Constant } \\
& \bar{\alpha}=\text { Average absorption coefficient } \\
& \mathrm{S}=\text { Total surface area, } \mathrm{ft}^{2}
\end{aligned}
$$




\section{Purpose of study}

The purpose of this study is to investigate the effects of varying opening sizes on the noise reduction (NR) and insertion loss (IL) of one enclosure for different octave center frequencies. The results are compared to current methods that can be used to predict these effects.

As will be discussed, such a study is needed because current methods make assumptions that may not be true in real applications. Furthermore, the published literature does not appear to shed much light on the subject. An extensive review of published literature found only six studies (Blanks (1997), Yerges et.al (1973), Oldham et.al, (1991), Hunt (1956), Byrne and Fischer (1988), Mooreland (1981)) that experimentally determined the noise reduction due to enclosing noise sources. Only one researcher (Mooreland, 1981) studied the effects of holes in enclosures. No textbook or published study considered the effects of room conditions and opening areas.

Based on the purpose of the study the following hypotheses will be studies:

1. $\mathrm{H}_{0}$ : Change in $\mathrm{NR}$ or IL with varying opening area $=0$

$\mathrm{H}_{1}$ : Change in NR or IL with varying opening area $\neq 0$

2. $\mathrm{H}_{0}$ : Change in NR or IL with varying frequency $=0$

$\mathrm{H}_{1}$ : Change in NR or IL with varying frequency $\neq 0$

3. $\mathrm{H}_{0}$ : Observed NR or IL $=$ Predicted NR or IL

$\mathrm{H}_{1}$ : Observed NR or IL $\neq$ Predicted NR or IL 


\section{Introduction}

\section{Noise Problem in Industries}

Noise is one of the most pervasive health hazards affecting workers in manufacturing, the military, and construction. Noise-induced hearing loss is fully preventable, but once acquired it is irreversible. A person exposed to a noise level of $85 \mathrm{dBA}$ for over 8 hours per day over a period of many years is susceptible to suffer hearing loss. Hearing loss increases dramatically at higher exposures.

It is estimated that approximately 30 million workers are exposed to hazardous noise on the job (CDC/NIOSH, 2003). The costs associated with hearing loss compensation for the workers are several hundred million dollars (CDC/NIOSH, http://www.cdc.gov/niosh/hpworkrel.html). Between 1974 and 1994 the U.S. Army saved $\$ 504.3$ million by reducing hearing loss among combat arms personnel (CDC/NIOSH, http://www.cdc.gov/niosh/hpworkrel.html). The loss of productivity due to noise in the manufacturing industries is difficult to calculate. Some believe that hearing relates directly to performance, job safety and communication. The latter is important for workers to successfully work in teams (CDC/NIOSH, http://www.cdc.gov/niosh/hpworkrel.html). In noisy work places workers tend to make more mistakes, work for fewer hours, and take more days off. However compliance with the noise standards can be costly as well. Numerous studies conducted by OSHA have indicated that compliance to the noise standards in 1976 would cost industries up to $\$ 31$ billion, averaging $\$ 1430$ per production worker in 1976 (Meinhold, 1976). The costs today would be similar if adjusted for inflation.

\section{Noise Control Approaches}

There are three approaches to controlling noise:

1. Source Treatment - Reducing the noise generated at the source by employing engineering controls. 
2. Path Treatment - Blocking or absorbing noise in its path from source to the receiver by using absorption material, barriers, and/or enclosures.

3. Receiver Treatment - Protecting the receiver from the noise using hearing protection like earplugs and muffs.

Among the three approaches, engineering controls at the source can be the most effective since they reduce the noise at the source of generation. However it is not always feasible to develop or apply engineering controls at the source. Because of the difficulties of obtaining good protection in the workplace, OSHA allows hearing protection only as a temporary solution, albeit one that has lasted decades in many locations.

Path treatment is a type of engineering control categorized into "Passive Noise Control" and "Active Noise Control" (ANC). The ANC approach requires state-of-the-art instrumentation, which is currently very expensive. It works best when there is a standing wave produced and frequencies are relatively low $(<500 \mathrm{~Hz})$. A typical application of ANC is noise reduction for an industrial exhaust stack. By contrast, passive controls do not need a standing wave and are effective for a broader range of frequencies, though they are often ineffective at low frequencies.

There are several approaches to implementing passive noise controls, such as sound absorption using acoustical materials, installing barriers between the source and the receiver, and enclosing the receiver or source. The subject of this study is enclosures. Enclosures have proven to be one of the most effective path treatment methods, able to achieve up to $50 \mathrm{dBA}$ (Yerges et.al, 1973) reductions in noise levels. When designing an enclosure, it is important to (M.P Norton, 1999):

1. Use a sealed material for the outer surface of the enclosure.

2. Install mufflers on duct openings which are used for passage of cooling air.

3. Line the inner surfaces of the enclosure with suitable sound absorbing materials.

4. Isolate the enclosure from the machine to prevent vibration transfer.

5. Ensure that the inspection hatches have easy access for maintenance personnel. 
The enclosure for this study was isolated to prevent conduction of noise vibrations and was well sealed except where holes were deliberately introduced.

\section{Noise Terminology}

Transmission loss (TL), Noise reduction (NR) and Insertion Loss (IL) are three important terms that must be understood while evaluating an acoustical enclosure.

\section{Transmission Loss}

Buckingham (1924) defined transmission loss as the logarithmic (base 10) ratio of the amount of pressure wave transmitted through a surface to the pressure wave incident on it. This theory considered only the pressure waves that are normally incident on the surface. Such models in the early 1900s were very simplistic, without consideration of randomly incident pressure waves or any boundary conditions (Crocker, 1994).

Miller and Monotone (1978) defined sound transmission loss (TL) as the amount of sound transmitted from a source to the receiver separated by a barrier. It can be computed in the laboratory by measuring the difference between the sound pressure levels on the source and receiver side. The formula is shown in Equation (1).

$$
\begin{aligned}
T L=L_{p(s)} & -L_{p(r)}+10 \log (S / A) \\
\mathrm{L}_{\mathrm{p}(\mathrm{r}),} \mathrm{L}_{\mathrm{p}(\mathrm{s})}= & \text { Sound pressure levels are receiver and source respectively } \\
\mathrm{S}= & \text { area of test wall in } \mathrm{ft}^{2} \\
\mathrm{~A}= & \text { absorption in the receiving room in Sabins }
\end{aligned}
$$

Transmission loss of an acoustical wall can also be determined based on Newton's second law of motion. The force required to set a wall in motion is equal to the product of mass and acceleration. As the frequency increases the force exerted by the sound wave on the wall increases. Thus, the transmission loss is dependent on the mass of the wall and the frequency of the sound wave (Equation (2)) (Thornton, et. al, 2001).

$$
\begin{aligned}
T L_{\text {plywood }} & =20 \log \left(\sigma^{*} f\right)-28 \\
\sigma & =\text { mass per unit area of the plywood panel, } \mathrm{lbs} / \mathrm{ft}^{2} \\
\mathrm{f} & =\text { frequency, } \mathrm{Hz}
\end{aligned}
$$


$\mathrm{TL}_{\text {plywood }}=$ Transmission loss of the plywood panel, $\mathrm{dB}$

The Equation 2 is known as the "mass law equation". From this equation it can be seen that each time weight or frequency is doubled the TL increases by $6 \mathrm{~dB}$. Beranek and Work (1949) studied the mass law behavior of the panels with varying thickness. They found that the panels deviate from the mass law behavior as the thickness is increased.

\section{Noise Reduction}

Noise reduction (NR) is defined as the difference in the sound pressure levels measured between two locations at same frequency.

$$
\begin{aligned}
& N R=L_{p 1}-L_{p 2}, \quad d B \\
& \mathrm{Lp}_{1}, \mathrm{Lp}_{2}=\text { Sound pressure levels at locations } 1 \text { and } 2 \text { respectively }
\end{aligned}
$$

\section{Insertion Loss}

Insertion Loss (IL) is defined as the difference between the sound power level before and after the installation of an enclosure, measured at a location, which lies outside the enclosure after its installation.

$$
I L_{w}=10 \log \left[\frac{W_{o}}{W_{E}}\right]=\left(L_{w O}-L_{w E}\right), \quad d B
$$

$\mathrm{W}_{\mathrm{o}}$ and $\mathrm{W}_{\mathrm{E}}=$ sound power radiated for an source before and after installation of the enclosure

$\mathrm{L}_{\mathrm{wO}}$ and $\mathrm{L}_{\mathrm{wE}}=$ sound power levels before and after installation of the enclosure $\mathrm{W}_{\mathrm{o}}$ and $\mathrm{W}_{\mathrm{E}}$ are measured in a reverberation room or by using a sound intensity meter. Whenever enclosures are to be used for equipment outdoors, a less precise method of determining the IL using pressure levels can be used. In this method the IL is the difference between the sound pressure levels before and after the installation of the enclosure (Equation (5)), (Beranek and Ver, (1992)).

$$
I L_{p}=\left(S P L_{O}-S P L_{E}\right), \quad d B
$$

SPLo and SPLE $=$ sound power level radiated from an source before and after installation of the enclosure 
Equation (4) uses the sound power level to compute the IL, which is constant regardless of its location in different environment. While Equation (5) uses the sound pressure level which varies with locations.

For a perfectly sealed enclosure the IL depends on the following:

- Material and thickness of the enclosure wall.

- Vibration pattern of the source.

- Air gap between the source and the enclosure.

- Type of absorbing material on the interior of the enclosure surface.

\section{Absorption and Attenuation}

Acoustical performance of a material is determined by its ability to absorb sound. Absorption is desirable to reduce noise within a space. Open cell materials (high porosity) generally are good absorbers of sound. However materials with relatively high absorption coefficient are not good attenuators of sound waves and often lack structural properties.

Attenuation is a property of a material to obstruct the amount of sound waves passing through it. Materials with good attenuation are usually not very good absorbers of sound but have good structural properties. However, for any particular application a combination of a good absorber and a good attenuator can be used to achieve desired results.

\section{Prediction of Noise Reductions Due to Openings in Enclosures}

When a noise source is enclosed, the SPL values inside the enclosure will change. To predict the noise reduction due to installing the enclosure, one must be able to predict the new noise level inside the confines of the enclosure, which is difficult to do. If no absorptive materials were used to line the enclosure, the noise levels would increase because of reverberation. With more and more absorption, the noise level falls, perhaps to levels lower than were initially measured near the source. 
For noise levels outside the enclosure, the enclosure reduces the sound power available to fill the room. The sound power that escapes the enclosure $\left(\mathrm{L}_{\mathrm{wE}}\right)$ depends on the enclosure, but the effects of that escaped sound power will vary depending on the absorptivity of the room and the distance from the source (in this case, the enclosure) (Beis and Hansen, (2003)).

The sound pressure level in an enclosed space depends on the absorptive and reflective properties of the enclosure. If the enclosure material is very reflective then a reverberant sound field is established. The resulting $\mathrm{L}_{\mathrm{p}(\mathrm{source})}$ inside the enclosure would be the total energy contained in the direct and the reverberant field and can be predicted by using Equation (6).

$$
\begin{aligned}
& L_{p(\text { source })}=L_{w}+10 \log \left(\frac{Q}{4 \pi r^{2}}+\frac{4}{R}\right)+10 \log \left(\frac{\rho c}{400}\right) \\
& \mathrm{L}_{\mathrm{w}}=\text { sound power level of the noise source, } \mathrm{dB} \text {. } \\
& \mathrm{Q}=\text { Directivity factor of the source. } \\
& \text { At } 20^{\circ} \mathrm{C}, \quad \rho c=414 \text { in SI units. } \\
& \mathrm{R}=\text { Room constant (accounts for the absorptivity of the interior } \\
& \text { surfaces of the enclosure) } \\
& R=\frac{S \bar{\alpha}}{1-\bar{\alpha}} \\
& \bar{\alpha}=\text { average absorption coefficient of the inner surfaces of the } \\
& \text { enclosure } \\
& \mathrm{S}=\text { Total inner surface area of the enclosure }
\end{aligned}
$$

If the last term $\rho c$ of Equation (6) were to be omitted there would be an error of $0.1 \mathrm{~dB}$. For this study since the error is very negligible the last term in the Equation (6) has been omitted. Absorptive material was not used in the test enclosure but the plywood itself absorbs a small fraction of the sound power (absorptivity of 0.12 at $1000 \mathrm{~Hz}$ ). More importantly, the sound pressure level at the source $\mathrm{L}_{\mathrm{p}(\text { source) }}$ was measured directly using a pressure field microphone inside the enclosure. Hence, $\mathrm{L}_{\mathrm{p}(\text { source) }}$ was determined without knowing $\mathrm{L}_{\mathrm{w}}$ and without using Equation (6). 
Except for some hermetically sealed enclosures, most enclosures are likely to be leaky. Indeed, most enclosures are purposefully provided with openings for ventilation, worker access, etc. The combined transmission loss of such enclosures with openings can be computed using Equation (8). In this equation it is assumed that any opening in the enclosure has a zero transmission loss.

$$
T L_{\text {combined }}=10 \log \left(\frac{\sum S_{i}}{\sum S_{\text {not_hole }} * 10^{-T L / 10}+\sum S_{\text {hole }} * 10^{-0 / 10}}\right)
$$

$\sum \mathrm{S}_{\mathrm{i}}=$ Total surface area of the enclosure, sq.inch

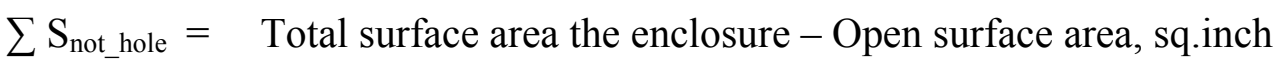

$\sum S_{\text {hole }}=$ Open surface area of the enclosure, sq.inch

\section{Prediction of Noise Reduction}

The $\mathrm{L}_{\mathrm{p} \text { (outside_enclosure) }}$ outside the enclosure due to the total energy contained in it, can be predicted by using the combined transmission loss of the enclosure. Thus the sound pressure level "just outside" the enclosure (i.e., 8 inches from the front panel) is given by the Equation (9).

$$
L_{p(\text { outside_enclosure })}=L_{p(\text { source })}-T L_{\text {combined }}+10 * \log \left(\frac{1}{4}+\frac{S_{\text {wall }}}{R_{\text {receiver }}}\right)
$$

$\operatorname{Lp}_{\text {(outside_enclosure) }}=$ Average sound pressure level immediately outside the enclosure, $\mathrm{dB}$

$\mathrm{TL}_{\text {combined }}=$ Combined transmission loss after accounting for the open surface area, $\mathrm{dB}$

$\mathrm{S}_{\text {wall }}=$ Total surface area outside the enclosure on the receiver side, sq. inch

However, as one moves further from the enclosure variation in the SPL will occur with its interaction with room condition and increasing distances. Equation (9) only accounts for the SPL immediately outside the enclosure. Hence, for an enclosure placed in a room, the effect of distance from the source must be also taken into account. By knowing the sound power of the source, SPL at specific locations can be computed using Equation (6). 
Since the sound power was not known in this study, an alternate method of computing the sound pressure level at the receiver (i.e., varying microphone positions) was used. In this method the property of sound power of a source not to change with varying distance is considered. The SPL at the receiver is computed using the previously calculated SPL outside the front panel of the enclosure using Equation (10), which is an algebraic manipulation of Equation (6).

$$
\begin{aligned}
L_{p(\text { receiver })}= & 10 \log \left(\frac{4}{R}+\frac{Q}{4 \pi r_{2}^{2}}\right)-10 \log \left(\frac{4}{R}+\frac{Q}{4 \pi r_{1}^{2}}\right)+L_{p(\text { outside_enclosure })} \\
\mathrm{r}_{1}= & \text { distance from the center of the source to a location i.e } 8 \text { inches } \\
& \text { from the enclosure (just outside the enclosure), } \mathrm{ft.} \\
\mathrm{r}_{2}= & \text { distance from the center of the source to receiver, } \mathrm{ft.}
\end{aligned}
$$

Thus the SPL at various distances can be obtained from the Equation (10). The noise reduction at that specific location can then be determined by computing the difference between the SPL at the specific location and the SPL at source. However, note that the effect of orientation is not taken in into account in this equation.

Assuming that the room was fairly reverberant, the Room constant was assumed to be $3000 \mathrm{ft}^{2}$ (Berger, et.al., (2000)). Directivity (Q), which is the directional characteristic of a sound source, was computed using Equation (11).

$$
\begin{aligned}
& Q=\left(\frac{4 \pi r^{2}}{\text { Area_of_Opening }}\right) \\
& \mathrm{Q}=\text { Directivity of the sound source } \\
& \mathrm{r}=\text { radius of the imaginary sound wave sphere generated by the source } \\
& =0.5 * \text { (width of the enclosure) }
\end{aligned}
$$

\section{Prediction of Insertion Loss}

In order to predict the Insertion Loss (IL) for a large close fitting enclosure the Equation (12) derived by Norton (1999) can be used. The combined transmission loss in this equation is computed using Equation (8). 


$$
\begin{aligned}
I L_{\text {enclosure }}= & T L_{\text {combined }}-10 \log \left(\frac{A_{E}}{S_{E}}\right)+10 \log \left(\frac{\alpha_{E_{-} a v g}}{1-\alpha_{E_{-} a v g}}\right) \\
\mathrm{A}_{\mathrm{E}}= & \text { total internal surface area of the enclosure } \\
\mathrm{S}_{\mathrm{E}}= & \text { total external surface area of the enclosure } \\
\alpha_{\mathrm{E}_{-} \text {avg }}= & \text { average absorption coefficient of the inner surfaces of the } \\
& \text { enclosure }
\end{aligned}
$$

Further the predicted noise reductions and insertion losses are compared to the actual obtained noise reduction levels by plotting graphs for microphones at varying distances for different frequencies. 


\section{Literature Review}

Enclosures are very effective path treatment approach for noise control. They are used to contain the noise emitted from a source or to protect a receiver from the noise source. Also they can be useful as machine guards and safety devices by installing interlocks on access doors. A well-built enclosure with no openings can provide an insertion loss (IL) of 30-50 dBA (Yerges et.al (1973)). The effectiveness of the enclosure depends on its design, materials used for construction, and absorptive lining. The material of the enclosure should provide sufficient transmission loss, and the absorptive lining of the enclosure should provide the sufficient absorption to reduce the noise on the receiver side of the enclosure. Absorptive materials commonly used are acoustic foam, asbestos, mineral wool, etc.

Installation of any particular enclosure is limited by the space surrounding the equipment. If the distance between the noise source and the panel is less than a meter, it is said to be a "Close Fitting" enclosure. According to Oldham et.al, (1991), there is always considerable coupling between the enclosure and the noise source, because of which the acoustical field inside the close fitting enclosure does not behave in the same manner as it would in a large room. Thus the complex acoustical behavior inside close-fitting enclosures makes it difficult to make accurate predictions.

Openings provided for ventilation and servicing will reduce the noise reduction efficiency of the enclosure. Although an enclosure may be very well designed, incorrect positioning of holes for access could cause significant reduction in effectiveness. Even a slight opening present at an ill-fitting joint can cause a huge reduction in attenuation (as high as $30 \mathrm{~dB}$ ) (Bell and Bell (1994)). Also, openings have a significant effect on the TL. For, example, a heavy metal plate with holes over $13 \%$ of its surface will transmit $97 \%$ of the sound incident on it (Environmental Noise Control, ATCO Noise Management). Hence, depending on the position of the source, the propagation of sound waves inside the enclosure must be thoroughly studied to determine the optimum location of openings. 
Hunt (1956) found that by correctly sizing the access opening in the enclosure for a rotary knife cutter, an additional noise reduction of $9 \mathrm{~dB}$ was obtained. He achieved an overall reduction of $15 \mathrm{~dB}$ (from $110 \mathrm{~dB}$ to $95 \mathrm{~dB}$ ).

A plot of the noise attenuation levels at varying opening sizes for materials with different transmission losses can be plotted using the combined transmission loss ( $\left.\mathrm{TL}_{\text {combined }}\right)$ equation (Equation (8)). The curve obtained is purely theoretical, based on the concept that the hole-portion of the panel does not contribute to the noise reduction.

\section{Effects of Openings for varying Transmission Loss}

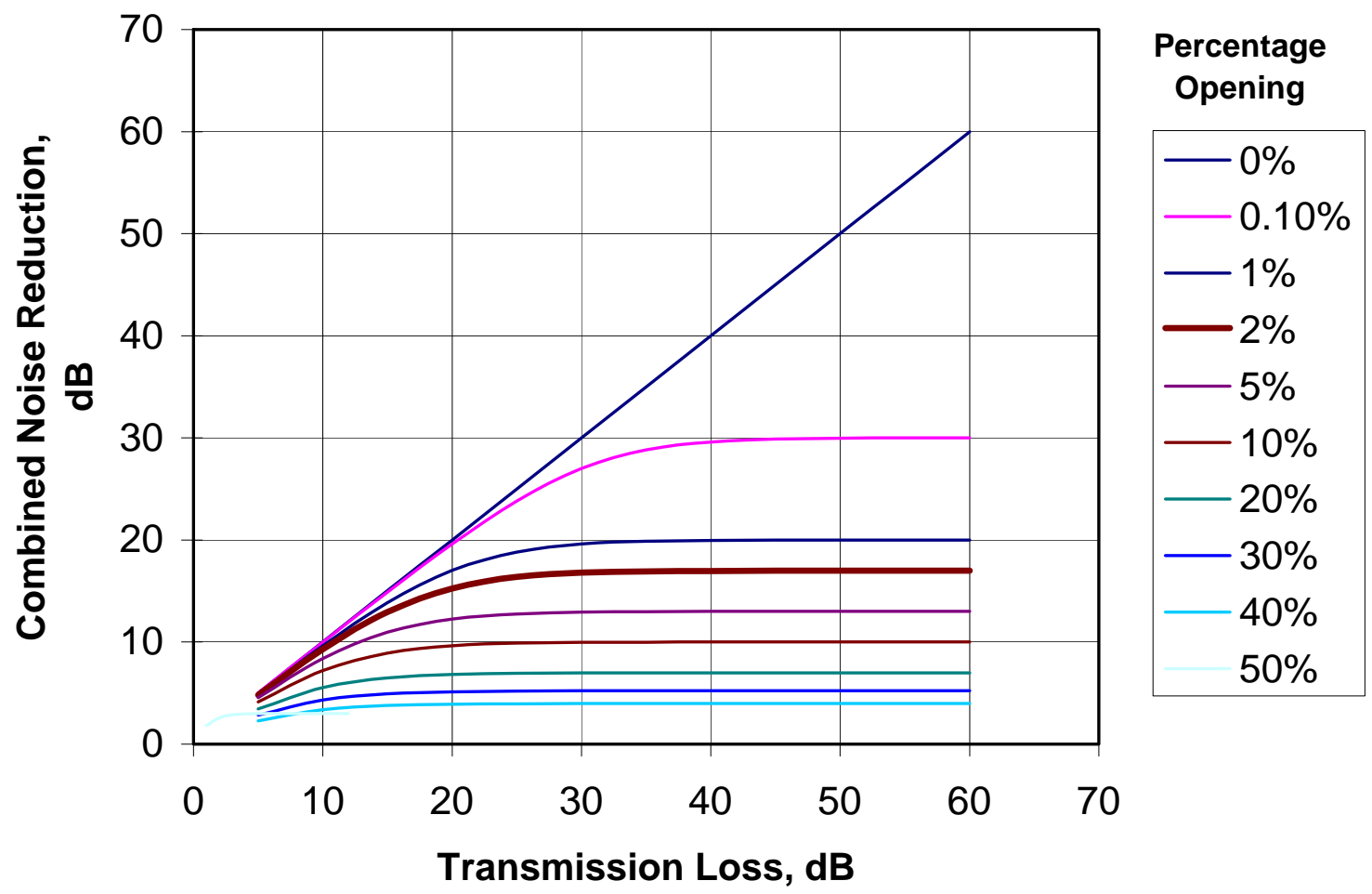

Figure 1. Effects of openings on potential noise reduction using $\mathrm{TL}_{\text {combined }}$ equation

The curve fits obtained using the combined transmission loss equation does not take into consideration, the room constant and the effect of increasing distances.

Hence, in this study these factors are taken into consideration both to compute and to experimentally verify the IL or NR at different locations outside the enclosure. By 
knowing the $\mathrm{TL}_{\text {combined }}$ and the aborptivity of the room, the SPL "just outside" the enclosure $\left(\mathrm{L}_{\mathrm{p} \text { (outside_enclosure) }}\right)$ can be computed. Further by knowing $\mathrm{L}_{\mathrm{p} \text { (outside_enclosure), }} \mathrm{SPLs}$ at different locations can be computed using Equation (10) and hence the noise reduction (the difference between the SPL at specific location and the source) can be determined. This study used only one distance from the source.

Environmental Protection Department, Department of Highways, Hong Kong (2003), published the effects of increasing percentages of leaks on the reduction in the transmission loss of the panel. According to this report, as the amount of barrier attenuation needed increases, the significance of leaks increases dramatically (Table 1). For example, the reduction in the TL of a panel that has a TL of $20 \mathrm{~dB}$ without leaks would be $9 \mathrm{~dB}$ with just $1.5 \%$ of opening area. Also, it can be seen that openings above $20 \%$ would completely negate the effect of the panel by causing a $0 \mathrm{~dB}$ TL (Table 1 ).

Table 1. Reduction in Transmission Loss due to Leaks (Environmental Protection Department, Department of Highways, Hong Kong (2003))

\begin{tabular}{|c|c|c|c|c|}
\hline \multirow{2}{*}{$\begin{array}{c}\text { Percentage } \\
\text { area } \\
\text { occupied } \\
\text { by leaks }\end{array}$} & \multicolumn{5}{|c|}{ Transmission Loss without leaks at $\mathbf{5 0 0 ~ H z}$} \\
\cline { 2 - 5 } & $\mathbf{5}$ & $\mathbf{5} \mathbf{~ d B} \mathbf{~ d B}$ & $\mathbf{2 0} \mathbf{~ d B}$ & $\mathbf{2 5} \mathbf{~ d B}$ \\
\cline { 2 - 5 } & \multicolumn{5}{|c|}{ Reduction in transmission loss, dB } \\
\hline 50 & $10+$ & $15+$ & $20+$ & $25+$ \\
\hline 25 & 10 & 15 & 20 & 25 \\
\hline 13 & 8 & 12 & 17 & 22 \\
\hline 6 & 5 & 10 & 14 & 19 \\
\hline 3 & 4 & 7 & 11 & 16 \\
\hline 1.5 & 2 & 5 & 9 & 13 \\
\hline 0.78 & 1 & 3 & 6 & 10 \\
\hline 0.39 & 1 & 2 & 4 & 8 \\
\hline 0.2 & 0 & 1 & 3 & 5 \\
\hline 0.1 & 0 & 1 & 1 & 4 \\
\hline 0.05 & 0 & 0 & 1 & 2 \\
\hline
\end{tabular}

Blanks (1997) conducted research on the optimal design of an enclosure for a portable generator. However, he did not consider the degradation of insertion loss due to an opening (e.g., exhaust). For future studies he suggested use of active noise control (ANC) 
at the exhaust openings. Since ANC is best suited to cancellation of noise in the presence of a standing wave; this will not be an efficient solution for most of the industrial applications. A more practical and cost-effective approach to this problem is controlling the size and position of the opening in the enclosure. This combination of controlling the size and the position can possibly lead to significant reduction in the noise levels escaping the enclosure when compared to a wrongly positioned or sized opening. The aim of this study is to study the effect of varying size openings on the IL and NR.

Byrne and Fischer (1988) discussed the procedure for analytically predicting the acoustic performance of sealed, close-fitting, machine-mounted acoustic enclosures. They measured the performance by determining the insertion loss, which is the difference between the sound power radiated from the machine before and after enclosing it. Similar to this study, they used a speaker enclosed in a box as the source of noise. They observed that minor variation in the construction of enclosure and its mounting can produce significant variations in the acoustic performance.

Similarly, Davern and Lhuede (1978) in their study on enclosures for saw mill operators used tape (loop) recording of band-saw noise played through a speaker. The microphone was placed 5' 9" above the floor, which they considered as an average band saw operator's head level from the ground. In the current study, the height selected ( $\left.5^{\prime} 3^{\prime \prime}\right)$ was based on an average operator's ear level from the ground. Davern and Lhuede (1978) obtained a maximum noise reduction of $20 \mathrm{dBA}$ when the back panels of the enclosure were removed, an improvement on the $12 \mathrm{dBA}$ when none of the panels were removed. Apparently, when the enclosure is completely closed there is sound energy build up inside the enclosure causing the panels to vibrate and transmit energy. However, when the back panel is removed the energy does not build up. Also, reflections from the other panels are dissipated through the back panel instead of causing pressure build up inside the enclosure. 


\section{Apparatus}

For this study, an eight Channel Real-Time Analyzer (OROS OR38, Dulles, VA) was used for data collection. The OROS real time analyzer consists of a data acquisition front-end, with resources required to provide real-time processing of the 8 inputs and 2 analog outputs. Using the OROS Noise and Vibration software platform NVGate ${ }^{\circledR}$, it can be interfaced with a computer, giving access to a wide range of functions such as user defined control panel, macros, and TCP/IP control, customized graph generation, calibration suite, project-based settings etc... This software controls all the analyses and measurements carried out by the OR38 analyzer.

Sound pressure levels inside and outside the enclosure were measured with six pressure field ICP microphones (Model No: 130D20, PCB Piezotronics ${ }^{\circledR}$, Depew, NY) (Figure 2) with inbuilt pre-amplifiers and one condenser type microphone (Model No: 4130, Preamplifier type: 2642, microphone power supply type: 2810, Bruel and Kjaer).

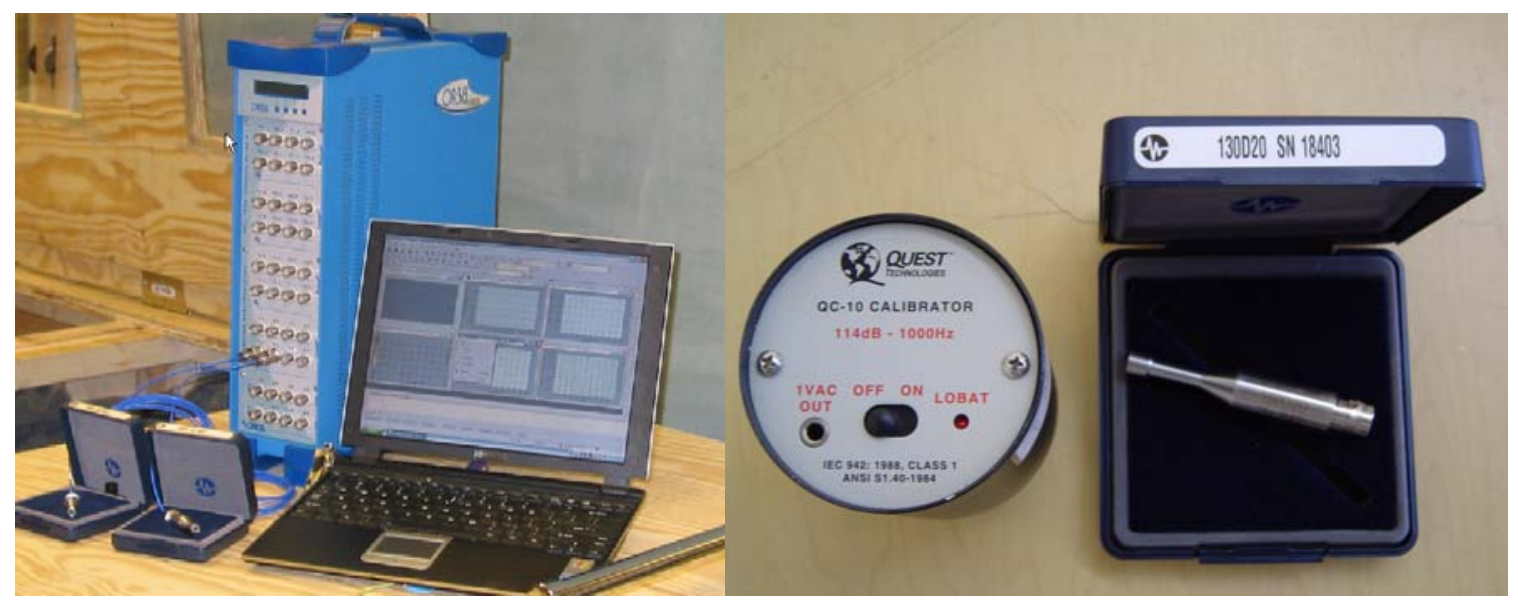

Figure 2. OROS Multi-Channel Analyzer with PCB-ICP Microphones and Pentium-M processor, 256MB RAM processor laptop with NVGate ${ }^{\circledR}$ software

An empty room with dimensions $70 \mathrm{ft} * 50 \mathrm{ft} * 46 \mathrm{ft}$ was chosen for the experiment. The test enclosure was setup in the geometric center of the room floor. An opening 855 square inch was made in order to study the effect of varying openings. 5 different pairs of $3 / 4$ inch thick plywood plugs were prepared (see Table 2). These specific openings were selected 
so that they are fairly equally spaced on a logarithmic scale. Six different cases including no holes were considered. Microphones were located 5 feet from the center of the source with an orientation of zero degree from the opening. The set up is shown in Figure 3 . All necessary connections were made between the microphones and the analyzer. The sensitivities of the microphone inputs were set in the NVGate ${ }^{\circledR}$ software as shown in Figure 4.

Table 2. Opening Sizes

\begin{tabular}{|c|c|c|c|c|c|}
\hline 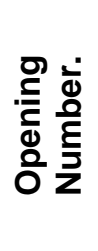 & 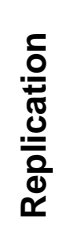 & 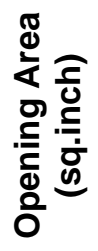 & 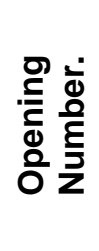 & 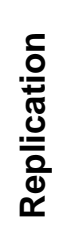 & 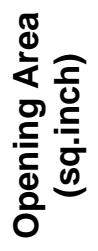 \\
\hline \multirow{3}{*}{1} & 1 & 0 & \multirow{3}{*}{4} & 1 & 114 \\
\hline & 2 & 0 & & 2 & 114 \\
\hline & 3 & 0 & & 3 & 114 \\
\hline \multirow{3}{*}{2} & 1 & 4 & \multirow{3}{*}{5} & 1 & 252 \\
\hline & 2 & 4 & & 2 & 252 \\
\hline & 3 & 4 & & 3 & 252 \\
\hline \multirow{3}{*}{3} & 1 & 64 & \multirow{3}{*}{6} & 1 & 855 \\
\hline & 2 & 64 & & 2 & 855 \\
\hline & 3 & 64 & & 3 & 855 \\
\hline
\end{tabular}




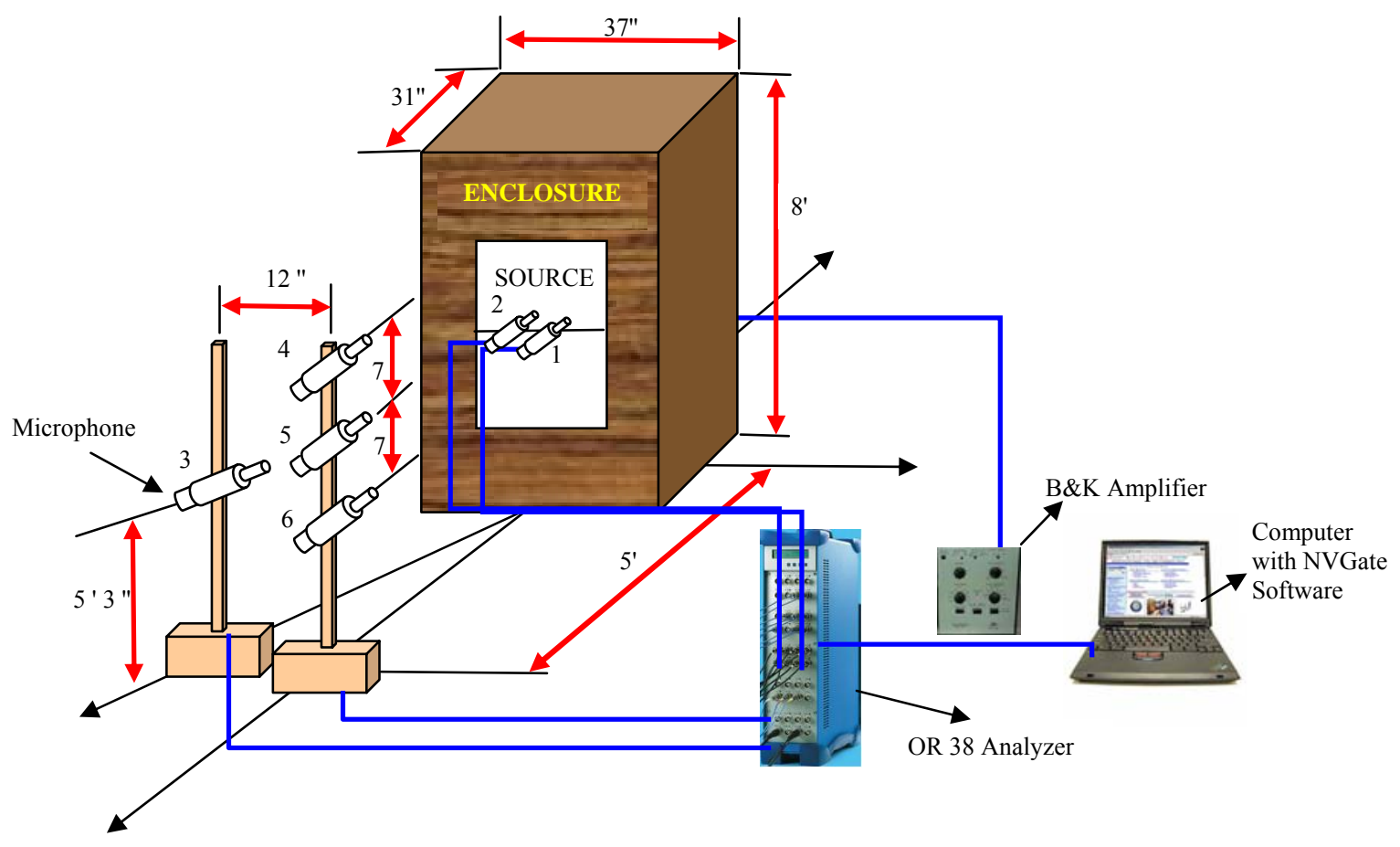

Figure 3. Schematic representation of Experimental Setup

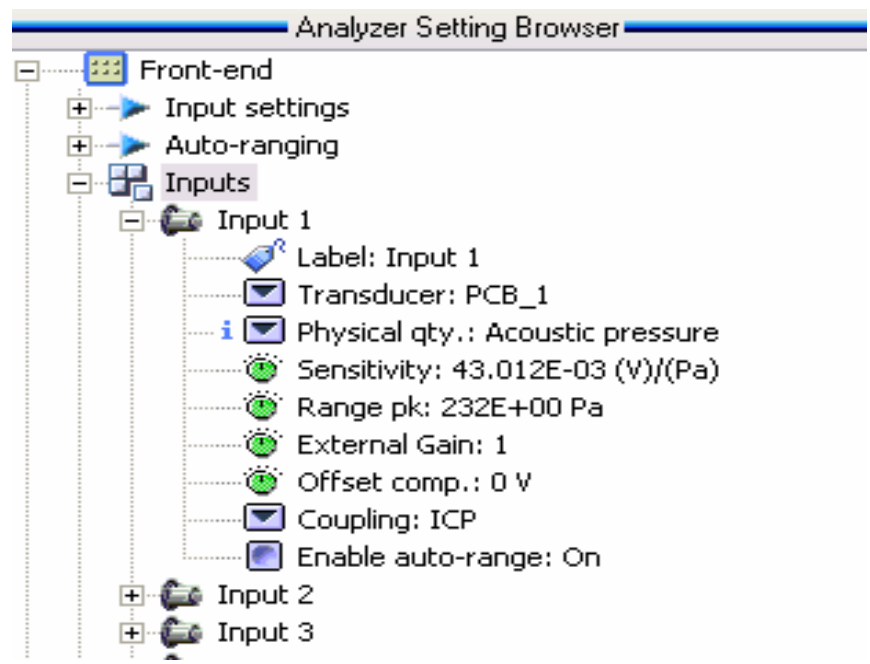

Figure 4. Analyzer input settings

This study determined the effects of holes on the noise reduction afforded by a 37 inch $x$ 31 inch x 96 inch cabinet grade plywood ( $3 / 4$ inch thick) enclosure (see Figure 5). This was done both in a normal, somewhat reverberant room. 


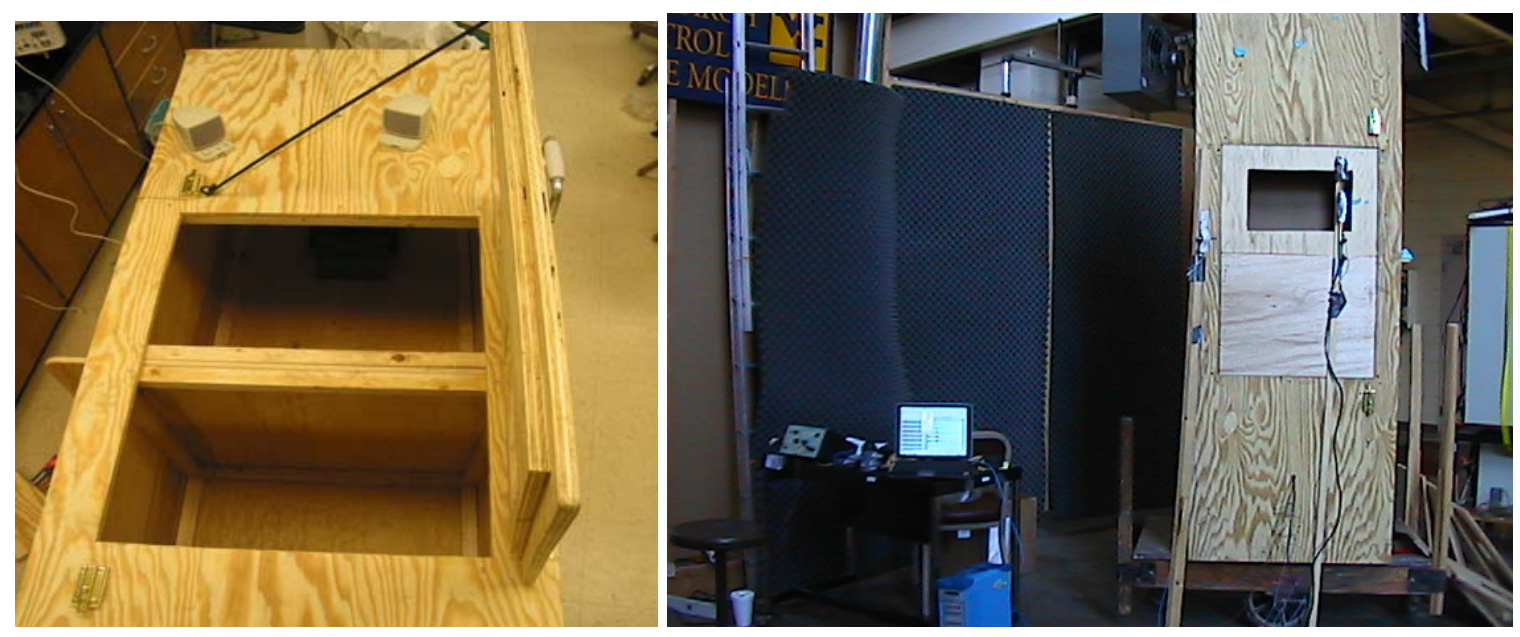

Figure 5. Experimental wooden enclosure model 


\section{Study Design}

The study design was two mixed-level factorials.

Dependent variable: IL or NR

Independent variables:

1. Opening Area: $0,4,64,114,252,855$ sq. inch

2. Frequencies: 250, 500, 1000, 2000, and $4000 \mathrm{~Hz}$

3. Position of the Microphone with respect to the source:

- $5 \mathrm{ft}$ in front and in line with center of the source

- $5 \mathrm{ft}$ in front and 7 inches below the center of the source

- $5 \mathrm{ft}$ in front and 14 inches below the center of the source

- $5 \mathrm{ft}$ in front, 7 inches below and 12 inches to the right of the center of the source

The aims of this study were to:

1. Determine how the IL values changed with the independent variables.

2. Determine how the NR values changed with the independent variables.

3. Compare observed and predicted noise reductions. 


\section{Experimental Procedure}

Modeling is very useful when analytical predictions are too cumbersome and on-site fullscale situation are inconvenient and time consuming. While designing an acoustic enclosure many factors apart from reducing noise like ventilation, worker accessibility and safety have to be considered. But since this study is aimed only at the noise reduction aspect of the enclosure, other factors have not been taken into consideration.

Measurements were taken for different opening areas, for different frequencies.

\section{Estimation of Transmission Loss (TL) for the Enclosure material}

The mass per unit area was considered as the determining parameter in estimating the TL for the $3 / 4$ " cabinet grade plywood used as the enclosure material, (Equation (2)) (Thornton, et. al, (2001)).

Each of the three samples of the plywood were measured and weighted. The mass per unit area $\left(\mathrm{lbs} / \mathrm{ft}^{2}\right)$ for each sample was then computed and used in Equation (2) to compute the transmission loss for each frequency. The estimated transmission loss at each octave band center frequency is shown in Table 3.

Table 3. Transmission Loss for $3 / 4$ inch plywood

\begin{tabular}{|c|c|}
\hline \multicolumn{2}{|c|}{$\begin{array}{c}\text { Transmission Loss for } 3 / 4 \\
\text { inch Cabinet grade plywood }\end{array}$} \\
\hline $\begin{array}{c}\text { Frequency } \\
\text { (Hz) }\end{array}$ & TL dB \\
\hline 125 & 20 \\
\hline 250 & 26 \\
\hline 500 & 32 \\
\hline 1000 & 38 \\
\hline 2000 & 44 \\
\hline 4000 & 50 \\
\hline 8000 & 56 \\
\hline
\end{tabular}




\section{Enclosure Leak Test}

Before conducting any experiments the enclosure was tested for leaks. For the test, enclosure was completely sealed and a $90 \mathrm{~dB}$ sound signal at $1000 \mathrm{~Hz}$ was generated at the source speaker inside the enclosure. Sound levels outside the enclosure at all edges, corners and centers of each side were measured using the Quest 2900 Sound Level Meter (SLM). As compared to the expected transmission loss (TL) for $3 / 4$ " plywood i.e. $38 \mathrm{~dB}$ (Table 3) the enclosure had only minor leaks, which were sealed by caulking with acrylic latex caulk.

\section{Experiments}

To avoid inadvertent confounding with events that may have occurred over the duration of the study, the order in which different opening sizes were tested (including three replications) was set using random numbers including all 3 replication. The frequencies were done from lowest to highest each time without changing openings. Each sequence took about 15 to 20 minutes. For every session of experiments all the microphones were pre and post calibrated based on a criterion of $114 \mathrm{~dB}$ at $1000 \mathrm{~Hz}$. A new project with all the required input and source settings was set up in the NVGate ${ }^{\circledR}$ software. Macros were created in order to facilitate the ease of changing the frequencies. For this study five frequencies $(250 \mathrm{~Hz}, 500 \mathrm{~Hz}, 1000 \mathrm{~Hz}, 2000 \mathrm{~Hz}$, and $4000 \mathrm{~Hz})$ were considered since

published TL data tables are limited to these frequencies.

The vertical heights of the microphones were adjusted with reference to the center of the hole, which represents an approximate height of a worker's ear from the floor level. The source was an inbuilt signal generator which is available in the NVGate ${ }^{\circledR}$ software. The analyzer was connected via an amplifier to a set of speakers placed in a cardboard box. The source was tested to be fairly non-directional (within $+/-3 \mathrm{~dB}$ ).

Each replication was conducted in the following steps:

1. The plywood plugs with specific opening were set in place for the particular replication based on the randomized opening size table.

2. Required frequency was set using the specific macro in the NVGate ${ }^{\circledR}$ software. 
3. Amplifier gain was adjusted to obtain an output signal that was at least $10 \mathrm{~dB}$ above the background noise level. This setting was kept constant throughout all the experiments in order to obtain a constant power level.

4. The project was then set in RUN mode. After the first 10 seconds the project was paused and sound pressure level readings in $\mathrm{dB}$ for that particular frequency were noted on data collection sheets.

5. Steps 1 to 4 were repeated for each set of replications for the randomized set of opening sizes.

These specific openings were selected so that they are fairly equally spaced on a logarithmic scale.

In order to compute the insertion loss (IL), SPL reading were taken with the source placed outside the enclosure at the same height as inside the enclosure. The NR and IL obtained were compared to the estimated values determined according to the procedure described in the earlier chapter on Prediction of Noise Reductions Due to Enclosures with Openings. 


\section{Results and Discussion}

Noise levels were measured a distance of 60 inches from the source for the facing orientation. The results for the mix of frequencies and opening sizes were then compared. The effects of frequency as well as opening size were shown to be significant.

All the data was first checked for normality and plotted against the studentized residuals to check for any outliers. It was found that the data was normally distributed (Figure 6) and no significant outliers were found.

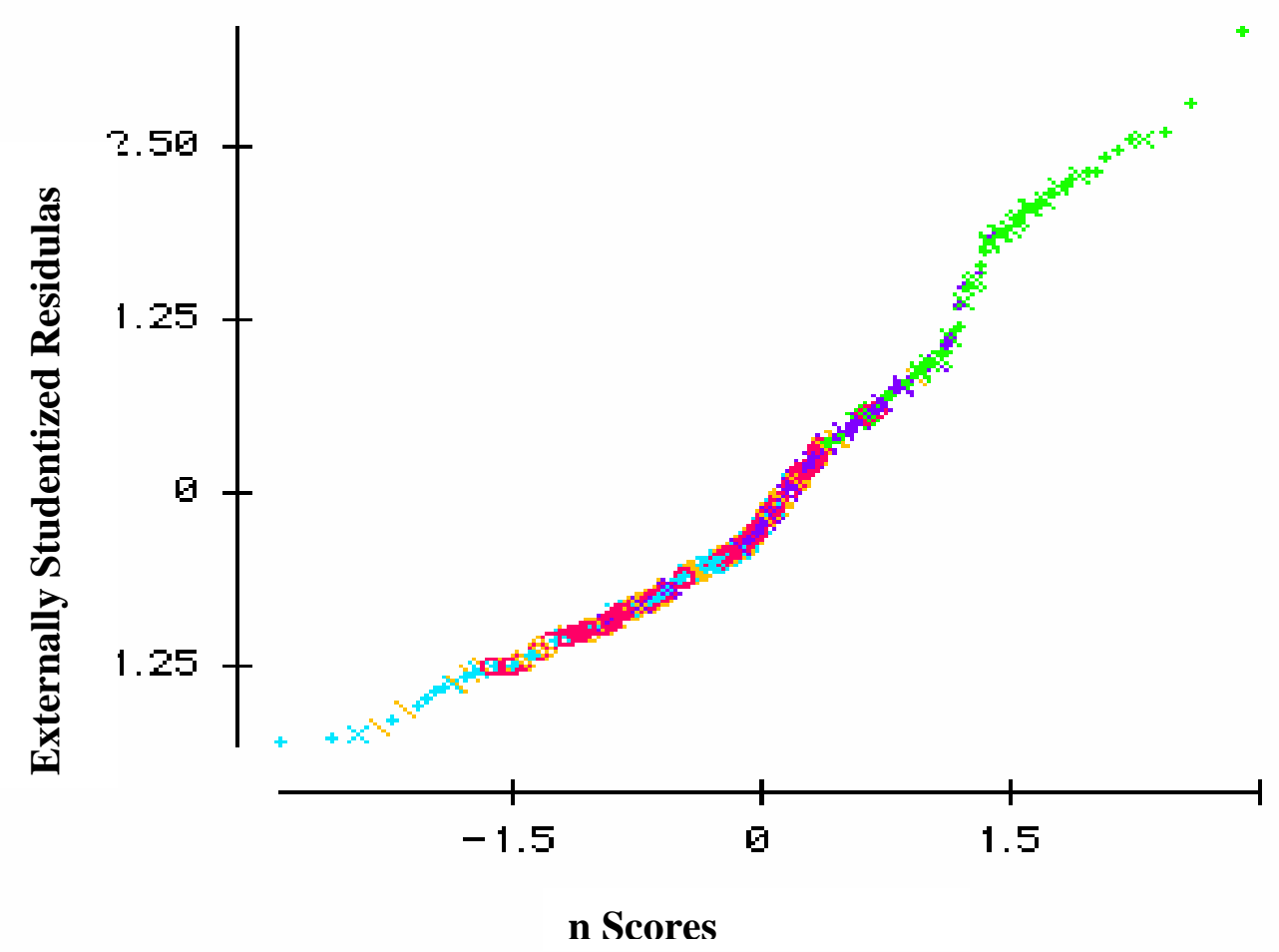

Figure 6. Normal Probability plot of the externally studentized residuals for the Regression of IL vs. Log (Opening Area)

\section{Effect of Opening size on Insertion Loss}

To observe the effect of varying opening sizes on the insertion loss (IL) of the enclosure, the average ILs for all the four microphones in front of the enclosure were employed. The 
average was used because an exposed ear could be at any of these microphone locations and there was no reason to prefer one location over another. Differences among the microphones are discussed in later sections.

In summary, IL varied roughly linearly with the log of opening size and it varied erratically with frequency. Only for the smallest size tested (4 sq.inch) was the IL value consistently positive across all frequencies. The maximum average IL for the 4 sq.in. opening varied from 3 to $20 \mathrm{~dB}$, depending on frequency.

As shown in Figure 7 to Figure 11, for the larger opening sizes the IL values were negative for 250,1000 and $2000 \mathrm{~Hz}$. Note that the "Zero opening" condition was plotted at 0.15 sq.in. for convenience. Negative IL values means that enclosing the source actually increased SPL values. On the other hand, IL values were generally positive for $500 \mathrm{~Hz}$ and $4000 \mathrm{~Hz}$. Indeed, for $500 \mathrm{~Hz}$ a positive IL was achieved even for largest opening areas ( $4 \mathrm{~dB}$ for both 855 sq.in. and 252 sq.in.). For $4000 \mathrm{~Hz}$, IL values were positive for all except the largest opening.

As shown in Figure 7 to Figure 11, IL appeared to decline linearly with increasing logtransformed opening sizes. Note that the scatter of the observed values is considerably exacerbated by using all 5 microphone location's values. As shown in Table 4, the slopes for all the frequencies were negative and varied from -7.15 to -4.62 . The adjusted Rsquare for $250 \mathrm{~Hz}$ and $2000 \mathrm{~Hz}$ was fairly high at 81.5 and 76.2, respectively. However other frequencies had more modest adjusted R-square values ranging between of 48.7 and 54.5. Note that the "Zero opening" condition was not included in the regression since the log-transformed value of zero is minus infinity. In any case, the zero case clearly did not fit on the same predictive lines as the other opening sizes. Note, also, that the regression coefficients were about the same (not shown) using any one of the microphone locations instead of the average of all. 


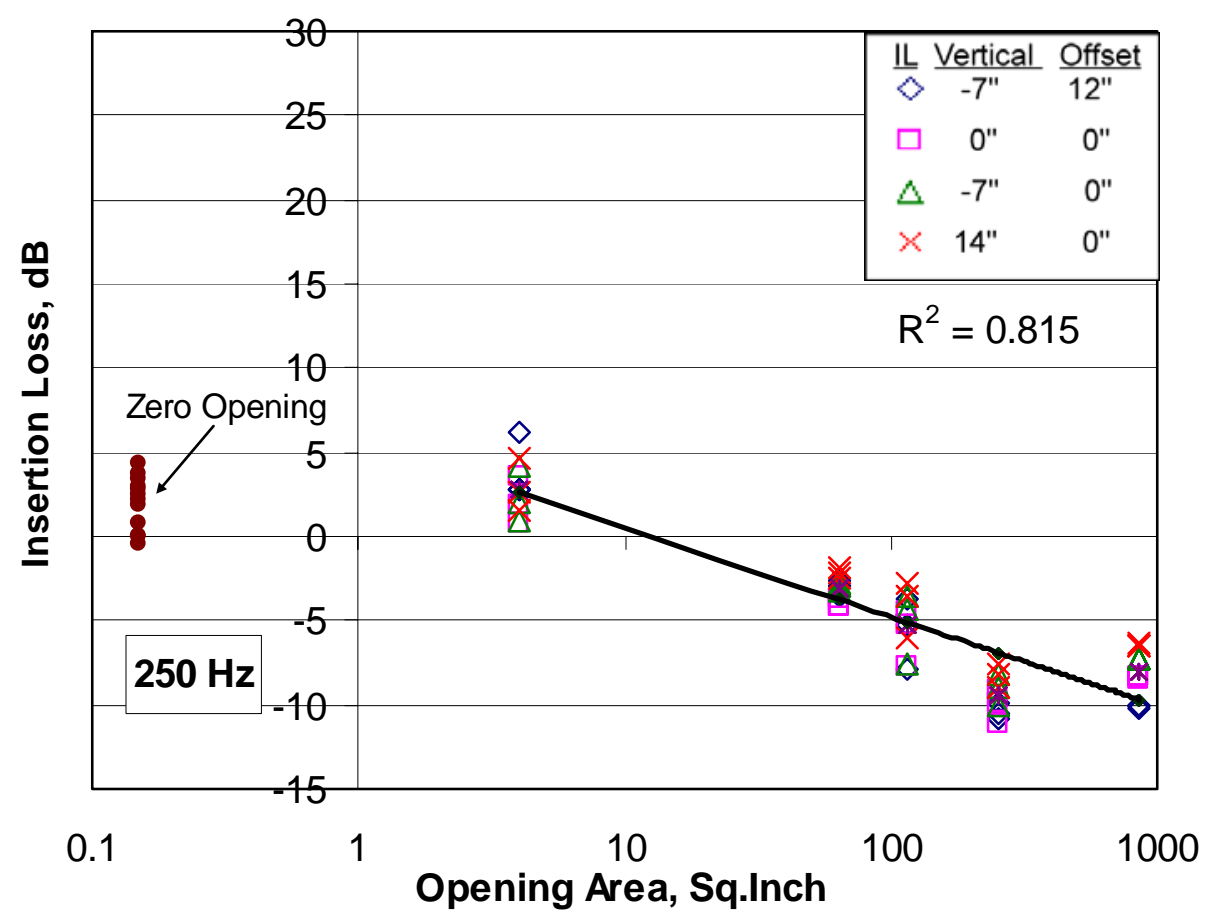

Figure 7. Variation of Insertion Loss with Opening Area for $250 \mathrm{~Hz}$

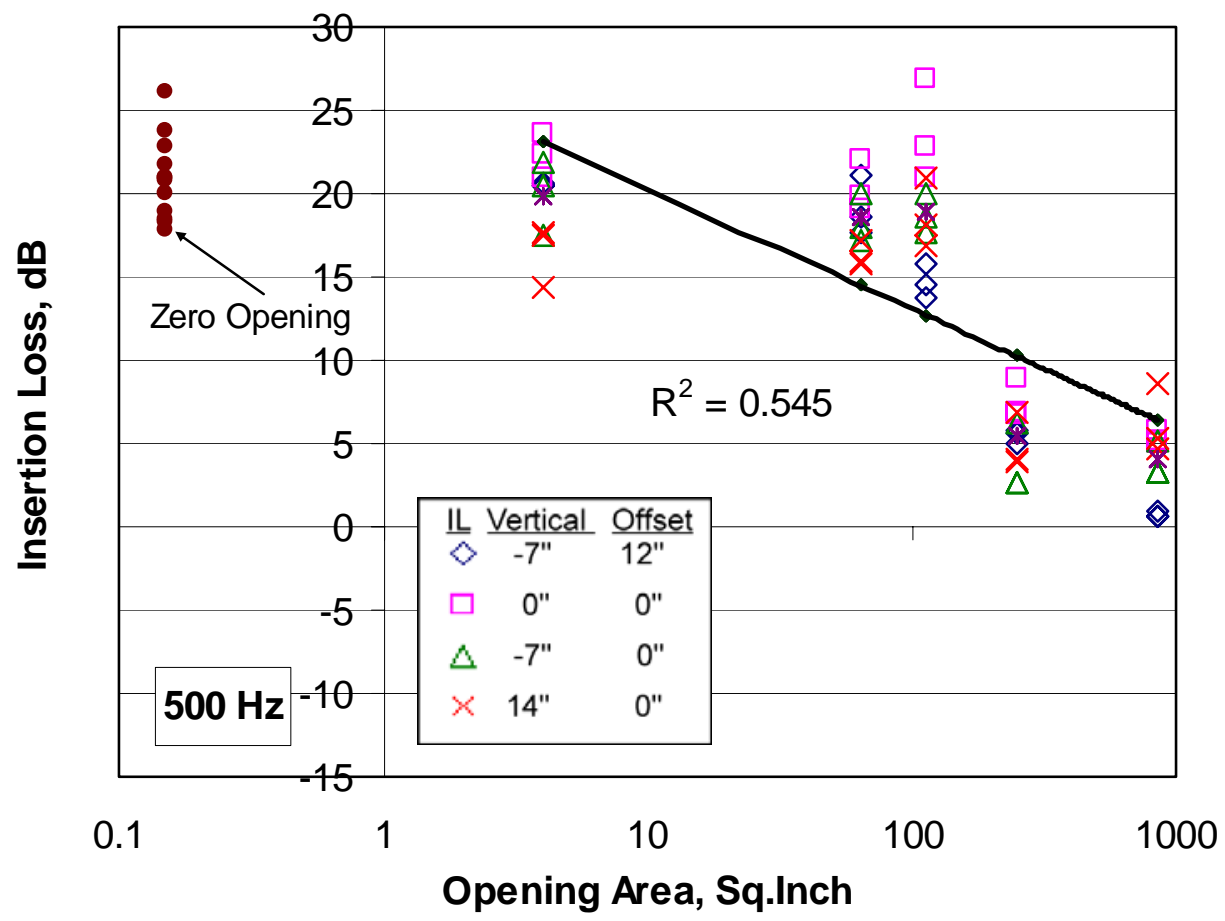

Figure 8. Variation of Insertion loss with Opening Area for $500 \mathrm{~Hz}$ 


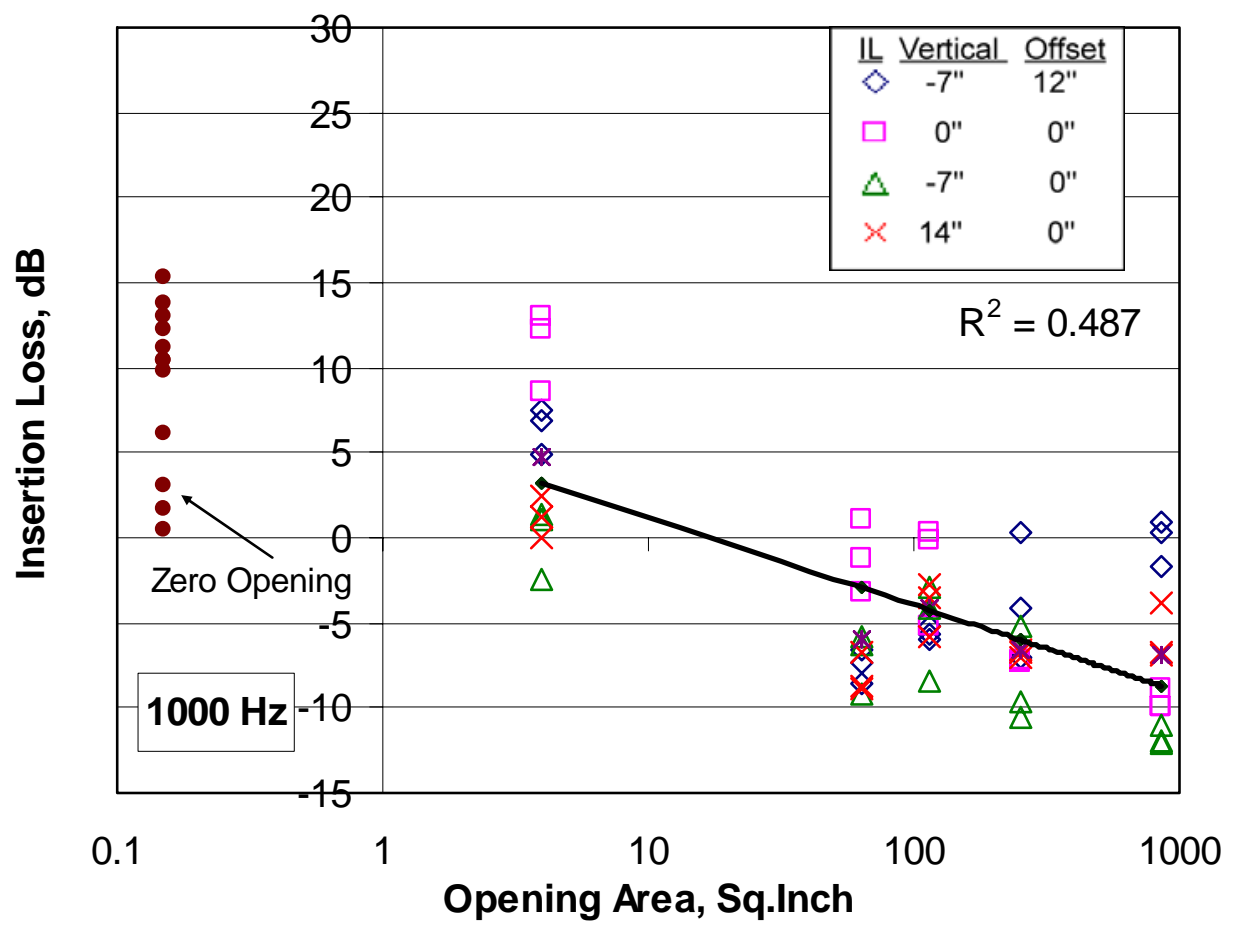

Figure 9. Variation of Insertion Loss with Opening Area for $1000 \mathrm{~Hz}$

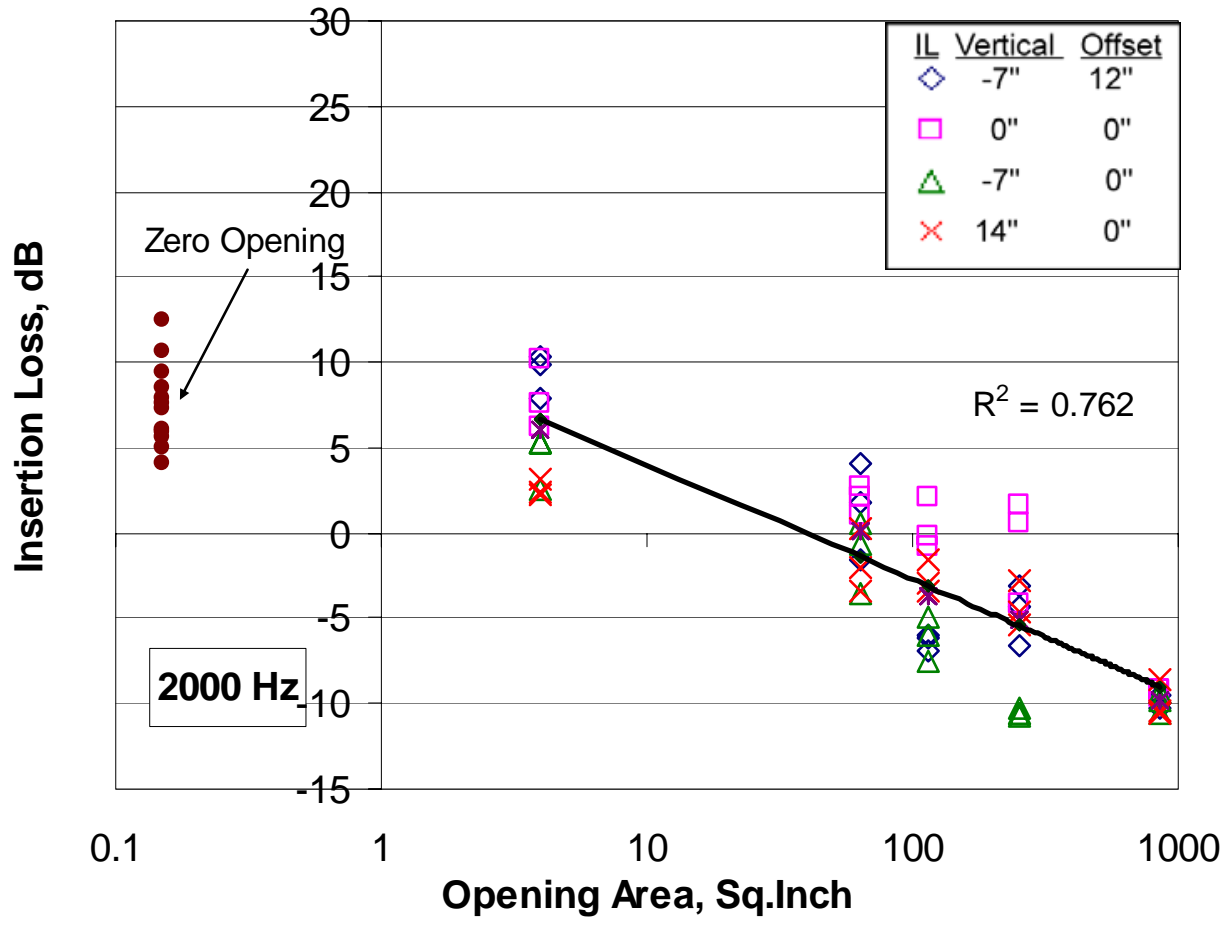

Figure 10. Variation of Insertion loss with Opening Area for $2000 \mathrm{~Hz}$ 


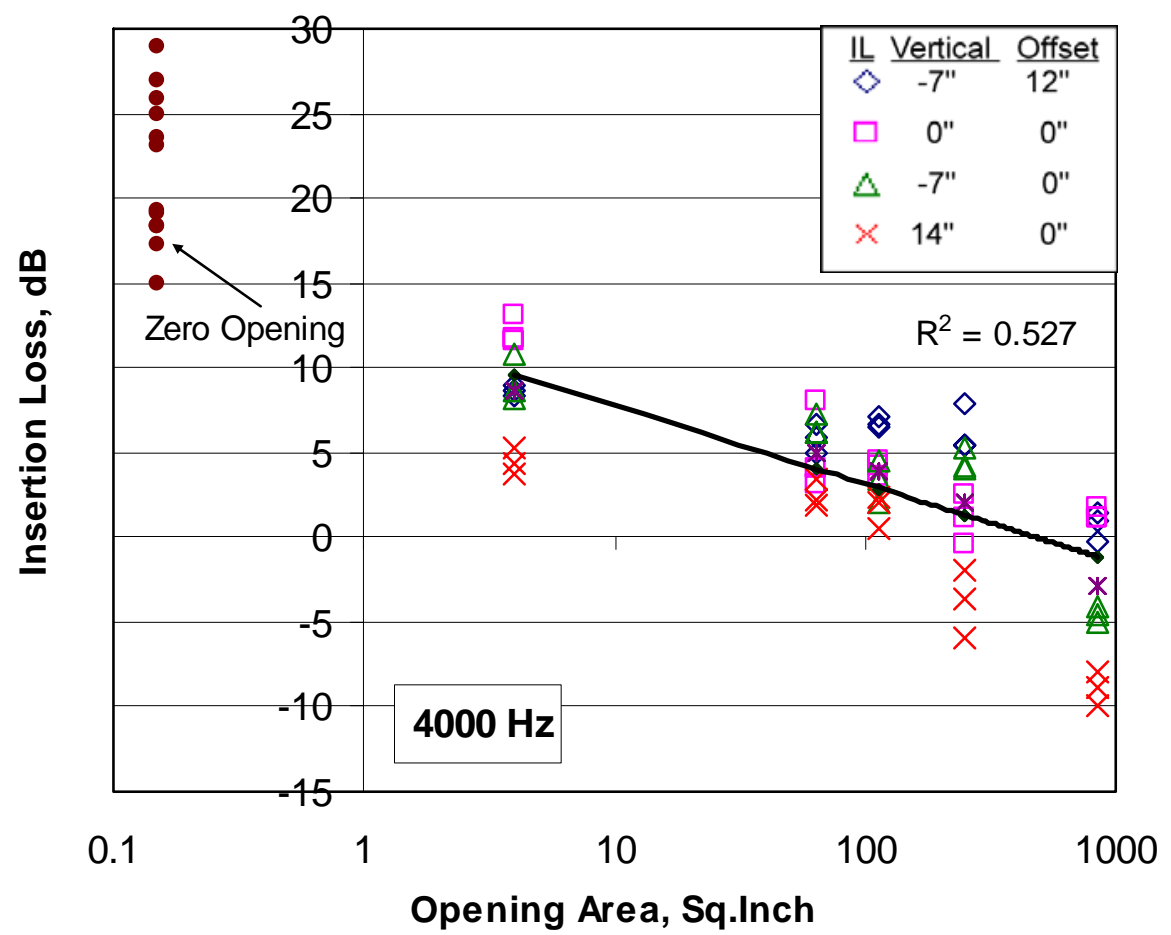

Figure 11. Variation of Insertion Loss with Opening Area for $4000 \mathrm{~Hz}$

Table 4. Slopes for variation of Insertion Loss with Opening Areas for average of all Microphones

\begin{tabular}{|c|c|c|c|}
\hline $\begin{array}{c}\text { Frequency } \\
(\mathbf{H z})\end{array}$ & Regression Equation & Slope & R-square \\
\hline 250 & $\mathrm{IL}=-5.255^{\star} \log ($ Opening_Area)+ 5.718 & -5.23 & 81.5 \\
\hline 500 & $\mathrm{IL}=-7.153^{\star} \log ($ Opening_Area)+ 27.377 & -7.15 & 54.5 \\
\hline 1000 & $\mathrm{IL}=-5.113^{\star} \log ($ Opening_Area)+ 6.280 & -5.11 & 48.7 \\
\hline 2000 & $\mathrm{IL}=-6.744^{\star} \log ($ Opening_Area)+ 10.754 & -6.74 & 76.2 \\
\hline 4000 & $\mathrm{IL}=-4.62{ }^{\star} \log ($ Opening_Area)+ 12.393 & -4.62 & 52.7 \\
\hline
\end{tabular}

Table 4 shows various regression models for the variation of IL with the opening area for different frequencies. For "Zero Opening" condition the IL is simply equal to the intercept value in the regression model. 
From Table 4, it can be seen that the regression models show high and varied regression constants with values as high as $27 \mathrm{~dB}$ and as low as $-5 \mathrm{~dB}$. These regression constants and for some frequencies $(500 \mathrm{~Hz}, 1000 \mathrm{~Hz}$, and $4000 \mathrm{~Hz})$ modest adjusted R-square values suggest that the logarithmic transformation of the opening area is not a sufficient estimator of IL (except possibly for $250 \mathrm{~Hz}$ and $2000 \mathrm{~Hz}$ ). They also suggest that frequency is a powerful and erratic variable.

However since frequency has a major effect on the prediction of IL, including it and other variables like microphone position and the effect of replication in the model would help in developing a common model for all the frequencies.

A statistical fixed effects model was first assumed in order to check the contribution of each variable to the model (Equation (13)).Further an ANOVA including all possible variables was computed (and Table 5). Based on the percentage contributed by each term to the total sum of squares they were either included or excluded from the model.

$$
\begin{aligned}
& I L_{i j k l}= \\
& {\left[\mu+\text { Freq }_{i}+\log (\text { Op_Area })_{j}+\text { repl }_{k}+\text { MicPosition }_{l}+\left(\text { Freq* Log }\left(O p_{-} \text {Area }\right)\right)_{i j}+\right.} \\
& \left(\text { Freq }^{*} \text { repl }\right)_{i k}+\left(\log \left(O \mathrm{P}_{-} \text {Area }\right) * \text { repl }\right)_{j k}+\left(\log \left(\mathrm{Op}_{-} \text {Area }\right) * \text { MicPositio }\right)_{j l}+ \\
& \left(\text { Freq }^{*} \text { MicPosition }\right)_{i l}+\left(\text { repl }^{*} \text { MicPosition }\right)_{k l}+\left(\text { Freq }^{*} \log \left(O \text { Op_Area }^{*} * \text { MicPositio }\right)_{i l}\right. \\
& +\left(\text { Freq*Log }\left(O p_{-} \text {Area }\right) * \text { repl }\right)_{i j k}+\left(\log \left(O p_{-} \text {Area }\right) * \text { repl* MicPositio }\right)_{j k l}+ \\
& (\text { Freq* repl* MicPosition })_{i k l}+\varepsilon_{i j k l}
\end{aligned}
$$

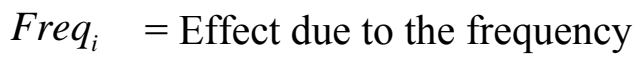

$\log \left(\mathrm{Op} \_ \text {Area }\right)_{j} \quad=$ Effect due to the Logarithm of the opening area

$$
\operatorname{repl}_{k}=\text { Effect due to different replications }
$$

MicPosition $_{l}=$ Effect due to position of the microphone

$$
\begin{aligned}
\varepsilon_{i j k l} & =\text { Random Error component that incorporates all other sources of } \\
& \text { variability in the experiment including measurement, variability arising } \\
& \text { from uncontrolled factors and general background noise in the process }
\end{aligned}
$$


Table 5. Analysis of Variance for Insertion Loss Averaged over all Microphones with all variables included

\begin{tabular}{|c|c|c|c|c|c|c|}
\hline Source & df & $\begin{array}{l}\text { Sums of } \\
\text { Squares }\end{array}$ & $\begin{array}{l}\text { Mean } \\
\text { Square }\end{array}$ & Prob & $\begin{array}{c}\text { Percentage } \\
\text { Contribution } \\
\text { (of SS) to the } \\
\text { Model }\end{array}$ & Decision \\
\hline Constant & 1 & 419.492 & 419.492 & $<0.0001$ & - & - \\
\hline Frequency & 4 & 13417.5 & 3354.37 & $<0.0001$ & $57.11 \%$ & Include \\
\hline Log (Opening Area) & 4 & 6328.57 & 1582.14 & $<0.0001$ & $26.93 \%$ & Include \\
\hline Replication & 2 & 19.6664 & 9.8332 & 0.0007 & $0.08 \%$ & Exclude \\
\hline Microphone Postion & 3 & 365.85 & 121.95 & $<0.0001$ & $1.55 \%$ & Exclude \\
\hline $\begin{array}{c}\text { Frequency * } \\
\text { Log(Opening Area) }\end{array}$ & 16 & 1441.26 & 90.0789 & $<0.0001$ & $6.13 \%$ & Include \\
\hline $\begin{array}{l}\text { Frequency * } \\
\text { Replication }\end{array}$ & 8 & 49.2103 & 6.15128 & $<0.0001$ & $0.20 \%$ & Exclude \\
\hline $\begin{array}{c}\text { Log(Opening Area) * } \\
\text { Replication }\end{array}$ & 8 & 36.9133 & 4.61416 & 0.0009 & $0.15 \%$ & Exclude \\
\hline $\begin{array}{l}\text { Log(Opening Area)* } \\
\text { Microphone Postion }\end{array}$ & 12 & 205.981 & 17.1651 & $<0.0001$ & $0.87 \%$ & Exclude \\
\hline $\begin{array}{c}\text { Frequency * } \\
\text { Microphone Postion }\end{array}$ & 12 & 566.093 & 47.1744 & $<0.0001$ & $2.40 \%$ & Exclude \\
\hline $\begin{array}{c}\text { Replication * } \\
\text { Microphone Postion }\end{array}$ & 6 & 10.7589 & 1.79316 & 0.2119 & $0.04 \%$ & Exclude \\
\hline $\begin{array}{c}\text { Frequency * } \\
\text { Log(Opening Area) * } \\
\text { Microphone Postion }\end{array}$ & 48 & 723.534 & 15.0736 & $<0.0001$ & $3.07 \%$ & Exclude \\
\hline $\begin{array}{c}\text { Frequency * } \\
\text { Log(Opening Area) * } \\
\text { Replication }\end{array}$ & 32 & 160.967 & 5.03021 & $<0.0001$ & $0.68 \%$ & Exclude \\
\hline $\begin{array}{l}\text { Log(Opening Area) * } \\
\text { Replication * } \\
\text { Microphone Position }\end{array}$ & 24 & 23.1627 & 0.965114 & 0.7658 & $0.09 \%$ & Exclude \\
\hline $\begin{array}{c}\text { Frequency * } \\
\text { Replication * } \\
\text { Microphone Position }\end{array}$ & 24 & 22.3884 & 0.93285 & 0.7951 & $0.09 \%$ & Exclude \\
\hline Error & 96 & 120.553 & 1.25576 & & & \\
\hline Total & 299 & 23492.4 & & & & \\
\hline
\end{tabular}

From the Table 4, it can be observed that the log of opening area, frequency and their interaction contribute $90.1 \%$ towards the model. Hence they were included in the 
statistical model. The variables that contributed $5 \%$ or less were excluded from the model. Also, if any higher order interaction contributed marginally above 5\% they were excluded from the model. The reduced statistical model is shown in Equation (14).

$$
I L_{i j k l}=\left[\mu+\text { Freq }_{i}+\log \left(O p_{-} \text {Area }\right)_{j}+\left(\text { Freq }^{*} \log \left(O p_{-} \text {Area }\right)\right)_{i j}+\varepsilon_{i j k l}\right]
$$

Although the homogeneity of error variances computed using the regression models stated in Table 4 was not completely satisfied (Modified Levene Test (Nutter, et.al, (1996), for procedure see Appendix), the F test is only slightly affected in the balanced fixed effects models (Montgomery, 2001).

As in all analyses, the Zero opening condition was not taken into consideration. From ANOVA (Table 6), it can be observed that the interaction between opening area and frequency was significant $(\mathrm{p}=0.0111)$. Also, the difference between the three replications was not significant, indicating good repeatability of the experiment under same acoustic conditions.

Table 6. Analysis of Variance for Insertion Loss Averaged over all Microphones with Log(Opening Area)

\begin{tabular}{|c|c|c|c|c|c|}
\hline Source & df & $\begin{array}{c}\text { Sums of } \\
\text { Squares }\end{array}$ & Mean Square & F-ratio & Prob \\
\hline Const & 1 & 419.492 & 419.492 & 34.489 & $<0.0001$ \\
\hline Frequency & 4 & 13417.5 & 3354.37 & 252.23 & $<0.0001$ \\
\hline Log(Opening area) & 1 & 6041.54 & 6041.54 & 454.3 & $<0.0001$ \\
\hline $\begin{array}{c}\text { Log(Opening area) * } \\
\text { Frequency }\end{array}$ & 4 & 176.764 & 44.191 & 3.323 & 0.0111 \\
\hline Error & 290 & 3856.61 & 13.2986 & & \\
\hline Total & 299 & 23492.4 & & & \\
\hline
\end{tabular}


Table 7. Scheffe's post hoc test for comparison of Insertion Loss at different frequencies

\begin{tabular}{|c|c|c|}
\hline $\begin{array}{c}\text { Frequency } \\
\text { (Hz) }\end{array}$ & $\begin{array}{c}\text { Difference } \\
\text { between IL } \\
\text { (dB) Means }\end{array}$ & Prob \\
\hline $500-250$ & 17.94 & 0.0000 \\
\hline $1000-250$ & 0.84 & 0.7943 \\
\hline $1000-500$ & -17.10 & 0.0000 \\
\hline $2000-250$ & 2.12 & 0.0327 \\
\hline $2000-500$ & -15.82 & 0.0000 \\
\hline $2000-1000$ & 1.28 & 0.4243 \\
\hline $4000-250$ & 7.92 & 0.0000 \\
\hline $4000-500$ & -10.02 & 0.0000 \\
\hline $4000-1000$ & 7.08 & 0.0000 \\
\hline $4000-2000$ & 5.80 & 0.0000 \\
\hline
\end{tabular}

Comparison of means for different frequencies using scheffe's post hoc test suggested that average IL at frequencies $250 \mathrm{~Hz}$ and $1000 \mathrm{~Hz}, 250 \mathrm{~Hz}$ and $2000 \mathrm{~Hz}$, and $1000 \mathrm{~Hz}$ and $2000 \mathrm{~Hz}$ were not significantly different. On the other hand, $500 \mathrm{~Hz}$ and $4000 \mathrm{~Hz}$ behaved differently compared to other frequencies.

\section{Effect of Opening size on Noise Reduction}

Noise reduction is an alternate method used to predict the effectiveness of the enclosure. It is not as meaningful to lay people, who generally wish to know the effectiveness of an enclosure in reducing worker exposures, for which IL is a direct measure. Unlike the IL, NR is a measure of the noise differential inside and outside the enclosure measured at the same time. The difference in IL and NR values would be due to reverberant buildup inside the box. If the difference is high, then increasing the absorptivity inside the enclosure could reduce IL.

As with IL computations, the average NR for all four microphones in front of the enclosure was used in analyses of results, but all graphs include results from each microphone location separately. 
In general, NR values were much high than IL, presumably because no acoustical materials were used to line the inside of the enclosure. Even with an opening area of 855 sq.inch $(5.063 \%)$, NR values of 10-24 dB were found, depending on frequency (see Figure 12 to Figure 16). For $1000 \mathrm{~Hz}$, the NR decreased with increase in opening area from 4 sq.inch $(0.024 \%)$ to 64 sq.inch $(0.379 \%)$ and then increased with increases in the opening area (see Figure 12 to Figure 16). This phenomenon is difficult to comprehend since one might expect NR to decrease steadily with increases in the opening area. 


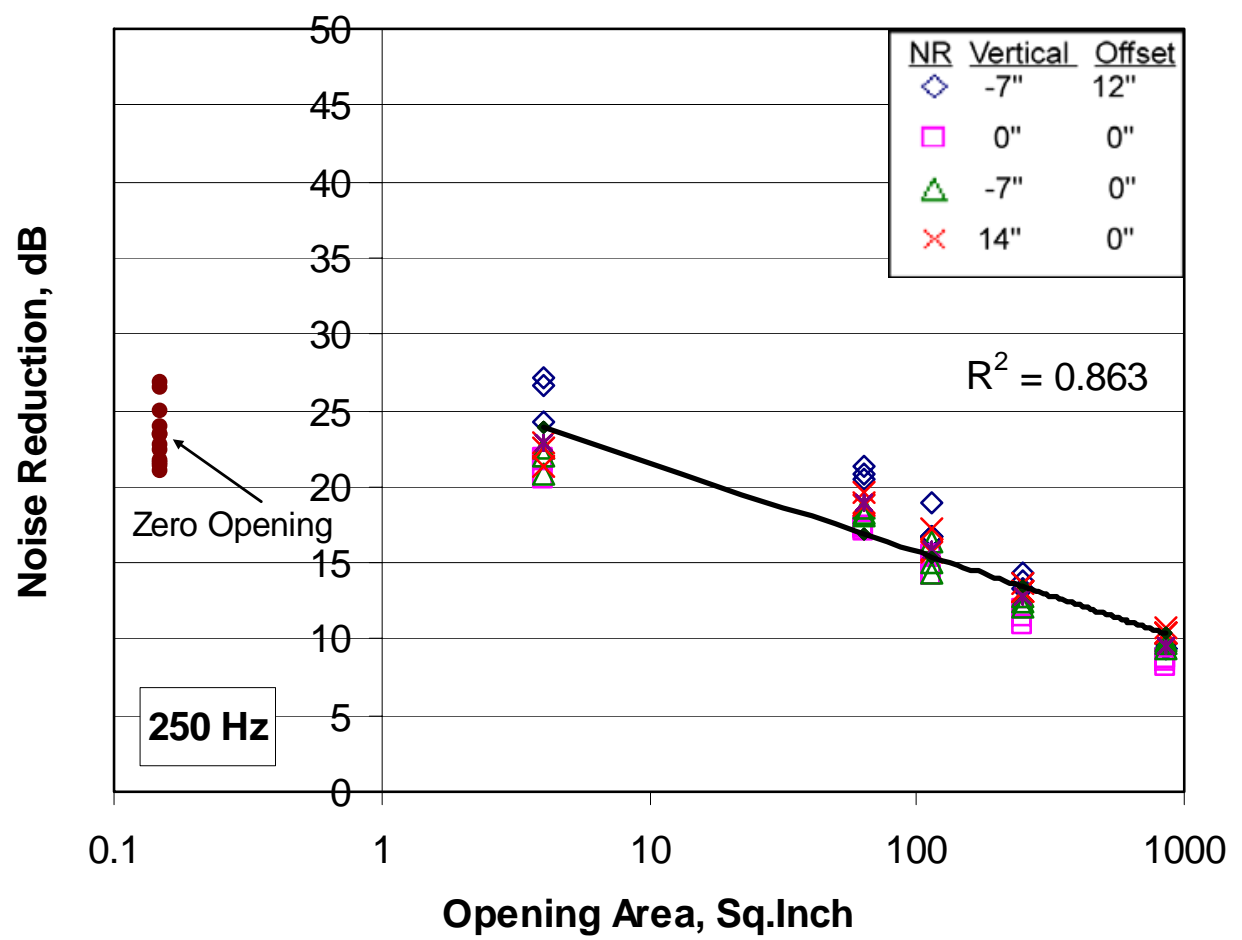

Figure 12. Variation of Noise Reduction with Opening Area for $250 \mathrm{~Hz}$

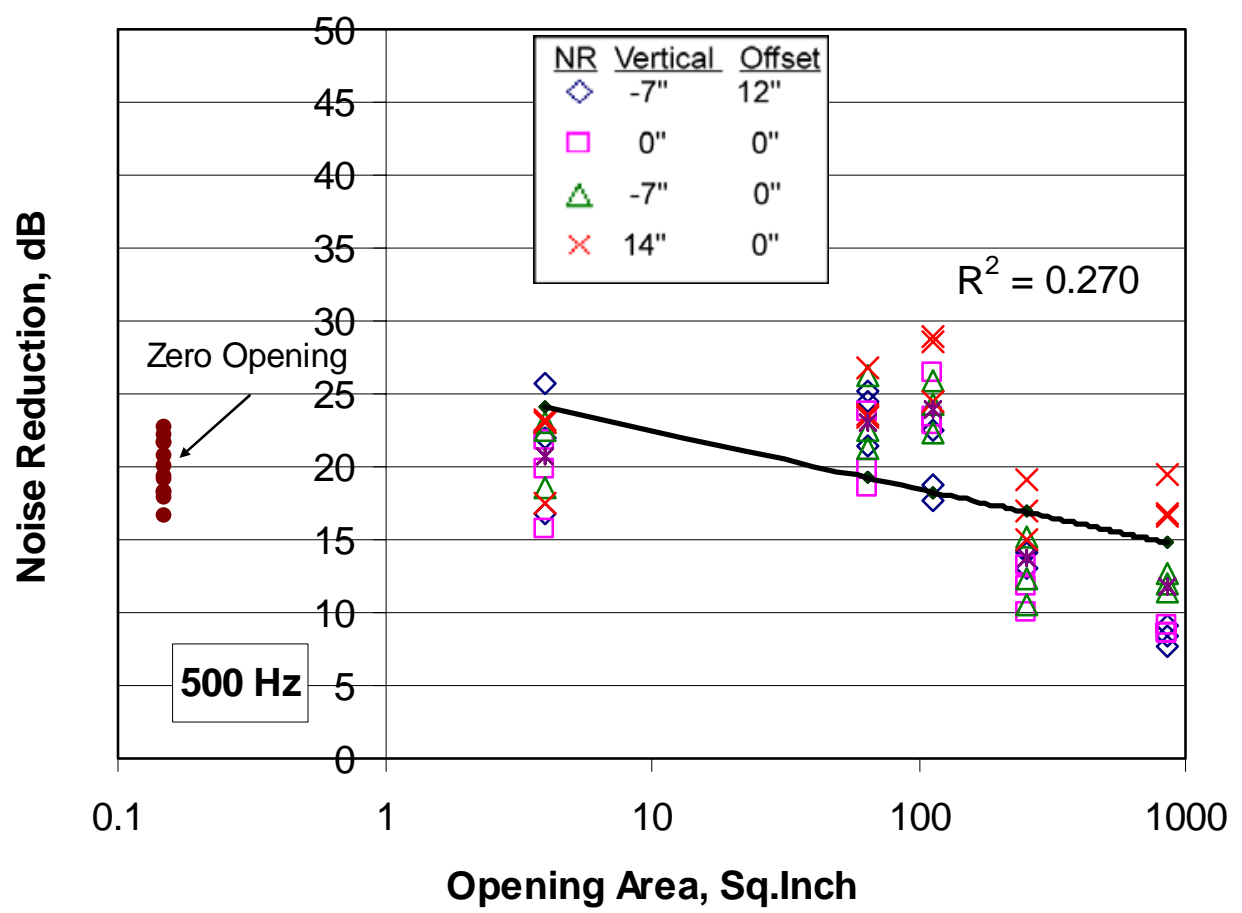

Figure 13. Variation of Noise Reduction with Opening Area for $500 \mathrm{~Hz}$ 


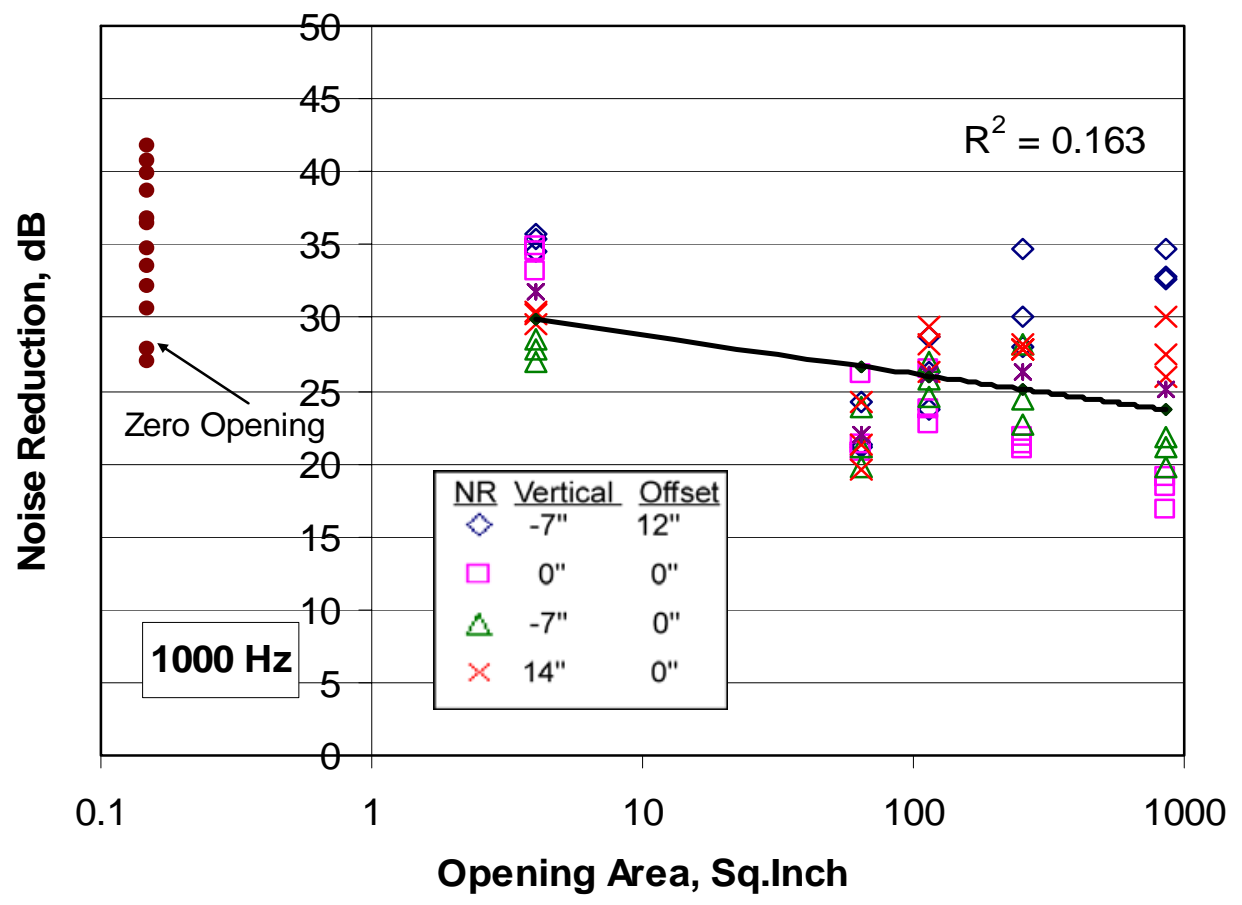

Figure 14. Variation of Noise Reduction with Opening Area for $1000 \mathrm{~Hz}$

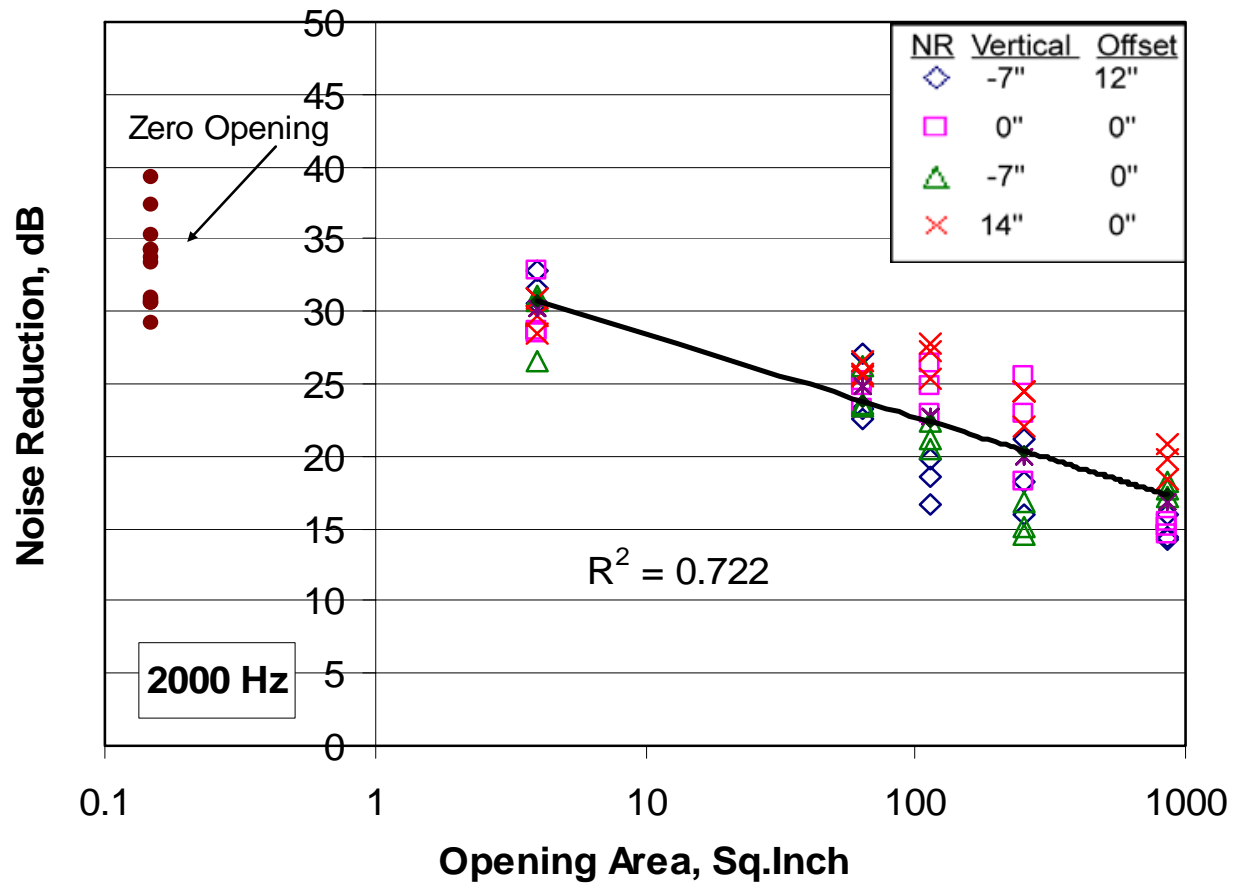

Figure 15. Variation of Noise Reduction with Opening Area for $2000 \mathrm{~Hz}$ 


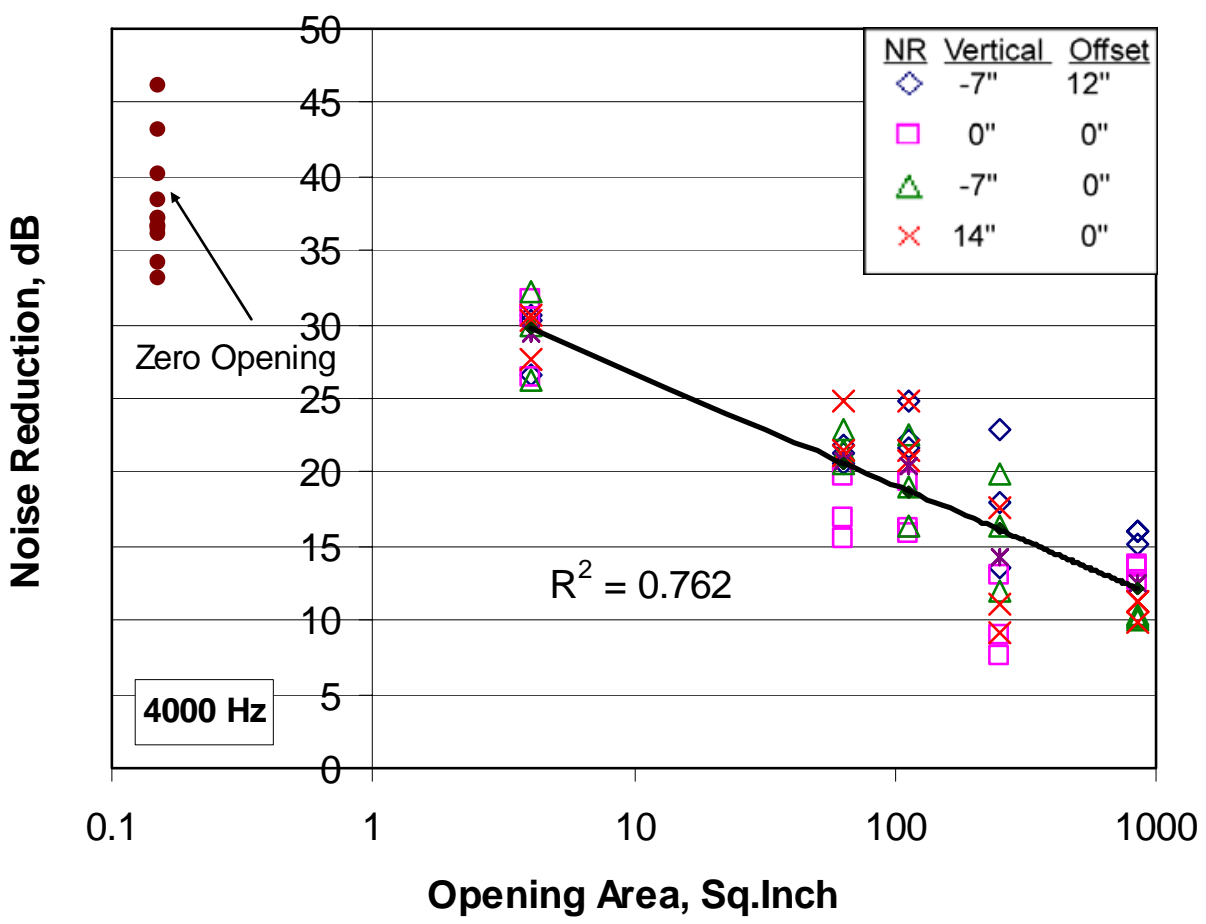

Figure 16. Variation of Noise Reduction with Opening Area for $4000 \mathrm{~Hz}$

Table 8. Slopes for variation of Noise Reduction with Opening Areas for average of all Microphones

\begin{tabular}{|c|c|c|c|}
\hline $\begin{array}{l}\text { Frequency } \\
(\mathrm{Hz})\end{array}$ & Equation & Slope & $\begin{array}{c}\mathrm{R}- \\
\text { square }\end{array}$ \\
\hline 250 & $N R=-5.787^{*} \log ($ Opening_Area $)+27.320$ & -5.79 & 86.3 \\
\hline 500 & $N R=-3.975^{\star} \log ($ Opening_Area $)+26.429$ & -3.98 & 27 \\
\hline 1000 & $N R=-2.653^{\star} \log ($ Opening_Area $)+31.468$ & -2.65 & 16.3 \\
\hline 2000 & $N R=-5.755^{\star}$ Log(Opening_Area $)+34.200$ & -5.76 & 72.2 \\
\hline 4000 & $N R=-7.534 *$ Log(Opening_Area $)+34.210$ & -7.53 & 76.2 \\
\hline
\end{tabular}

As shown in Table 8, the adjusted R-square for a linear relationship between $\log$ (Opening) and NR values for $250 \mathrm{~Hz}, 2000 \mathrm{~Hz}$, and $4000 \mathrm{~Hz}$ (considered separately) was fairly high (86.3, 72.2 and 76.2, respectively). However, for $500 \mathrm{~Hz}$ and $1000 \mathrm{~Hz}$ the adjusted R-square values were very low (27 and 16.3, respectively), indicating that increase in the opening area does not necessarily increase the noise reduction at these 
frequencies. This observation was consistent with the low slopes of their regression lines. In both cases, NR did not fall monotonically with increasing values of Opening.

Similar to IL, a statistical model with all possible variables was stated and ANOVA was computed to determine the percentage contribution to the Sum of Squares of each variable or interaction. It was found that the frequency, log of opening area and their interaction contributed over $86.6 \%$ to the model (Equation (15)).

$N R_{i j k l}=\left\lfloor\mu+\right.$ Freq $\left._{i}+\log \left(O p_{-} \text {Area }\right)_{j}+\left(\text { Freq* Log }\left(O p_{-} \_ \text {Area }\right)\right)_{i j}+\varepsilon_{i j k l}\right\rfloor$

Table 9. Analysis of Variance for effect of Opening Area and Frequency on the NR

\begin{tabular}{|c|c|c|c|c|c|}
\hline Source & $\mathbf{d f}$ & $\begin{array}{c}\text { Sums of } \\
\text { Squares }\end{array}$ & $\begin{array}{c}\text { Mean } \\
\text { Square }\end{array}$ & F-ratio & Prob \\
\hline Constant & 1 & 127935 & 127935 & 10354 & $<0.0001$ \\
\hline Frequency & 4 & 3841.2 & 960.3 & 71.255 & $<0.0001$ \\
\hline Log(Opening Area) & 1 & 4783.87 & 4783.87 & 354.97 & $<0.0001$ \\
\hline $\begin{array}{c}\text { Log(Opening area)* } \\
\text { Frequency }\end{array}$ & 4 & 509.144 & 127.286 & 9.4447 & $<0.0001$ \\
\hline Error & 290 & 3908.31 & 13.4769 & & \\
\hline Total & 299 & 13042.5 & & & \\
\hline
\end{tabular}

The significance of all independent variables was investigated using ANOVA. As shown in Table 9, log of opening area, frequency, and the interaction of frequency were significant at $\mathrm{p}<0.0001$. 
Table 10. Scheffe's post hoc test for comparison of Noise Reduction at different frequencies

\begin{tabular}{|c|c|c|}
\hline $\begin{array}{c}\text { Frequency } \\
(\mathbf{H z})\end{array}$ & $\begin{array}{c}\text { Difference } \\
\text { between IL } \\
\text { (dB) Means }\end{array}$ & Prob \\
\hline $500-250$ & 2.66 & 0.0049 \\
\hline $1000-250$ & 10.29 & 0.0000 \\
\hline $1000-500$ & 7.63 & 0.0000 \\
\hline $2000-250$ & 6.94 & 0.0000 \\
\hline $2000-500$ & 4.28 & 0.0000 \\
\hline $2000-1000$ & -3.35 & 0.0001 \\
\hline $4000-250$ & 3.47 & 0.0001 \\
\hline $4000-500$ & 0.81 & 0.8438 \\
\hline $4000-1000$ & -6.82 & 0.0000 \\
\hline $4000-2000$ & -3.48 & 0.0001 \\
\hline
\end{tabular}

From Scheffe's post hoc test in Table 10 one can observe that the except $4000 \mathrm{~Hz}$ and $250 \mathrm{~Hz}$, all other frequencies tend to behave differently with difference between the NR means ranging from 2.66 to $10.29 \mathrm{~dB}$.

\section{Effect of Frequency on Insertion Loss}

As shown on Figure 17 to Figure 23, for all the five frequencies a spike in the IL at 500 $\mathrm{Hz}$ was observed. The lowest IL observed was for $250 \mathrm{~Hz}$ and $1000 \mathrm{~Hz}$ for each opening size. 


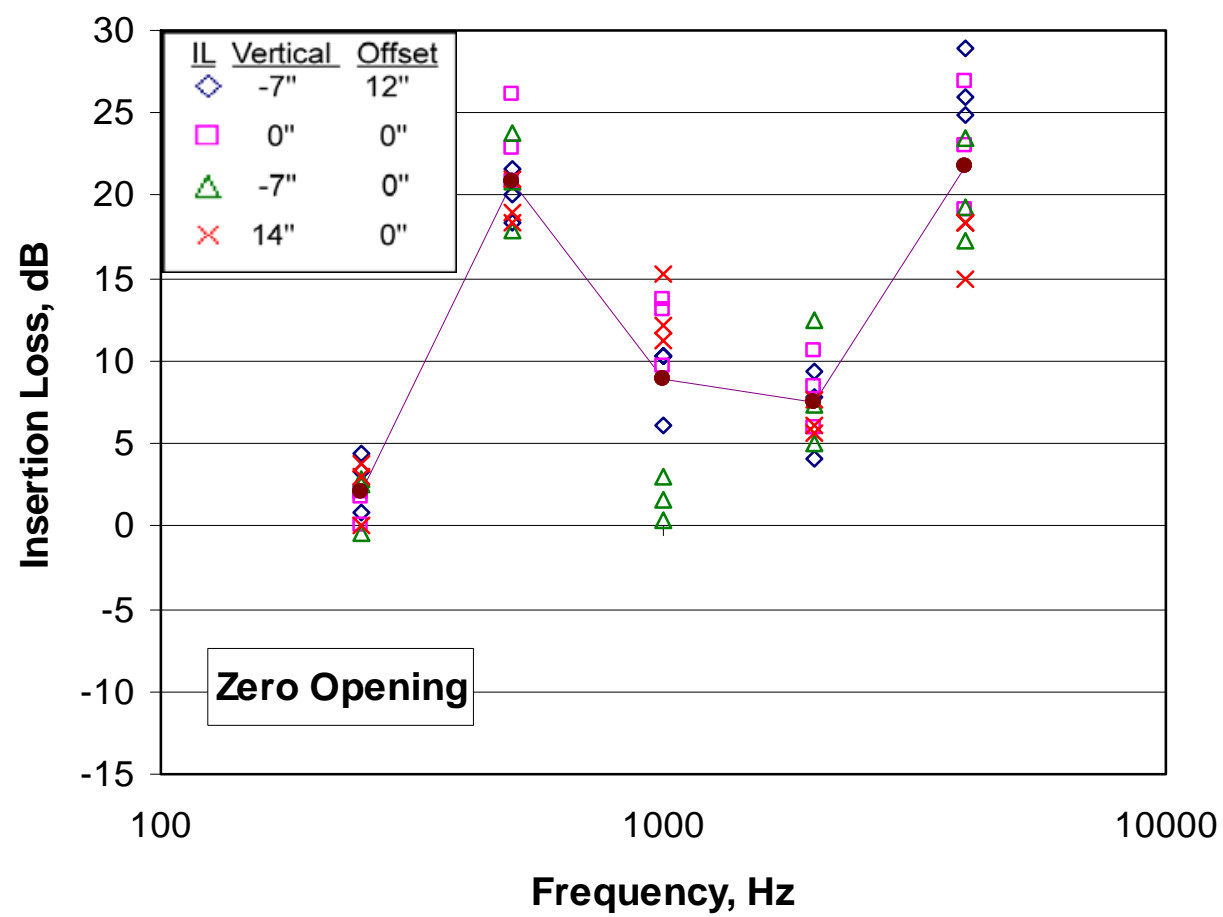

Figure 17. Variation of Insertion Loss with Frequency for Zero Opening area

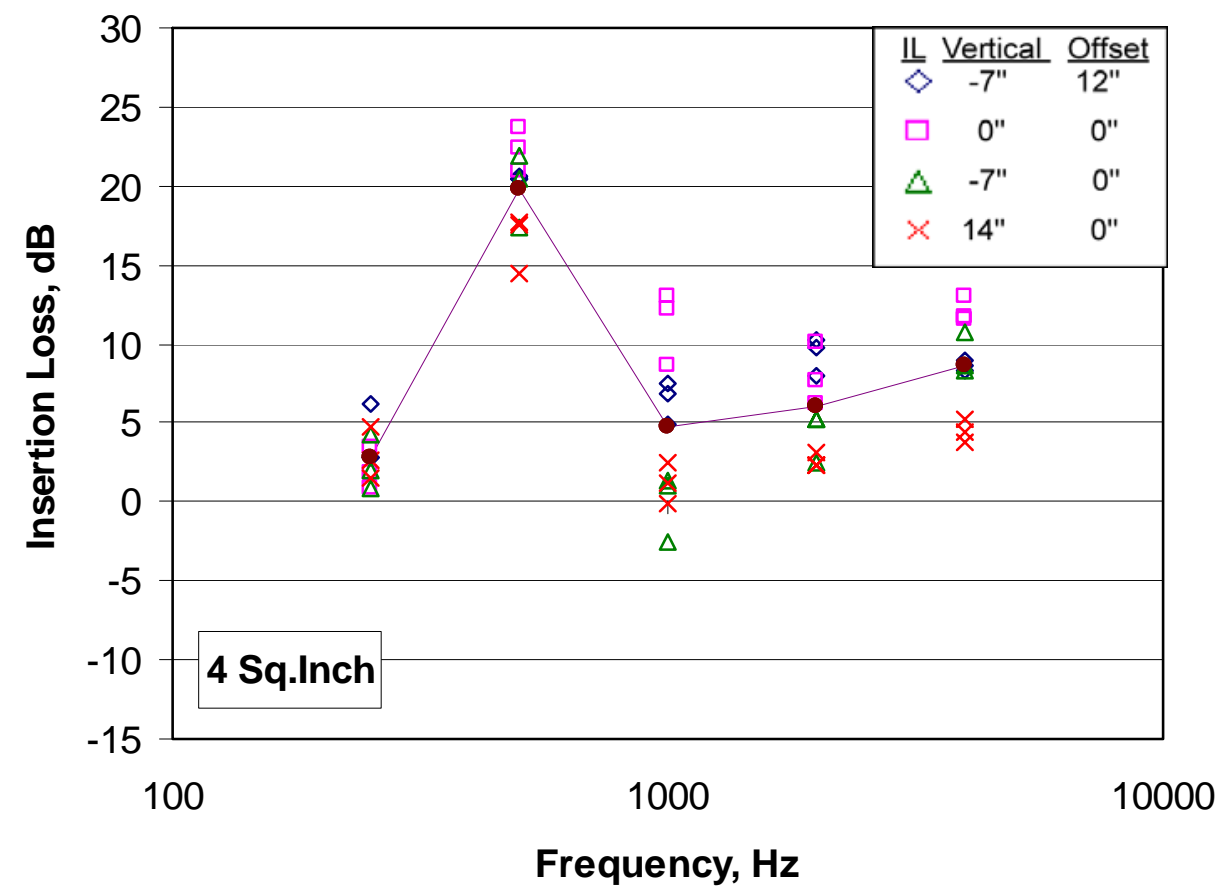

Figure 18. Variation of Insertion Loss with Frequency for 4 Sq.Inch Opening area 


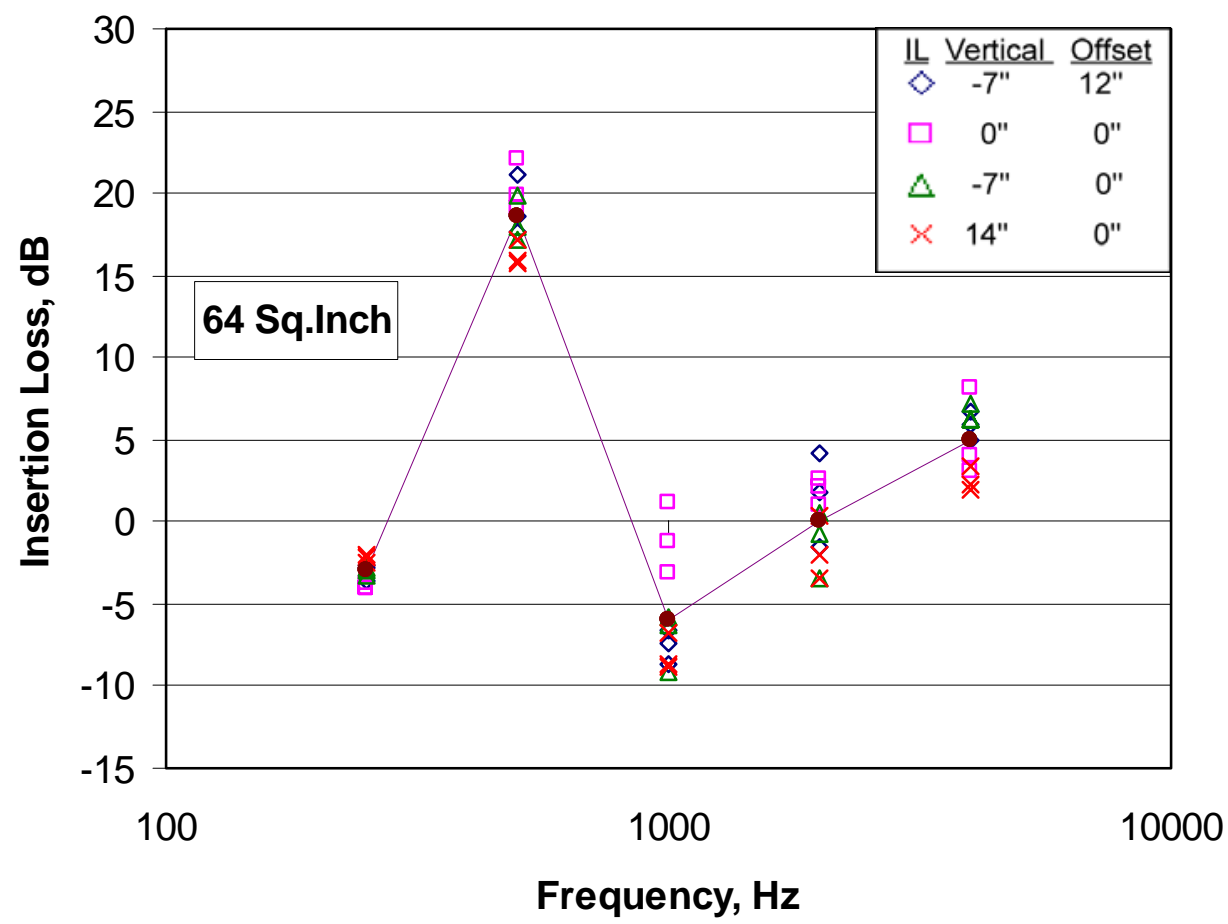

Figure 19. Variation of Insertion Loss with Frequency for 64 Sq.Inch Opening area

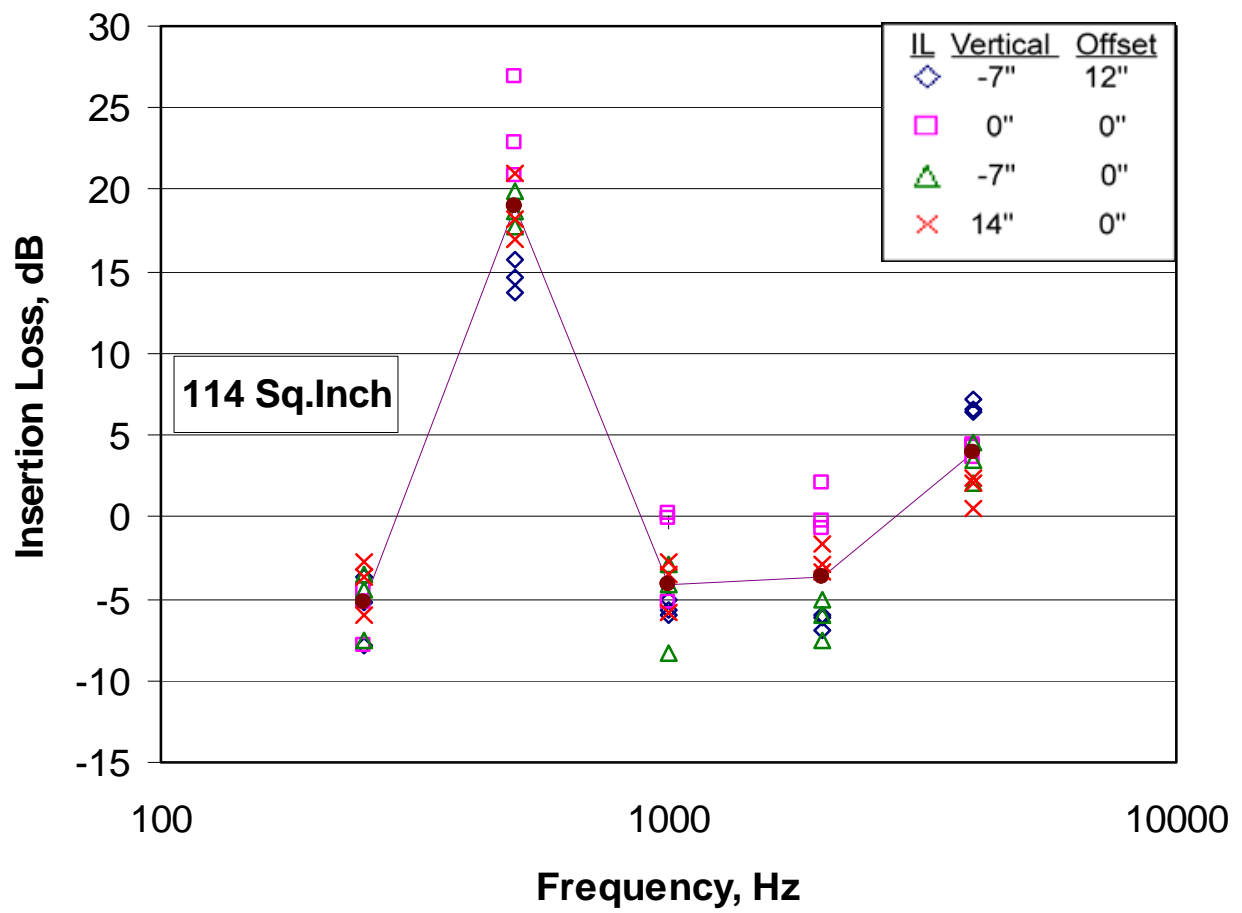

Figure 20. Variation of Insertion Loss with Frequency for 114 Sq.Inch Opening area 


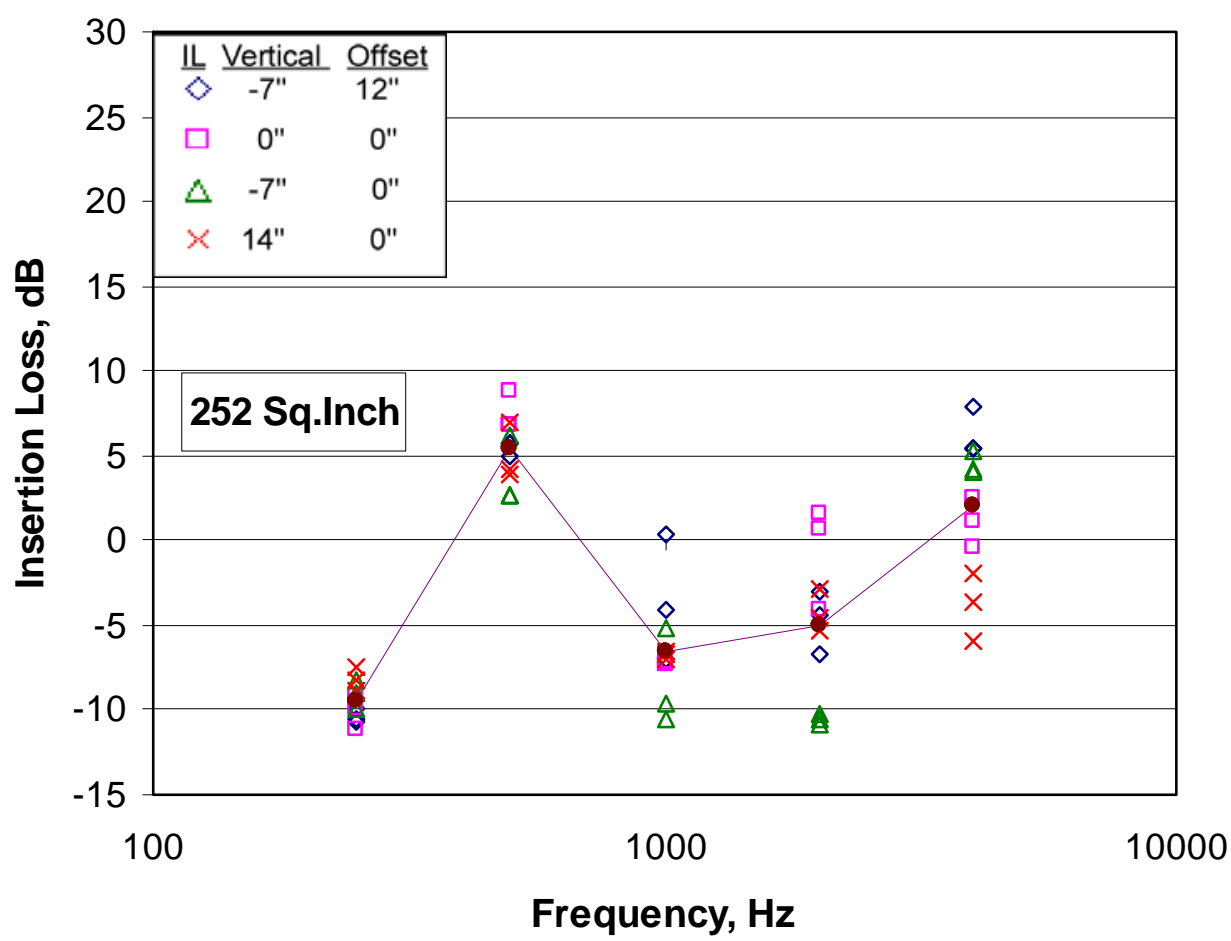

Figure 21. Variation of Insertion Loss with Frequency for 252 Sq.Inch Opening area

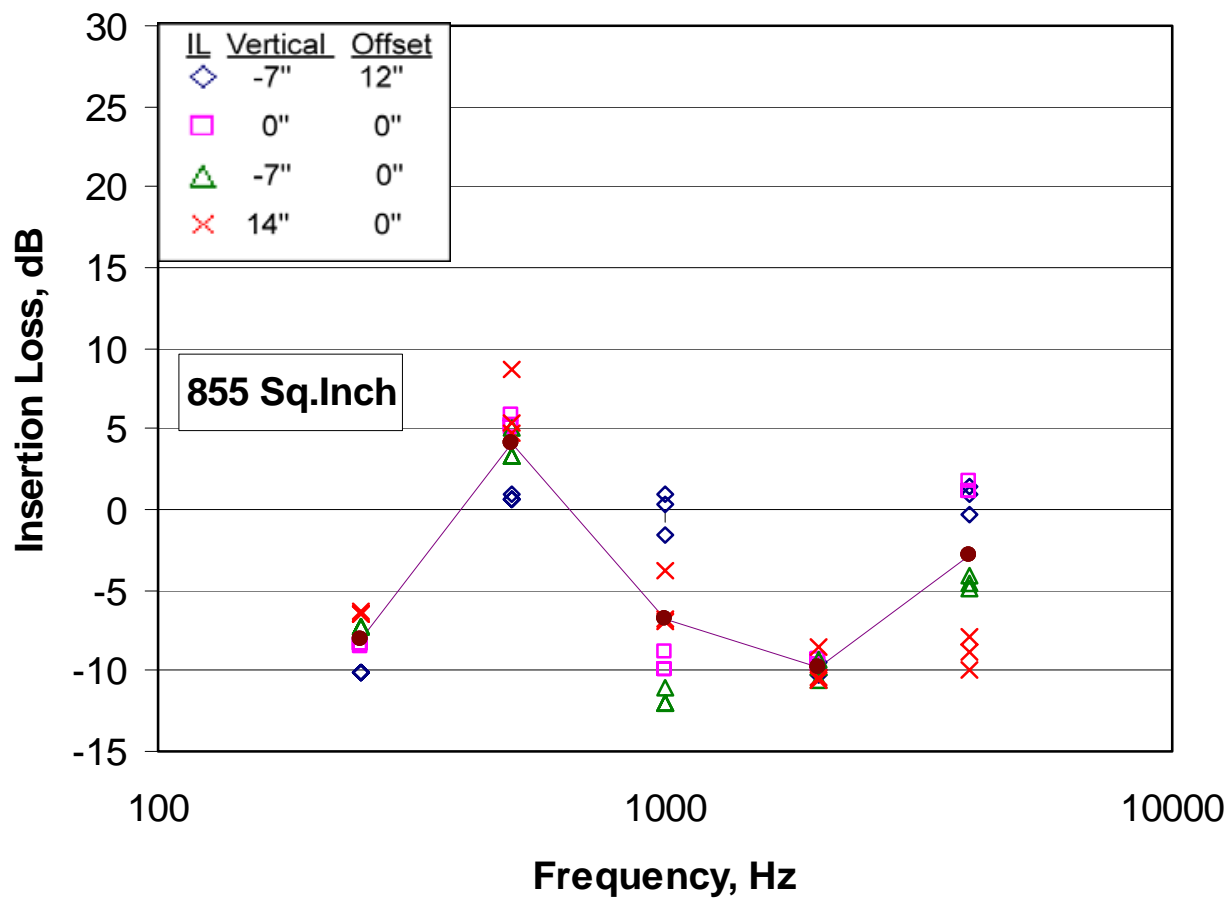

Figure 22. Variation of Insertion Loss with Frequency for 855 Sq.Inch Opening area 


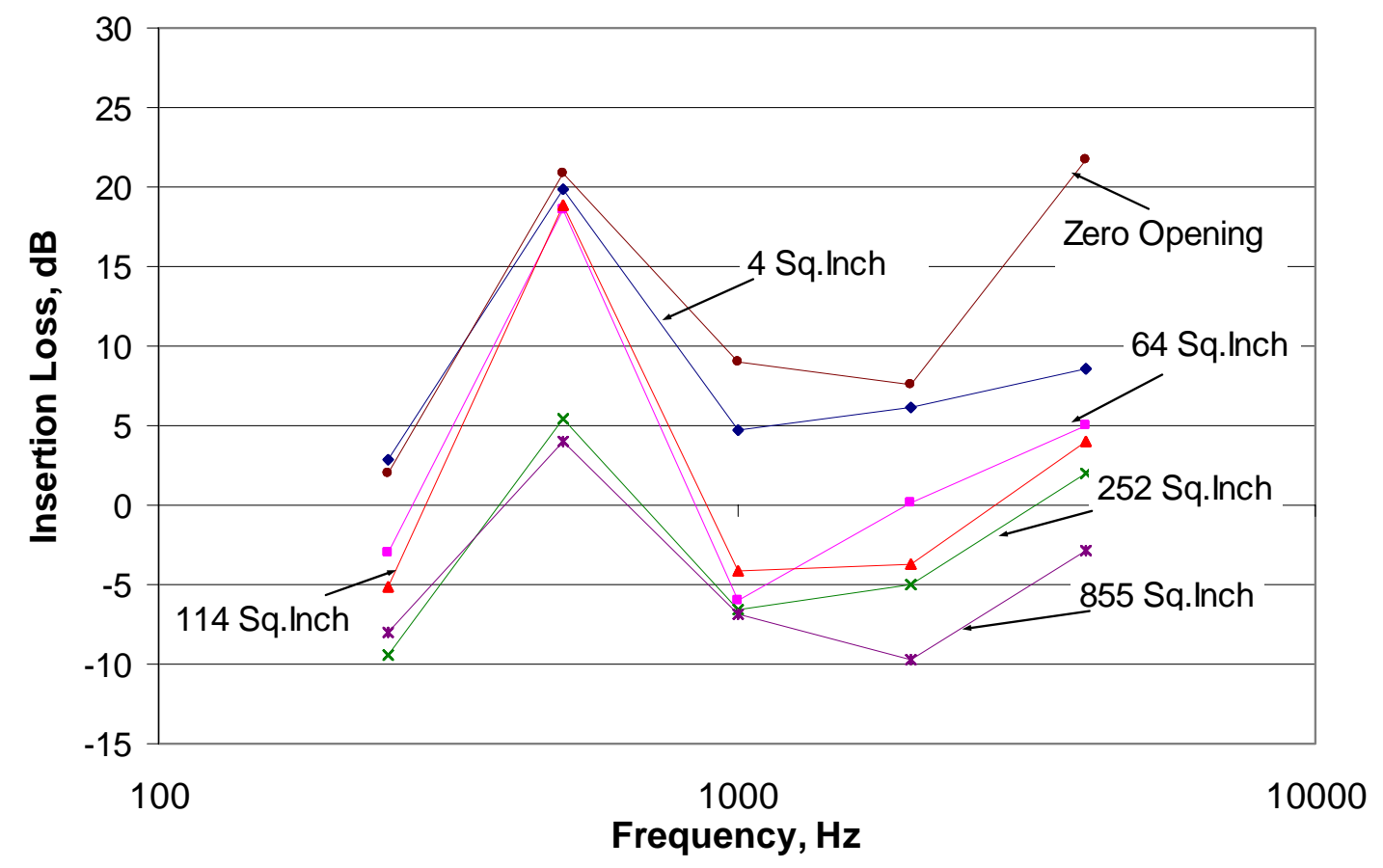

Figure 23. Variation of Insertion Loss with Frequency for all Opening Areas

From Figure 17, it can be observed that when the enclosure was completely closed, both $500 \mathrm{~Hz}$ and $4000 \mathrm{~Hz}$ had the highest IL of $22 \mathrm{~dB}$. However even for the small opening area of 4 sq.inch, the IL at $4000 \mathrm{~Hz}$ dropped substantially to $8 \mathrm{~dB}$ (Figure 18). Thus we can assert that for a pure tone of $4000 \mathrm{~Hz}$, the efficiency of this particular enclosure is drastically reduced by even a small opening. However for $500 \mathrm{~Hz}$ only the two largest opening areas of 252 sq.inch and 855 significantly degraded the IL of the enclosure. IL fell from $19 \mathrm{~dB}$ to $6 \mathrm{~dB}$ when the opening area increased from 114 sq.inch to 252 sq.inch. 
Table 11. Scheffe's post hoc test for comparison of Insertion Loss at different Opening Areas (Discrete Variable)

\begin{tabular}{|c|c|c|}
\hline $\begin{array}{c}\text { Opening } \\
\text { Area } \\
\text { (Sq.Inch) }\end{array}$ & $\begin{array}{c}\text { Difference } \\
\text { b/w } \\
\text { Means }\end{array}$ & Prob \\
\hline $4-0.01$ & -2.85 & 0.0137 \\
\hline $64-0.01$ & -7.95 & 0.0000 \\
\hline $64-4$ & -5.11 & 0.0000 \\
\hline $114-0.01$ & -8.04 & 0.0000 \\
\hline $114-4$ & -5.19 & 0.0000 \\
\hline $114-64$ & -0.09 & 1.0000 \\
\hline $252-0.01$ & -12.45 & 0.0000 \\
\hline $252-4$ & -9.60 & 0.0000 \\
\hline $252-64$ & -4.49 & 0.0000 \\
\hline $252-114$ & -4.41 & 0.0000 \\
\hline $855-0.01$ & -14.73 & 0.0000 \\
\hline $855-4$ & -11.88 & 0.0000 \\
\hline $855-64$ & -6.77 & 0.0000 \\
\hline $855-114$ & -6.69 & 0.0000 \\
\hline $855-252$ & -2.28 & 0.0992 \\
\hline
\end{tabular}

From previous observations it is now evident that different opening areas behave differently at different frequencies. This can also be observed from the Scheffe's Post Hoc tests in Table 11.Accept 114 sq.inch and 64 sq.inch all other opening sizes are significantly different. 


\section{Effect of Frequency on Noise Reduction}

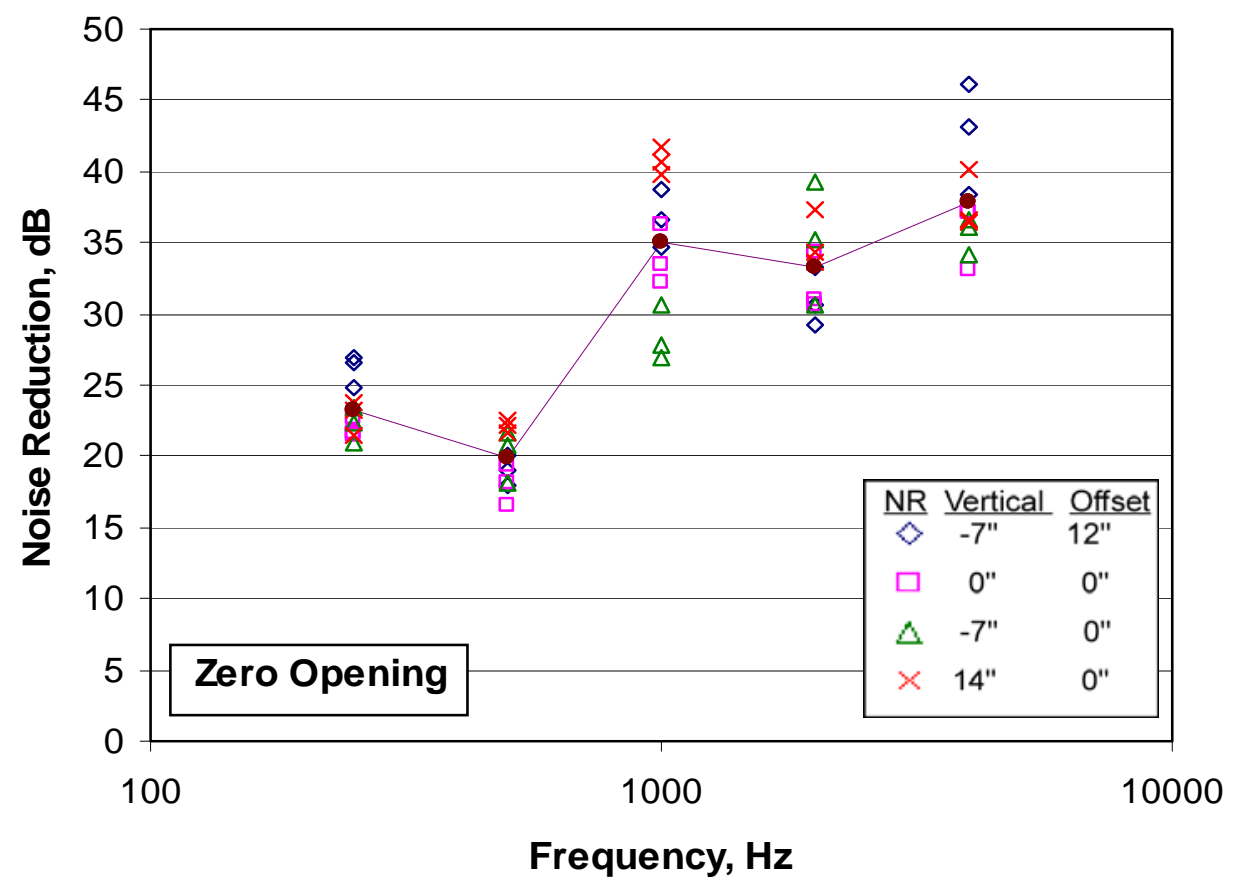

Figure 24. Variation of Noise reduction with Frequency for Zero Opening area

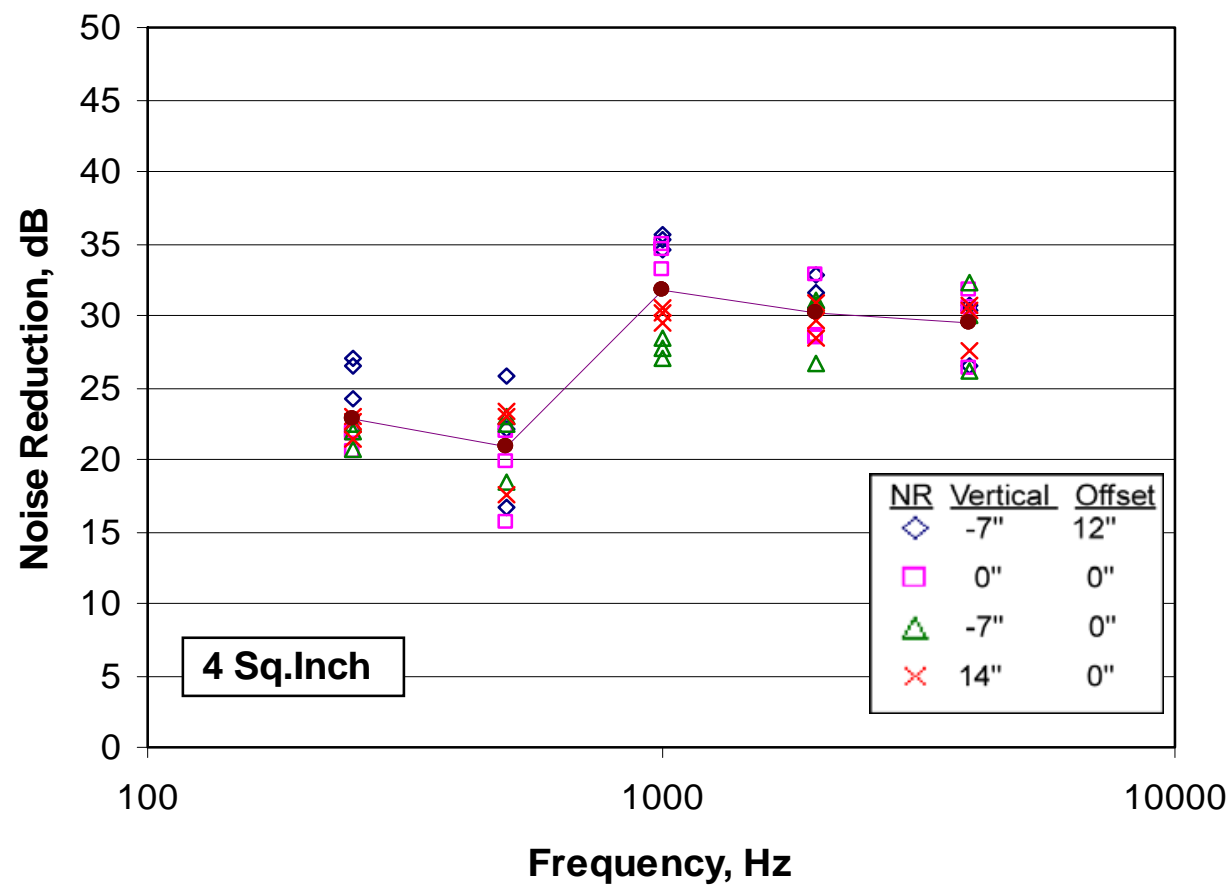

Figure 25. Variation of Noise reduction with Frequency for 4 Sq.Inch Opening area 


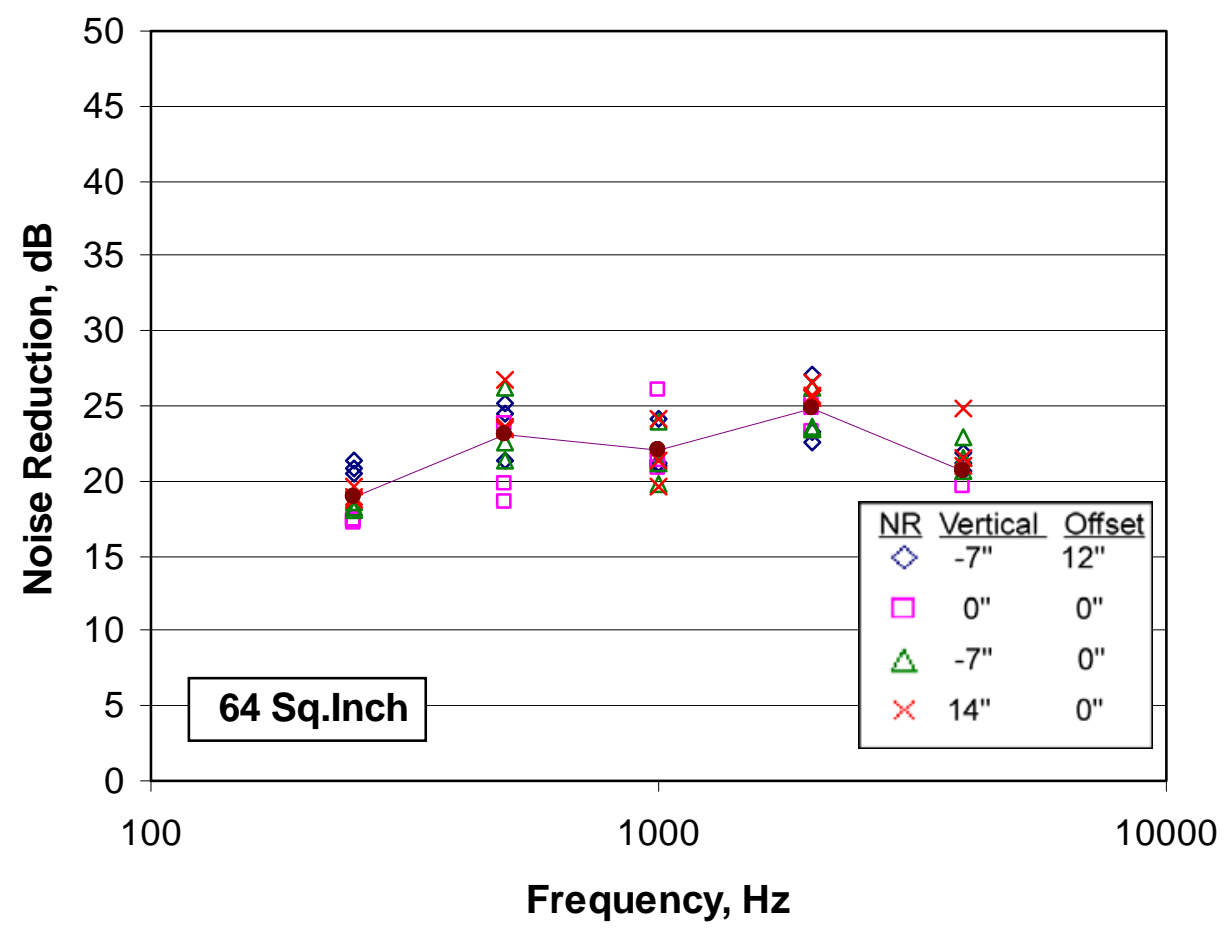

Figure 26. Variation of Noise reduction with Frequency for 64 Sq.Inch Opening area

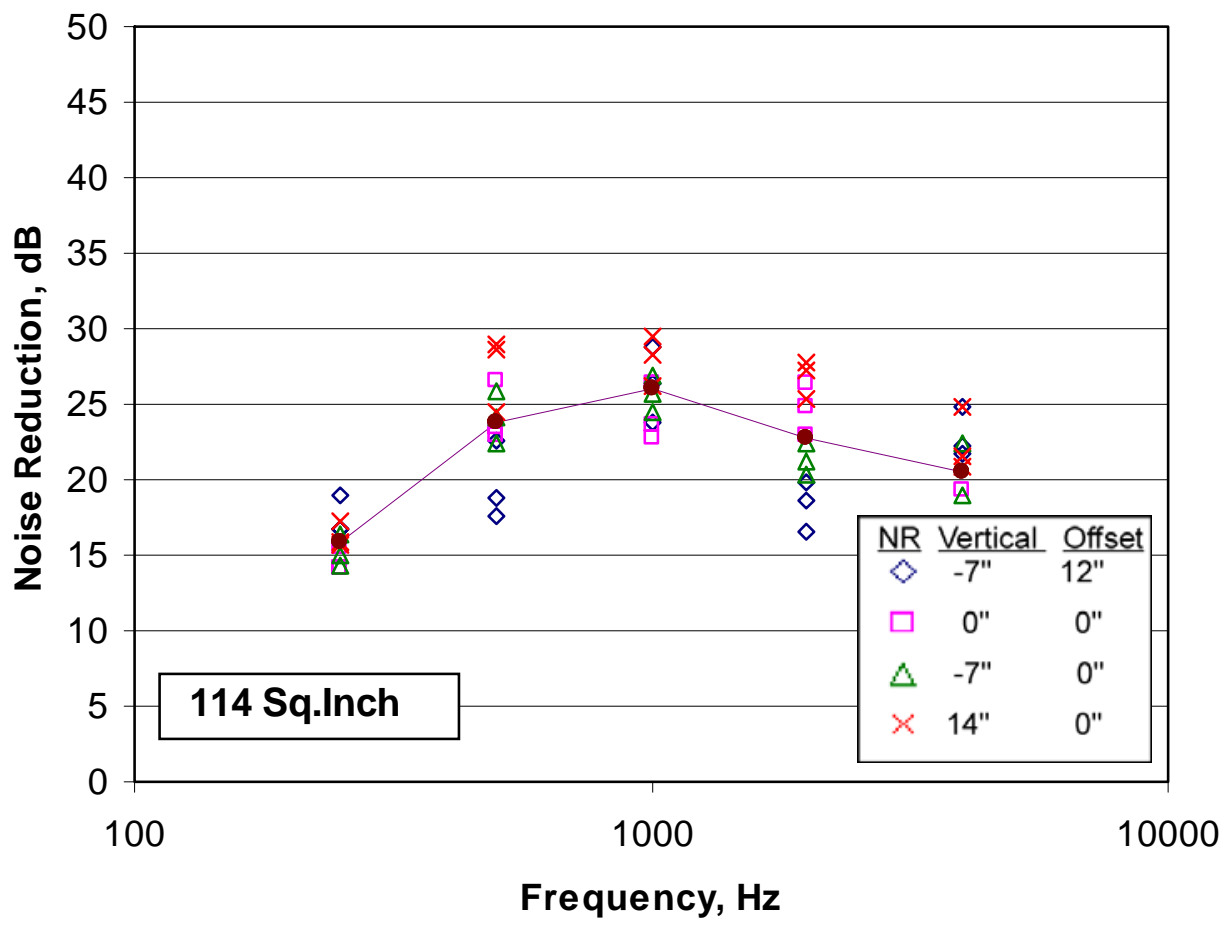

Figure 27. Variation of Noise reduction with Frequency for 114 Sq.Inch Opening area 


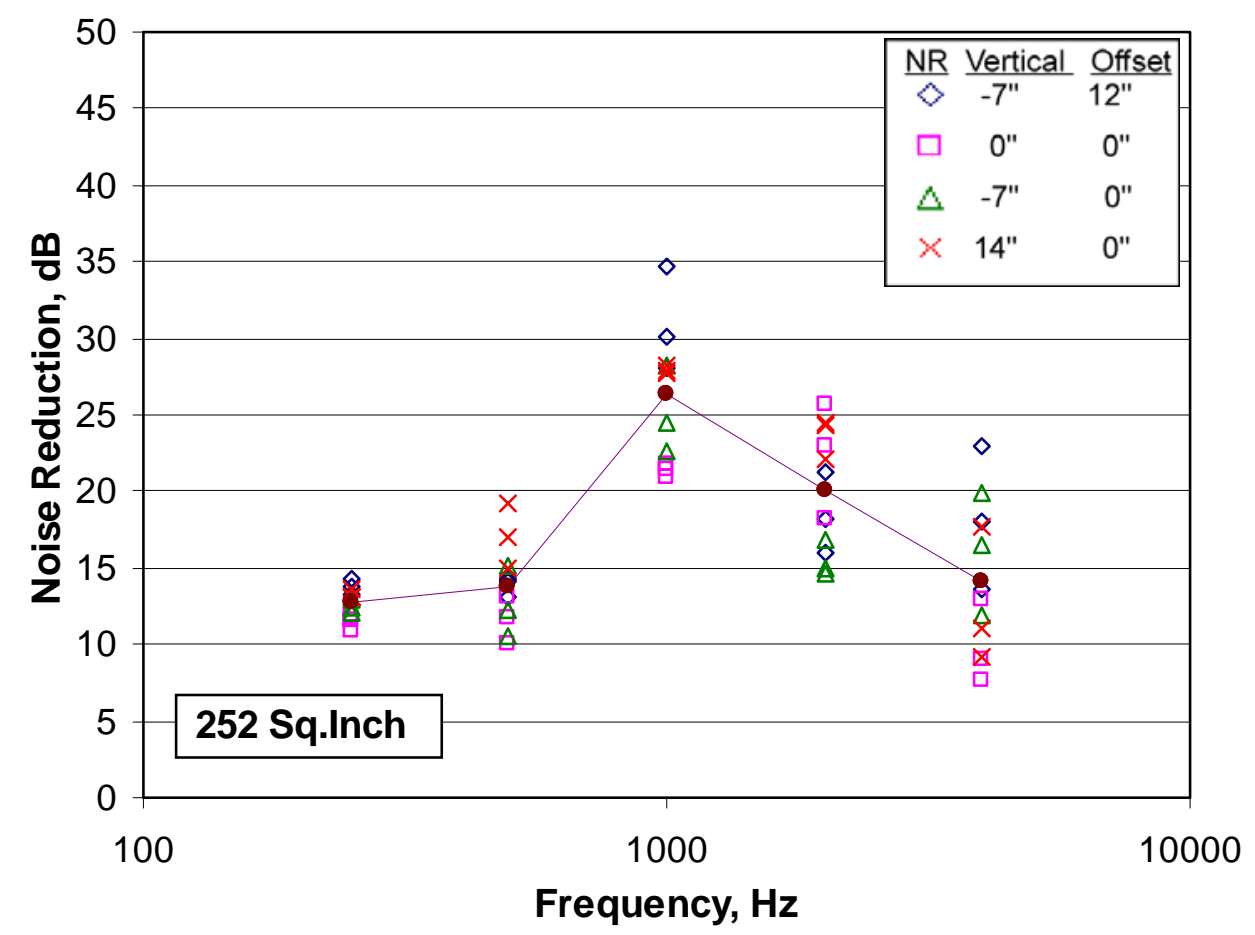

Figure 28. Variation of Noise reduction with Frequency for 252 Sq.Inch Opening area

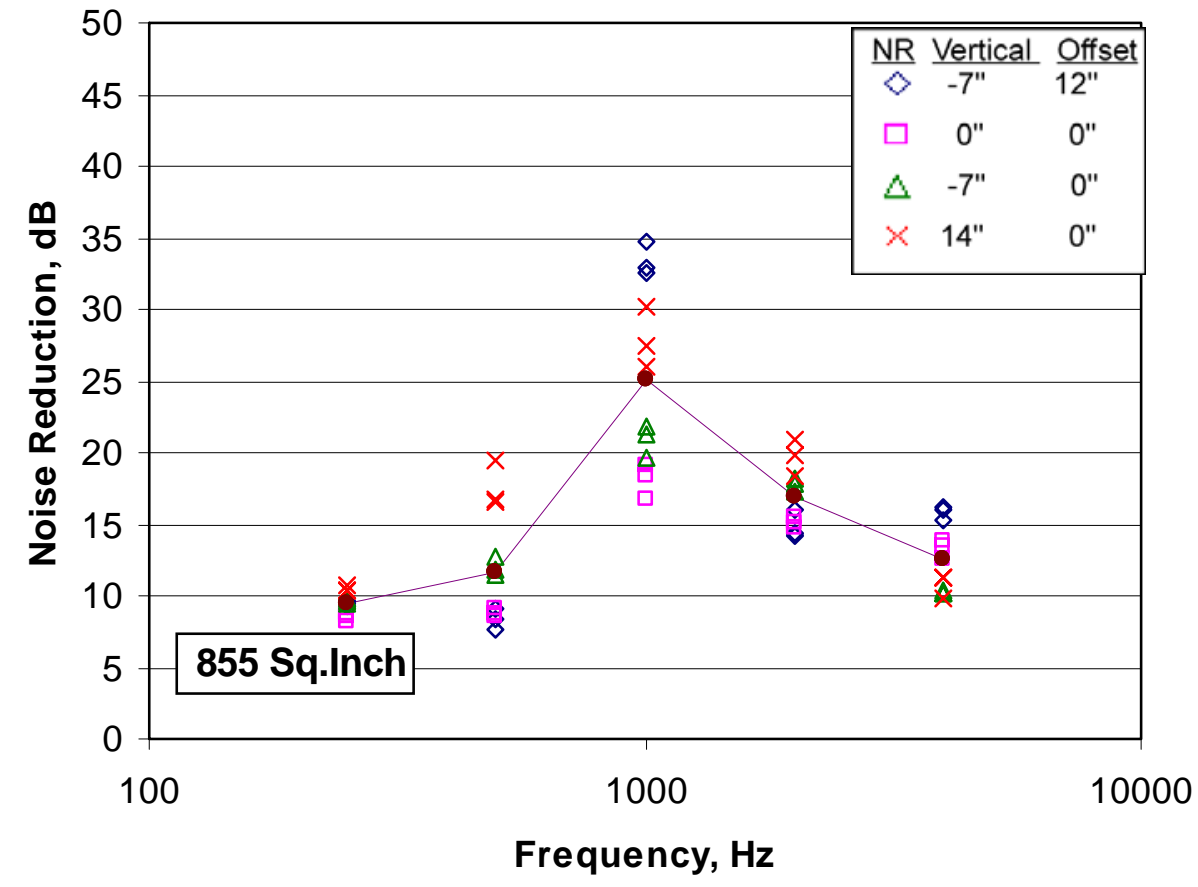

Figure 29. Variation of Noise reduction with Frequency for 855 Sq.Inch Opening area 


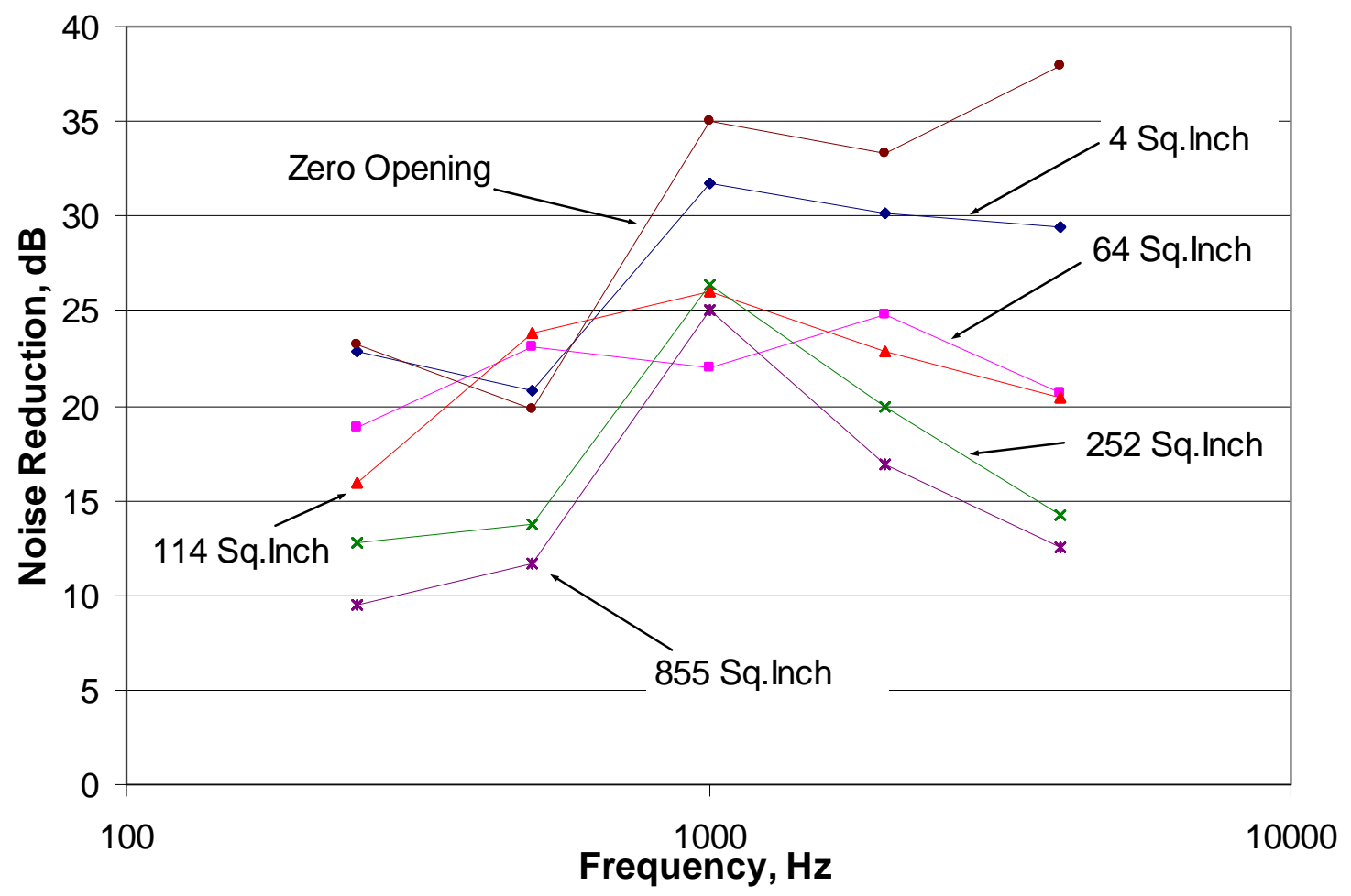

Figure 30. Variation of Noise Reduction with Frequency for all Opening Areas

Table 12. Scheffe's post hoc test for comparison of Noise Reduction at different Opening Areas (Discrete Variable)

\begin{tabular}{|c|c|c|}
\hline $\begin{array}{c}\text { Opening } \\
\text { Area } \\
\text { (Sq.Inch) }\end{array}$ & $\begin{array}{c}\text { Difference } \\
\text { b/w } \\
\text { Means }\end{array}$ & Prob \\
\hline $4-0.01$ & -2.85 & 0.0137 \\
\hline $64-0.01$ & -7.95 & 0.0000 \\
\hline $64-4$ & -5.11 & 0.0000 \\
\hline $114-0.01$ & -8.04 & 0.0000 \\
\hline $114-4$ & -5.19 & 0.0000 \\
\hline $114-64$ & -0.09 & 1.0000 \\
\hline $252-0.01$ & -12.45 & 0.0000 \\
\hline $252-4$ & -9.60 & 0.0000 \\
\hline $252-64$ & -4.49 & 0.0000 \\
\hline $252-114$ & -4.41 & 0.0000 \\
\hline $855-0.01$ & -14.73 & 0.0000 \\
\hline $855-4$ & -11.88 & 0.0000 \\
\hline $855-64$ & -6.77 & 0.0000 \\
\hline $855-114$ & -6.69 & 0.0000 \\
\hline $855-252$ & -2.28 & 0.0992 \\
\hline
\end{tabular}




\section{Comparison of Predicted NR and IL with Observed}

Using the previously discussed prediction methods (Equation (6) to (12)), the ILs and NRs for each frequency and opening size were computed. Figure 31 to Figure 35 illustrate the deviation of the observed values from the predicted. In summary, the congruence between predicted and observed was very poor.

To observe the adequacy of the prediction models, the residuals i.e., the difference between the predicted and observed values were then compared to the opening areas and frequencies.

From Equation (8), it can be seen that the $\mathrm{TL}_{\text {combined }}$ decreases linearly with the increase in the log of opening area. Also, in the prediction model for $\mathrm{NR}$, the $\mathrm{TL}_{\text {combined }}$ is the most significant term, with other factors accounting for directivity (Q), room constant (R) and distance (r) having minimal effect. Hence it can be said that $\mathrm{TL}_{\text {combined }}$ is a good estimator of the NR. But however other factors even though which have a minimal effect are important and have to be included in the prediction model. 


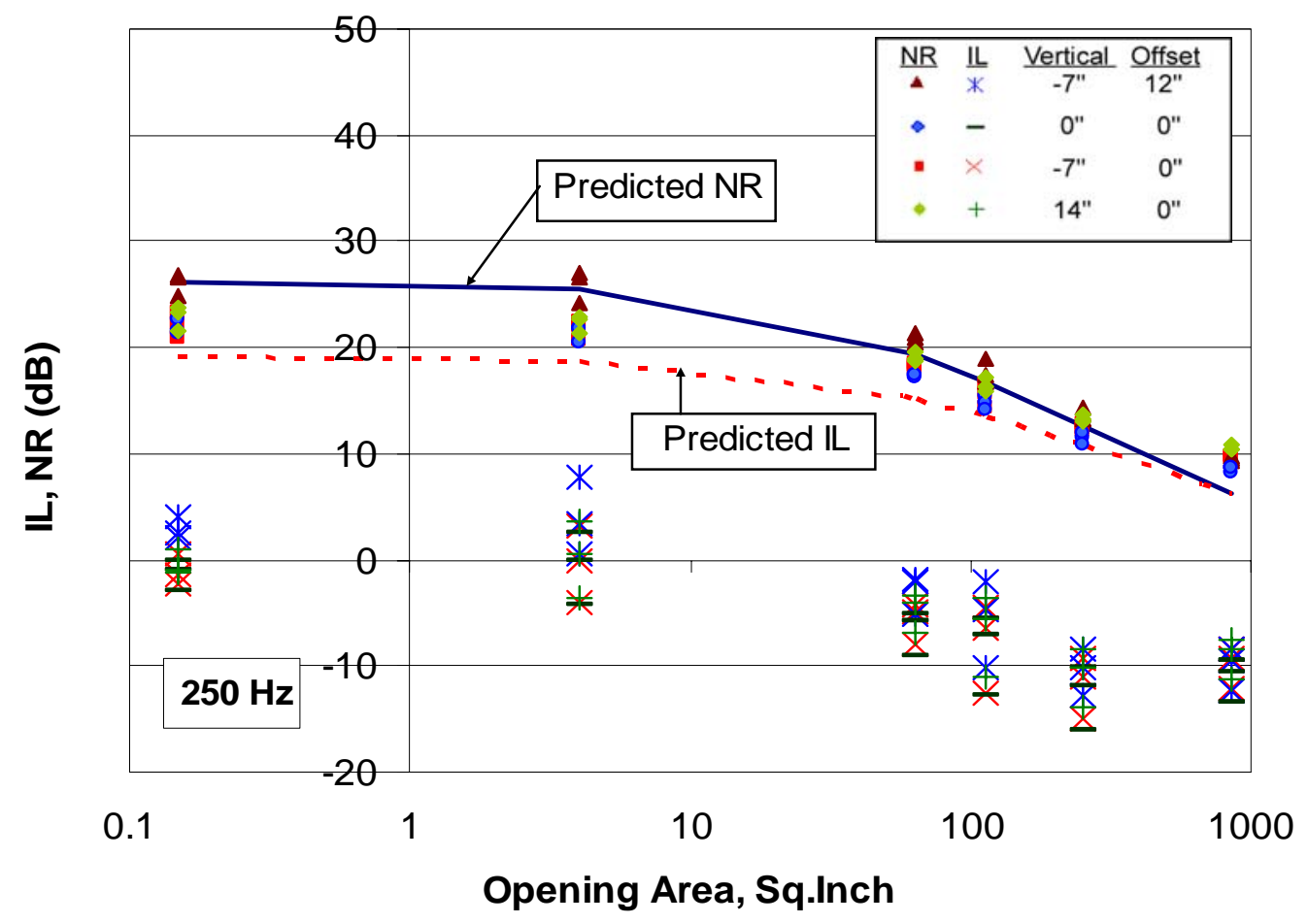

Figure 31. Comparison of IL and NR, Predicted Vs Observed for $250 \mathrm{~Hz}$

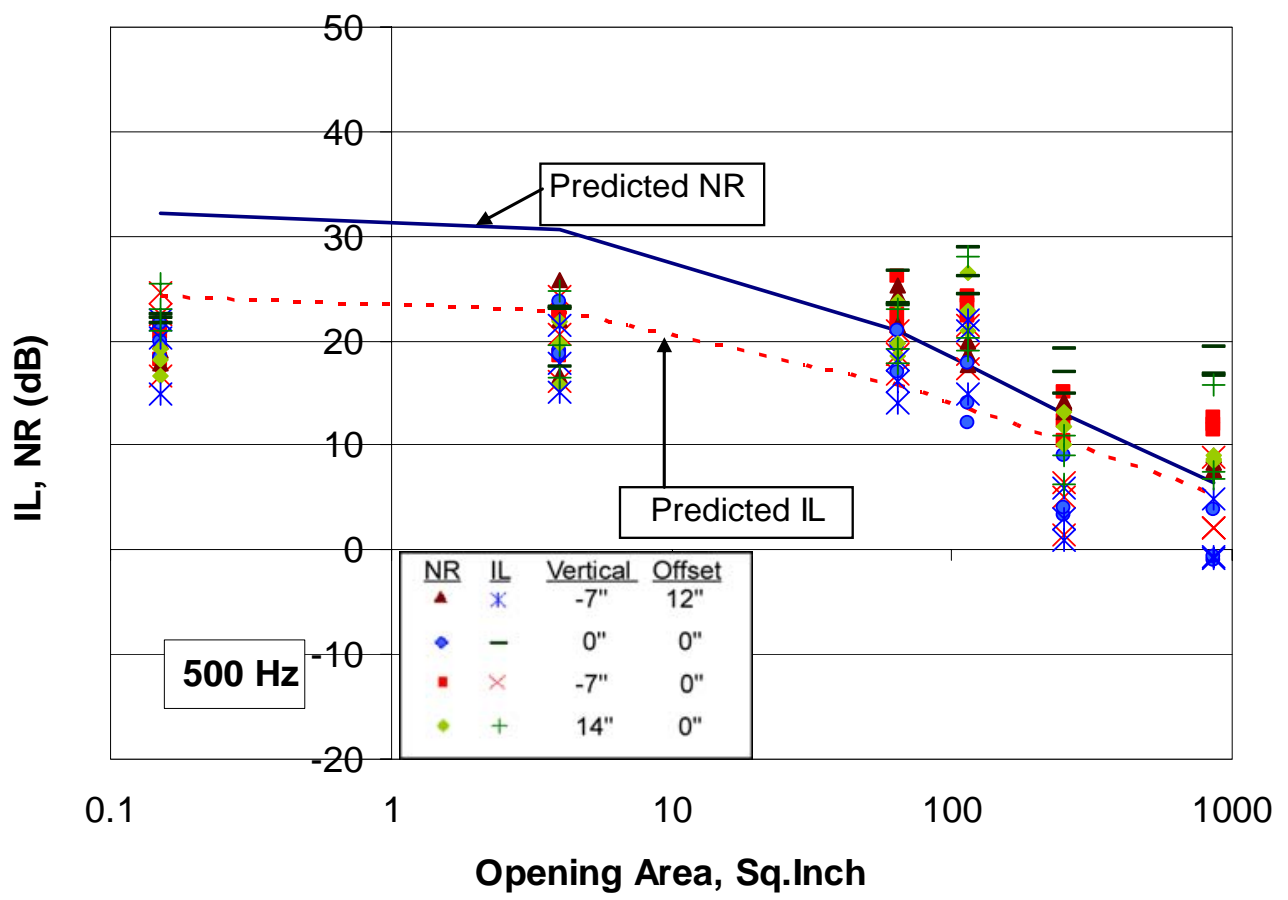

Figure 32. Comparison of IL and NR, Predicted Vs Observed for $500 \mathrm{~Hz}$ 


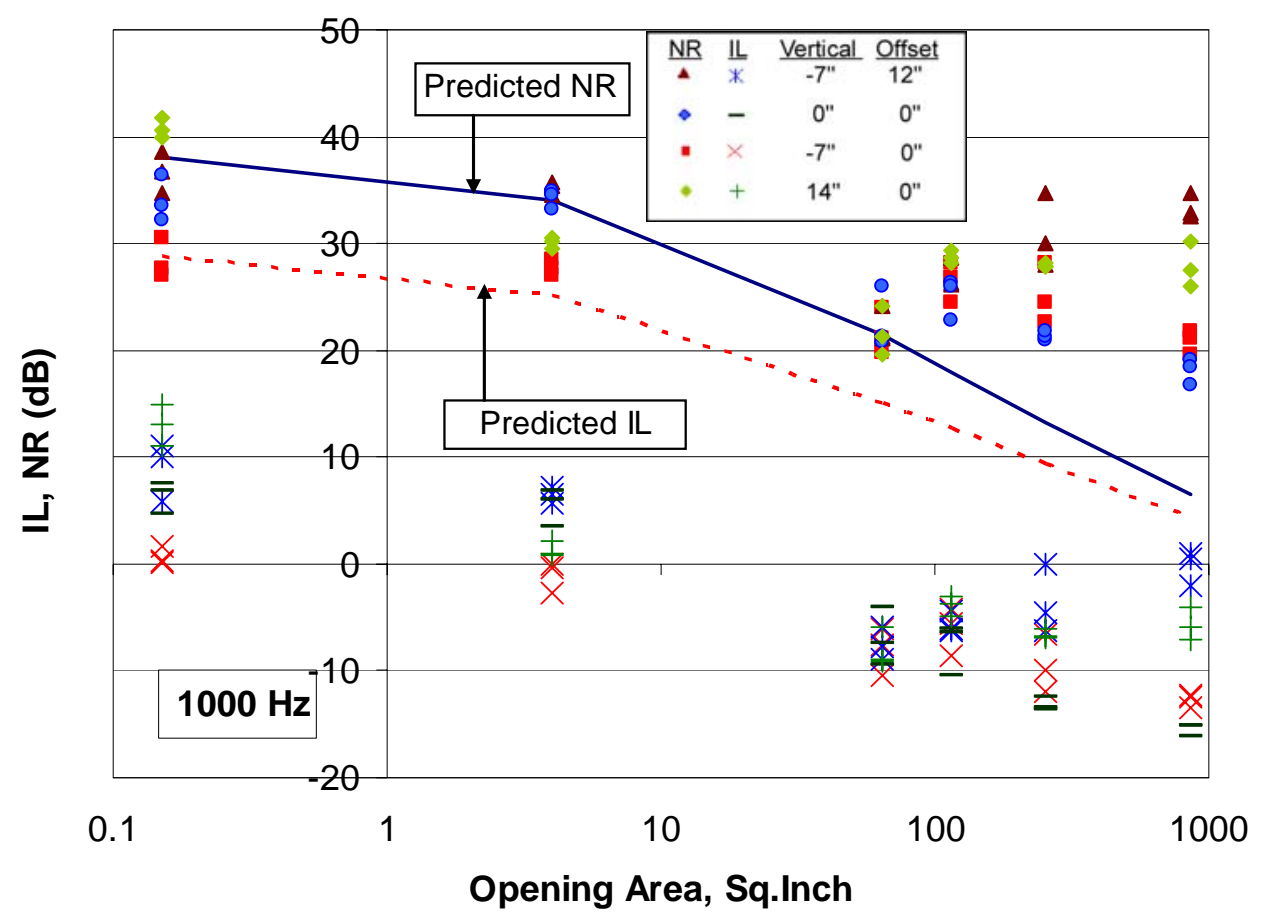

Figure 33. Comparison of IL and NR, Predicted Vs Observed for $1000 \mathrm{~Hz}$

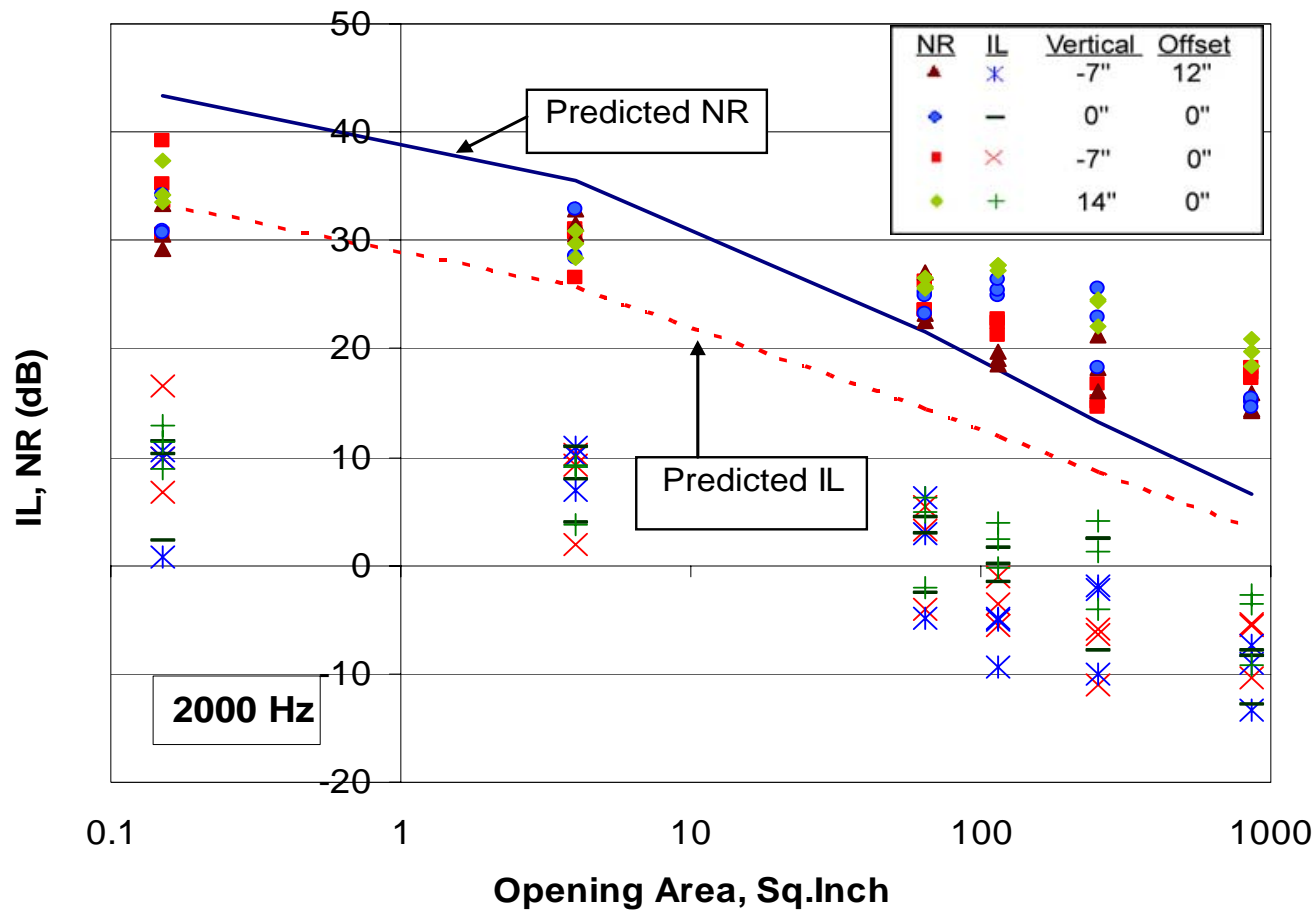

Figure 34. Comparison of IL and NR, Predicted Vs Observed for $2000 \mathrm{~Hz}$ 


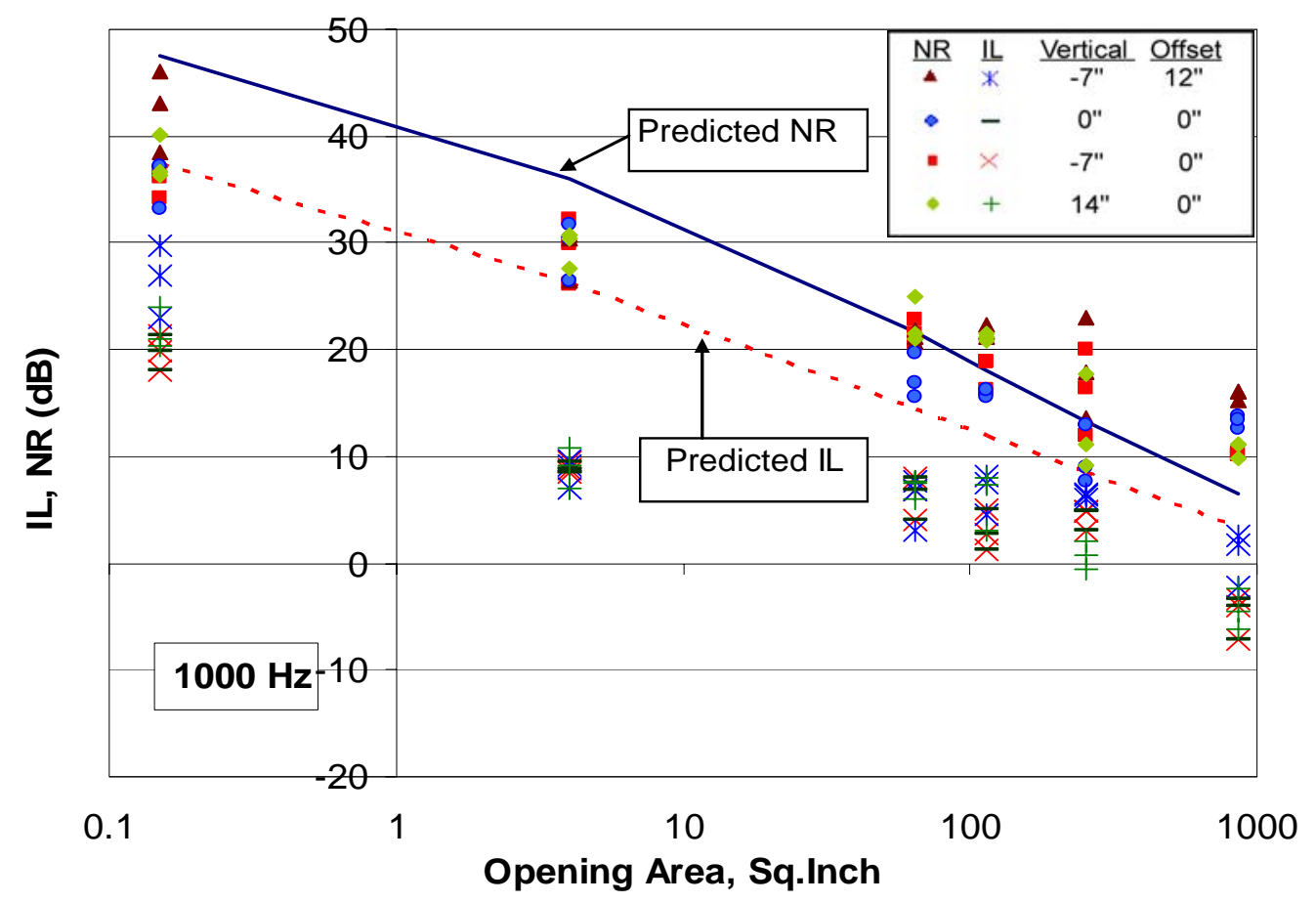

Figure 35. Comparison of IL and NR, Predicted Vs Observed for $4000 \mathrm{~Hz}$

From Figure 31 to Figure 35 it can be observed that the predicted NR is fairly close to the observed NR values for $250 \mathrm{~Hz}, 2000 \mathrm{~Hz}$ and $4000 \mathrm{~Hz}$. However for $500 \mathrm{~Hz}$ it over estimates the NR for zero opening and 4 Sq.inch opening area and for $1000 \mathrm{~Hz}$ underestimates the NR for zero opening and 4 Sq.inch opening area. The IL predicted using Equation (12) is always higher than the observed IL, except for $500 \mathrm{~Hz}$.

Modified levene test was performed in order to check for constancy of error variance, for difference frequencies. It was observed that the error variance was not constant, which was confirmed by plotting the residuals (difference between values predicted using previously discussed methods and the observed values) against the log of opening area. For IL the difference between the predicted and observed increased with the increase in the log of opening area for frequencies above $500 \mathrm{~Hz}$, but showed no trend for $250 \mathrm{~Hz}$ and $500 \mathrm{~Hz}$. For NR the residuals decreased with the increase in the log of opening area. 


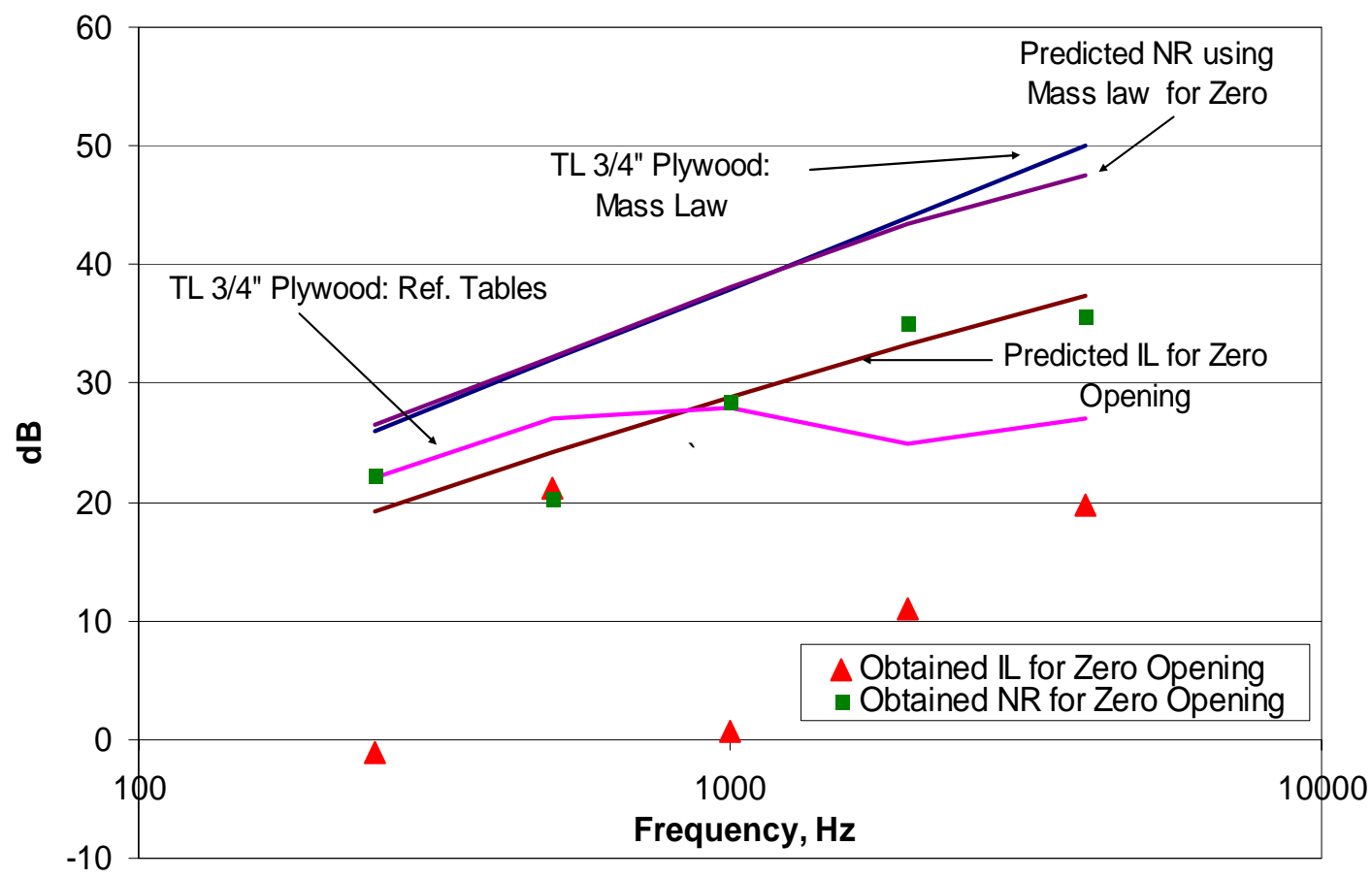

Figure 36. Comparison of TL obtained using Mass Law, TL from Reference Data, IL for Zero Opening and NR for Zero Opening

From Figure 36, it can be observed that even when the distance and Room constant are taken into consideration in the predictive model, the NR at "Zero Opening" is same as the TL. This suggests that the distance and Room constant have a small effect in the model. Also, the obtained NR for the "Zero Opening" lies between the TL estimated using "Mass Law" and TL obtained from reference data (Ghering, (1978)), which suggests either the assumed TL for plywood is either overestimated using the "Mass Law" or somewhat underestimated in the reference data.

This it can be concluded the prediction model for IL used in this study is not adequate for predicting the IL for this particular enclosure for zero opening case. However the prediction model for NR fairly closely predicts the NR for $250 \mathrm{~Hz}$ and $4000 \mathrm{~Hz}$. 


\section{Conclusion}

Enclosures intended to reduce the machine noise have to be well designed with minimal openings. This study demonstrated even a small opening will significantly reduce the effectiveness of the enclosure for certain frequencies $(4000 \mathrm{~Hz}$ for the enclosure in this study). The dominant frequencies which contribute significantly to the exposure levels of the workers must be determined first in order to use appropriate engineering controls. In this study it was observed that different frequencies respond differently for different opening areas.

From the analysis it can be observed that the IL and NR degrade, significantly with the $\log$ of opening area. But the variation is not monotonic and is different for all the frequencies. At $4000 \mathrm{~Hz}$, it was observed that even a small opening area of 4 sq.inch reduced the Insertion Loss by $14 \mathrm{~dB}$. On the other hand, at $500 \mathrm{~Hz}$ small openings did not significantly affect the Insertion Loss. Predominantly for $250 \mathrm{~Hz}, 1000 \mathrm{~Hz}$ and $2000 \mathrm{~Hz}$, negative Insertion Losses were obtained for opening areas above 64 Sq.inch. This might be because of reverberant build up within the enclosure or some effect of directionality.

The statistical model suggested that Frequency and Log of Opening Area are the most significant parameters affecting both NR and IL for the specific enclosure used in this particular study. Thus, the null hypotheses, which state that the change in NR and IL does not vary with the frequency and opening area, are rejected.

Also, the prediction models used in this study were not adequate enough to account for the variation of IL and NR due to openings in the enclosure. Thus the null hypothesis which states that the observed values are equal to the predicted values is rejected. Hence a better model has to be developed to accurately predicting the effects of opening areas. 


\section{Caveats}

- Source was placed at the center of the enclosure and in line with the opening

- Receiver microphone positions were directly in line with the opening

- Enclosure's interior was unlined with absorptive material 


\section{Future work considerations}

This study considered only one distance (60 inches) and one orientation (in front of the opening). Further research can be conducted to study the effect of varying distances and orientation. Also the enclosure in this study was not lined with any absorptive material. Lining with absorptive material might produce different results for different frequencies.

If an array of microphones is used for each location, the behavior of noise propagation can be studied better.

Also, better predictive models for IL and NR could be developed which take into consideration both opening area and frequency. 


\section{Bibliography}

1. Beis, D. A. and Hansen, C. H. (2003), "Engineering Noise Control: Theory and Practice", Taylor and Francis group, Third Edition, Pg 276

2. Bell, L. H. and Bell, D. H., (1994). "Industrial Noise Control, Fundamentals and Applications", Pg 239 - 274, Marcel and Dekker, Inc

3. Beranak, L.L. and Ver, I. L., (1992). "Noise and Vibration Control Engineering: Principles and Applications", John Wiley and Sons, p.484

4. Beranak, L.L. and Work, G.A., (1949). "Sound Transmission Through Multiple Structures Containing Flexible Blankets", Journal of the Acoustical Society of America, vol.7, p.419

5. Berger, E. H., Royster, L. H., Royster, J. D., Driscoll, D. P., and Layne, M., (2000) “The Noise manual", Fifth Edition, AIHA Press.

6. Blanks, J. E., (1997). "Optimal Design of an Enclosure for a Portable Generator", Virginia Tech ETD library, p.41.

7. Bryne, K.P., Fischer, H.M. and Fuchs, H.V., (1988). "Sealed, Close Fitting, Machine Mounted Acoustic Enclosures with Predictable Performance", Noise Control Engineering Journal, vol. 31, no. 1, pp. 7-14.

8. Buckingham, E. (1924). "Theory and Interpretation of Experiments on the Transmission of Sound through Partition Walls”, Sci. Papers Natn. Bur. Standards vol. 20, p.193

9. CDC/NIOSH, "Work-Related Hearing Loss", http://www.cdc.gov/niosh/hpworkrel.html

10. CDC/NIOSH, (June 2003), "Mining facts 2001", http://www.cdc.gov/niosh/mining/pubs/pdfs/2003-105.pdf

11. Crocker, M. J. (1994). "A Systems Approach to the Transmission of Sound and Vibration through Structures", Noise-Con 94, pp. 525 - 533.

12. Davern, W. A. and Lhuede, E. P., (1978),“ Enclosures and Screens for Saw Operators“, Applied Erogonomics, Vol. 9, No. 1, pp 2-6. 
13. Environmental Protection Department, Department of Highways, Hong Kong (2003), "Noise: Guidelines and References",

Environmental Protection Department, Department of Highways, Hong Kong

14. Environmental Noise Control, ATCO Noise Management http://www.atconoise.com/products services/products enclosures.htm

15. Ghering, W. L., (1978), "Reference Data for Acoustic Noise Control", Ann Arbor Science, p. 48.

16. Hunt, R. S., (1956), "Noise Reduction at a Hammer Mill and at a Knife Cutter", Industrial Hygiene Quaterly, Vol. 17, No. 1.

17. Meinhold, T. F., (1976),"Facts about Noise Enclosures, A summary of practical information, service and expert opnions on enclosure selection, design, installation and use", Plant Engineering, pp. 120 - 125, File \# 7560.

18. Montogomery, D. C., (2001), "Design and Analysis of Experiments", Fifth Edition, John Wiley and Sons, Inc., p 80.

19. Moreland, J. B., (1981) "Low frequency Noise Reduction of Acoustic Enclosures", NOISE-CON 81 Proceedings, pp. 59-63.

20. Neter, J., Kutner, M. H., Nachtsheim, and Wasserman, W., (1996), “Applied Linear Regression Models", Third Edition, IRWIN, pp 98 - 115.

21. Norton, M. P., (1999), "Industrial Noise Control”, , pp 11 -15.

22. Oldham, D.J. and Hilarby, S.N., (1991). "The Acoustical Performance of Small Close Fitting Enclosures, Part 1; Theoretical Models", Journal of Sound and Vibration, vol. 150 pp. 261- 81.

23. Thornton, W. and Earshen, J., (2001), "Applied Acoustics and Noise Control Course, Theory and Application“", AVNC, Ch. 3, p 18.

24. Yerges, L. F.,(1973), “Methods of Noise Control for Machinery Already Installed“, Noise-Con 73, Proceedings of the National Conference on Noise Control Engineering, October 15 - 17, 1973, Washington D. C., pp $376-381$. 


\section{Appendix}

\section{Modified Levene Test to check for Constancy of Error variance (Nutter, et.al, (1996)}

Using Modified Levene test a check for constancy of error variance for each frequency and microphone position was conducted. This test is based on variability of the residuals.

Two replications of the 6 opening sizes were arranged in ascending order and divided into two groups. These two groups were used to compute the two sample $\mathrm{t}-$ statistic $\left(\mathrm{t}^{*}\right)$. This $\mathrm{t}$ statistic was used to test the following hypotheses:

If $\mid \mathrm{t}^{*} \mathrm{I} \leq \mathrm{t}(1-\alpha / 2$, d.o.f), conclude the error variance is constant

If $\left|t^{*}\right|>t(1-\alpha / 2$, d.o.f), conclude the error variance is not constant

$$
\begin{aligned}
& \alpha=5 \%(0.05) \\
& \mathrm{df}=\text { total observations }-2=6 \text { opening sizes } * 3 \text { replications }-2=16 \\
& \mathrm{t}(0.975,16)=2.12
\end{aligned}
$$

\section{Comparison between Microphones}

Tables below show the variation of slopes for plots of IL and NR versus opening areas for different frequencies. The microphone position is defined in terms of horizontal distance from the center of the source, vertical height from the center of the source and the offset from the center in inches.

Table 13. Slopes for variation of Insertion Loss with Opening Areas for different individual Microphones

\begin{tabular}{|c|c|c|c|c|}
\hline $\begin{array}{c}\text { Frequency } \\
(\mathbf{H z})\end{array}$ & $\operatorname{Mic}(\mathbf{6 0}, \mathbf{- 7 , 1 2})$ & $\operatorname{Mic}(\mathbf{6 0}, \mathbf{0 , 0})$ & $\operatorname{Mic}(\mathbf{6 0}, \mathbf{- 7 , 0 )}$ & $\operatorname{Mic}(\mathbf{6 0}, \mathbf{- 1 4 , 0 )}$ \\
\hline 250 & -2.85 & -2.30 & -2.13 & -2.07 \\
\hline 500 & -3.26 & -2.94 & -3.01 & -2.34 \\
\hline 1000 & -2.88 & -4.58 & -2.58 & -4.19 \\
\hline 2000 & -3.45 & -2.97 & -3.94 & -2.91 \\
\hline 4000 & -4.83 & -4.68 & -4.29 & -4.74 \\
\hline
\end{tabular}


Table 14. $\mathrm{R}^{2}$ for variation of Insertion Loss with Opening Areas for different individual Microphones

\begin{tabular}{|c|c|c|c|c|}
\hline $\begin{array}{c}\text { Frequency } \\
\mathbf{( H z )}\end{array}$ & $\operatorname{Mic}(\mathbf{6 0}, \mathbf{- 7 , 1 2 )}$ & $\operatorname{Mic}(\mathbf{6 0 , 0 , 0 )}$ & $\operatorname{Mic}(\mathbf{6 0},-\mathbf{7 , 0})$ & $\operatorname{Mic}(\mathbf{6 0},-\mathbf{1 4}, \mathbf{0})$ \\
\hline 250 & 63.5 & 63.9 & 60.4 & 60.7 \\
\hline 500 & 44.4 & 34.5 & 39 & 37 \\
\hline 1000 & 53.2 & 75.2 & 70.6 & 88.1 \\
\hline 2000 & 58.6 & 60 & 78.5 & 81.3 \\
\hline 4000 & 91.8 & 93.7 & 87.6 & 90.1 \\
\hline
\end{tabular}

Table 15. Slopes for variation of Noise Reduction with Opening Areas for different Microphones

\begin{tabular}{|c|c|c|c|c|}
\hline $\begin{array}{c}\text { Frequency } \\
\text { (Hz) }\end{array}$ & $\operatorname{Mic}(\mathbf{6 0},-\mathbf{7 , 1 2})$ & $\operatorname{Mic}(\mathbf{6 0}, \mathbf{0 , 0})$ & $\operatorname{Mic}(\mathbf{6 0}, \mathbf{- 7}, \mathbf{0})$ & $\operatorname{Mic}(\mathbf{6 0}, \mathbf{- 1 4}, \mathbf{0})$ \\
\hline 250 & -3.09 & -2.54 & -2.38 & -2.31 \\
\hline 500 & -1.36 & -1.05 & -1.11 & -0.44 \\
\hline 1000 & -1.61 & -3.30 & -1.30 & -2.92 \\
\hline 2000 & -3.34 & -2.86 & -3.83 & -2.79 \\
\hline 4000 & -5.40 & -5.25 & -4.86 & -5.31 \\
\hline
\end{tabular}

Table 16. $\mathrm{R}^{2}$ for variation of Noise Reduction with Opening Areas for different Microphones

\begin{tabular}{|c|c|c|c|c|}
\hline Frequency (Hz) & Mic(60,-7,12) & Mic(60,0,0) & Mic(60,-7,0) & Mic(60,-14,0) \\
\hline 250 & 66.1 & 69.6 & 67.7 & 67.3 \\
\hline 500 & 11.3 & 3.8 & 7.1 & -2.8 \\
\hline 1000 & 19.2 & 71.1 & 41.4 & 65.2 \\
\hline 2000 & 66 & 64.6 & 80 & 85 \\
\hline 4000 & 92.2 & 84 & 83.8 & 82.5 \\
\hline
\end{tabular}




\title{
Curriculum Vitae
}

\author{
Amit Damodar Hegde \\ Email: ahegde@mix.wvu.edu \\ Birth Date: $2^{\text {nd }}$ March, 1980 \\ Place of Birth: Belgaum, Karnataka, India \\ Languages known: English, Konkani (mother tongue), Hindi, Kannada
}

\section{Education:}

Master of Science in Industrial Engineering

West Virginia University, Morgantown

Bachelor of Science in Mechanical Engineering

Manipal Institute of Technology, Manipal, India

Bachelors Project: Heat Treatment (Age Hardening) of Aluminum-Copper Alloy

Guide: Mr. S. S. Sharma

Experience:

Industrial Engineer (Intern)

Edlon Inc. (A unit of Robbins and Myers), Charleston, WV

Sep 2004 - Dec 2004

Graduate Research Assistant

Department of Industrial Engineering, West Virginia University, Morgantown, WV Jan 2003 - July 2004

Mechanical Engineer (Intern)

Hindustan Machine Tools, Bangalore, India

Summer 2000

Computer Skills:

Statistical Analysis: Design-Expert, Data-Desk

Simulation: ARENA 7.0, PROMODEL

Cost Estimation: PRICE, SEER

Spreadsheet and Database: MS Excel, MS Access

CAD/CAM: AutoCAD 2004, CNC programming

\section{Honors:}

Inducted in Alpha Pi Mu, Industrial Engineering Honor Society

"Rashtrapati Scout Award" (Eagle Scout) from the Honorable President of India

"Rajya Puraskar Scout Award" from the Honorable Governor of Karnataka 